\title{
Effects of GO FASTER on Morpheme Definition Fluency of High School Students with High Incidence Disabilities
}

\section{Dissertation}

Presented in Partial Fulfillment of the Requirements for the Degree Doctor of Philosophy in the Graduate School of The Ohio State University

By

Katelyn M. Fishley, M.Ed.

Graduate Program in Education

The Ohio State University

2011

Committee:

Dr. Moira Konrad- Advisor

Dr. Terri Hessler

Dr. Sheila Morgan 
Copyright by

Katelyn M. Fishley

2011 


\begin{abstract}
Although it is well-documented that vocabulary instruction can affect student achievement in many areas of literacy, there is a paucity of research on the most effective ways of explicitly teaching vocabulary to high school students with disabilities. One strategy, morphemic analysis, holds great potential for increasing student vocabulary knowledge in an efficient manner. An important component skill of morphemic analysis is the knowledge of morpheme definitions. Very few studies have investigated direct teaching of morpheme definitions in isolation. The current study examined the effects of GO FASTER, a direct teaching package, on the acquisition of morpheme definitions to a pre-determined fluency level. Participants were five high school seniors with high incidence disabilities. A multiple baseline across morpheme sets experimental design was used to investigate the effectiveness of the intervention package. GO FASTER included multiple evidence-based practices: scripted direct teaching procedure with graphic organizers, fluency timings, and self-graphing. The results support the use of $G O$ FASTER in teaching students morpheme definitions to a fluent level. Effects on generalization and maintenance, implications for practice, and future research are also discussed.
\end{abstract}




\section{Dedication}

I'd like to dedicate this to my family. 


\section{Acknowledgements}

I would like to express my sincere gratitude to my family, friends, and the Special Education faculty. These past three years have been an amazing journey and I have enjoyed every step. However, the success of my journey is due in large part to those who have supported me along the way.

A very special thank you to my advisor, Dr. Konrad, for her tireless support and encouragement. I would not have made it through the past three years without her and owe my success to her. I would also like to thank Dr. Hessler, who served as an unofficial co-advisor to me. In her role she was an amazing mentor and I am blessed to have had her to work with the last three years. I would like to express my gratitude to Sue Keesey for all of her help with data collection and for being a great emotional support for the last two years. A final thank you to Dr. Morgan, who has been an important influence in my graduate studies as a professor and as a member of my committee. 
Vita

December 12, 1979...............................Born-Dover, Ohio

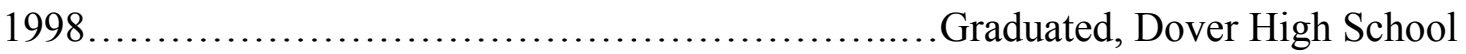

Dover, Ohio

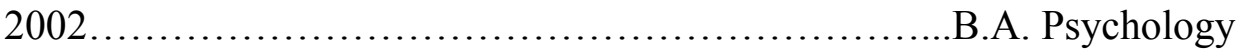

Walsh University

North Canton, Ohio

2004-2006......................................Aide for Children with Autism

Nationwide Children's Hospital

Westerville, Ohio

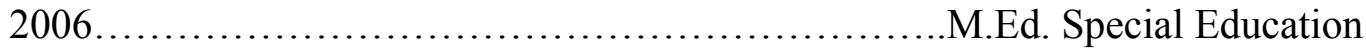

The Ohio State University

Columbus, Ohio

2006-2008

.Intervention Specialist

Worthington City Schools

Worthington, Ohio

2008-2010.

..Student Teaching Supervisor 
Special Education Department

The Ohio State University

Columbus, Ohio

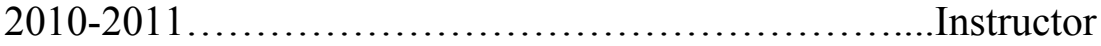

Introduction to Special Education

The Ohio State University

Columbus, Ohio

2008-present

Doctoral Student

Special Education

The Ohio State University

Columbus, Ohio

\section{Publications}

Konrad, M., Luu, K.C.T., Rowe, D.A., Mazzotti, V.L., Kelley, K.R., Mustian, A.L., Keesey, S., \& Fishley, K.M. (2009). In Other Sources. Career Development for Exceptional Individuals, 32(1), 182-192.

Konrad, M., Trela, K., Fishley, K.M. White, J., Mazzotti, V., \& Itoi, M. (2008). In Other Sources. Career Development for Exceptional Individuals, 31, 186-192.

Moser, L., Fishley, K.M., Konrad, M., \& Hessler, T. (in press). Effects of the copy, cover, and compare strategy on the acquisition, maintenance, and generalization of spelling sight words for elementary students with attention deficit/hyperactivity disorder. Child \& Family Behavior Therapy.

Major Field: Education

\section{Fields of Study}




\section{Table of Contents}

Abstract........................................................................

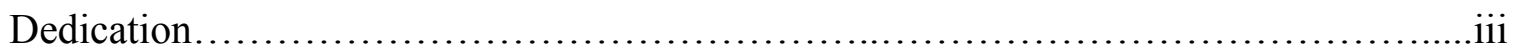

Acknowledgements.........................................................

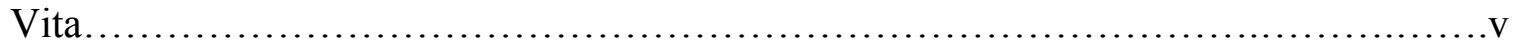

Table of Contents.......................................................... vii

List of Tables.................................................................

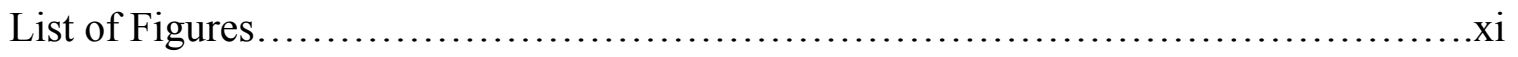

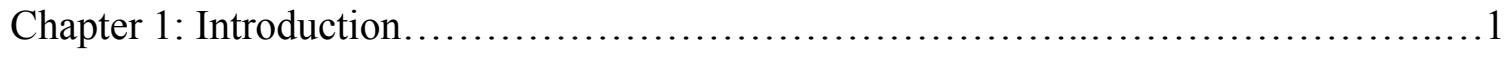

Potential Contributions..............................................8

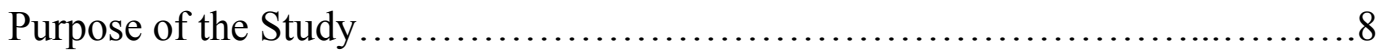

Definitions........................................................... 9

Chapter 2: Literature Review..............................................11

Current State of Vocabulary Research...................................11

Effective Instruction.............................................. 15

Implications and Recommendations.....................................33

Chapter 3: Method....................................................... 36

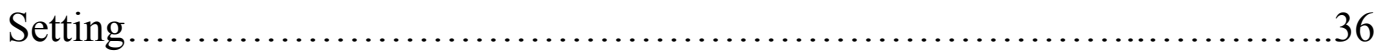


Participant Recruitment.............................................. 37

Participants............................................................. 37

Researchers....................................................... 38

Dependent Variables................................................. 39

Independent Variable: GO FASTER ......................................40

Social Validity.....................................................40

Instructional Materials................................................41

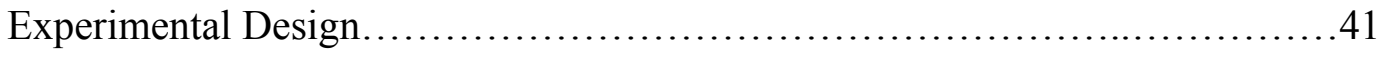

Procedures.......................................................42

Chapter 4: Results...................................................... 52

Inter-observer Agreement..................................................5

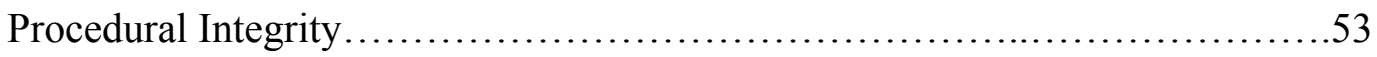

Effects of Intervention............................................54

Generalization...................................................65

Social Validity......................................................67

Chapter 5: Discussion.................................................... 70

What are the Effects of GO FASTER Training on Morpheme Definition

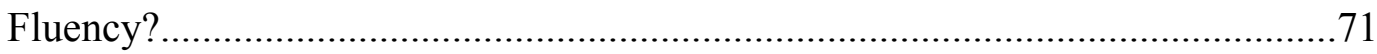

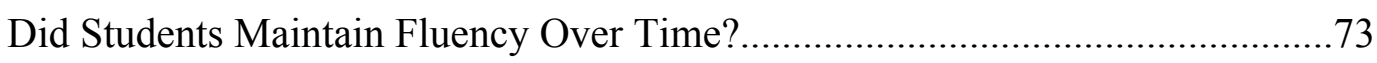

Did Student Knowledge of Morpheme Definitions Generalize to the Use of Whole Words Containing Taught Morphemes in Writing Samples? ...............75

Did Students Improve Their Performance on a Curriculum-based Measure From

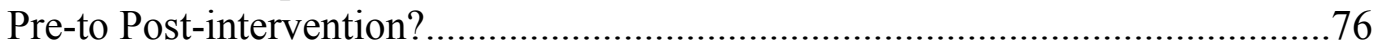

What are Teachers' and Students' Reported Opinions of This Intervention?......78 viii 


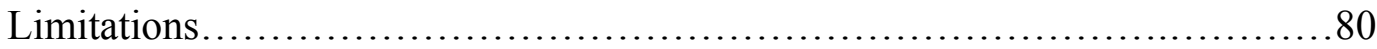

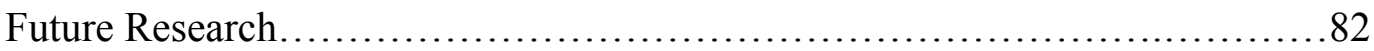

Classroom Implications.................................................. 84

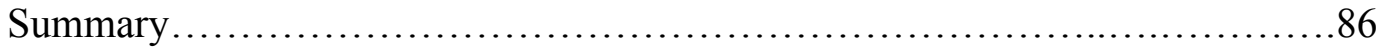

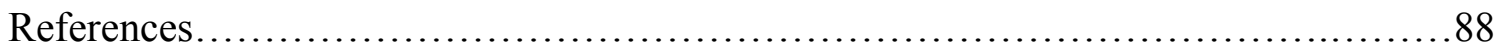

Appendices:

Appendix A: Principal Support Letter.......................................97

Appendix B: Student Consent Form........................................99

Appendix C: Intervention Schedule.......................................103

Appendix D: Social Validity Forms............................................ 105

Appendix E: Pre-intervention Training Script...............................109

Appendix F: Morpheme Sets...........................................114

Appendix G: Teaching Phase Script.......................................116

Appendix H: Graphic Organizer Template.................................122

Appendix I: PowerPoint Slides for Teaching Sessions.........................124

Appendix J: Sprint Training Scripts..........................................136

Appendix K: Sample Generalization Probe Form.............................139

Appendix L: Interobserver Agreement Checklist..............................141

Appendix M: Procedural Integrity Checklists.................................143 


\section{List of Tables}

Table 1. Participant Characteristics............................................ 38

Table 2. Writing Prompt Schedule..............................................49

Table 3. Morpheme Usage in Generalization Writing Probes..........................66

Table 4. AIMSweb Writing Probe Results.........................................67

Table 5. AIMSweb Correct Writing Sequence Percentile Ranks .......................67

Table 6. Student Social Validity Results......................................69 


\section{List of Figures}

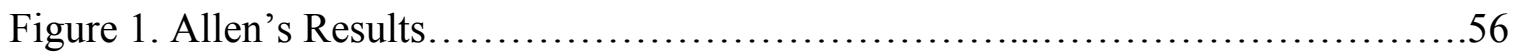

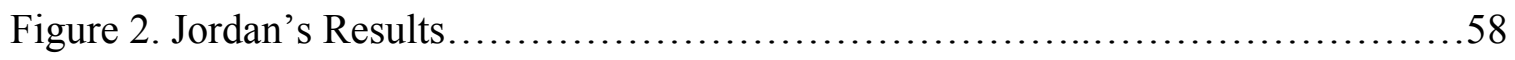

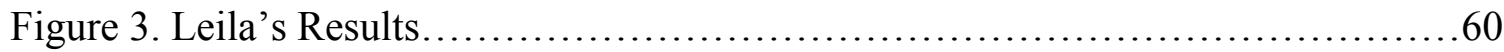

Figure 4. Nathan's Results.....................................................62

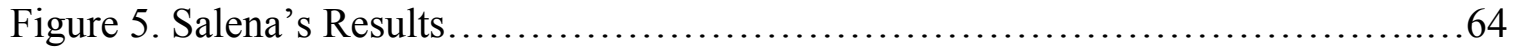




\section{Chapter 1: Introduction}

Students who are struggling with reading when they enter high school continue to do so throughout their high school years (Deschler, Palincsar, Biancarosa, \& Nair, 2007; Hasselbring \& Goin, 2004), indicating that current literacy practices are failing to address the needs of older students. These older struggling readers tend to have difficulty with more than one aspect of reading (Torgesen, 2005). At this age students can already be far behind their peers, which makes focused and intense instruction vital to their academic success.

In order to get struggling students the help they require, special education services are often needed. Students are being identified for special education at a substantial rate (Swanson \& Hoskyn, 1998). The most common reason for referral is difficulty with literacy skills. Ninety percent of students being referred for special education services have reading difficulties (Kavale \& Forness, 2000). Currently, an intense focus is being placed on early intervention for very young struggling readers, which makes sense given that research shows that what happens in the lower grades has a rather profound effect on students' long-term outcomes. For example, vocabulary assessed in $1^{\text {st }}$ grade predicted over $30 \%$ of reading comprehension variance in $11^{\text {th }}$ grade (Calderon, Hertz-Lazarowitz, \& Slavin, 2005; Cunningham \& Stanovich, 1997; Hiebert \& Kamil, 2005). This 
preventative approach is promising and should continue to be a priority. However, many students in United States high schools continue to struggle perhaps because they did not receive early intervention or because early intervention efforts were unsuccessful. The National Center for Education Statistics (NCES; 2007) found that only $74 \%$ of eighth grade students in the United States are considered to be at or above the basic level in comprehension. Student scores on state assessments are placed in one of five categories: advanced, accelerated, proficient, basic, and limited. Students pass the tests at the basic level, which means students can be less than proficient and still pass the tests. To earn scores at the basic level on the eighth grade reading assessment, students are able to identify information, make basic inferences, and identify main idea and author's purpose (NCES, 2010). The percentage of students performing at or above the basic level decreased from $80 \%$ in 1992 to $73 \%$ in 2005 , and the percentage of students performing at or above the proficient level decreased from $40 \%$ to $35 \%$. To be considered proficient, students can perform the skills at the basic level plus demonstrate higher-order thinking skills such as making and supporting inferences, analyzing text elements, and summarizing what they read. Overall reading scores at ages 17 and 13 were slightly lower than in previous years (NCES, 2007). For students with disabilities, the statistics are even more alarming. Some believe the job of educators is to be proactive by continuously assessing and improving its practices to meet the evolving needs of its students. The aforementioned data do not reflect that the education of students with reading deficits is continuously improving.

Failing to teach students to read proficiently can have serious social consequences. Almost half of the adolescent population with criminal records and 
substance abuse problems have reading difficulties (Kamil, 2004). Additionally, many struggling students end up in special education. Almost 91,000 students with disabilities dropped out of school in the 2007-2008 school year (NCES, 2010). Over half of those students qualified for special education under "specific learning disability," and many struggled with reading. Even when students with disabilities do not end up with a criminal record or drop out of school, they can experience other negative social consequences. There are common characteristics of students with learning disabilities that can lead to poor decision-making and negative behaviors that can have troublesome consequences. Some of those characteristics include poor impulse control, inability to see actions in terms of long-term consequences, need for instant gratification, and low frustration tolerance (Learning Disabilities Association of America, 2005). All of these characteristics have the potential to lead students down the wrong path. Although it can be argued which came first, poor reading skills or the problem behaviors, it remains a consistent characteristic of this population and deserves to be addressed.

When considering how children get to high school and remain struggling readers, it is important to understand how vocabulary and reading skills develop in young children. Before beginning to read, students have a much larger oral vocabulary than text vocabulary. Oral vocabulary serves as the foundation for developing reading vocabulary. As students begin to decode words, they will match those words to the ones they currently have in their oral vocabularies. When a child encounters a word that is not in his or her oral vocabulary, comprehension is affected. This decoded word becomes merely a group of letters and sounds, not a word that contains meaning (Hiebert \& Kamil, 2005). Therefore, the vocabulary that a child is exposed to, in the home before formal 
reading instruction, plays an important role in how quickly and easily a child begins to read. Hart and Risley's (1995) longitudinal study on the influence of environment and parental communication skills on children's development and school readiness provides insight into the importance of developing a large oral vocabulary as a building block to learning to read. In this study, researchers followed 42 children from ages one to three and recorded the interactions that took place within their homes. Words used in these interactions were counted and separated into categories. After much analysis, the data showed that the children's vocabulary achievement after two years was most affected by the number of interactions, number of words, and types of vocabulary spoken between the parents and the children. The second contributing factor to children's vocabulary achievement was the socioeconomic status of the children and their families. Children who lived in poverty interacted far less with the adults in their home, heard far fewer words, and were spoken to with many more directives (e.g., "Sit down!") than those whose families were from middle and upper socioeconomic (SES) backgrounds. Parents in higher SES homes used more statements that were "suggestive" (e.g., "Why aren't you sitting down?"). Additionally, Hart and Risley found that these early experiences greatly affected later vocabulary growth and IQ test scores.

Some children struggle to learn to read because of their early environments, whereas others have learning disabilities that make reading difficult. Whichever reason it may be, children who start behind have a difficult time catching up with their peers (Roberts, Torgesen, Boardman, \& Scammacca, 2008; Snow, Burns, Griffin, 1998). Falling behind in vocabulary acquisition can have detrimental effects on children's reading and comprehension skills. Vocabulary growth per year for low-achieving 
students is only 1,000 words and up to 5,000 for high achieving students (Hiebert \& Kamil, 2005). Therefore, if not remediated, the gap will continue to expand each year. Students are expected to learn at least 3,000 words per year (Hiebert \& Kamil, 2005; White, Graves, \& Slater, 1990). These numbers are more alarming when one considers that books and other reading materials used by students in their schooling contain over 100,000 different words across texts (Baumann \& Kame'enui, 2004). For a struggling student learning 1,000 words per year, understanding these materials becomes increasingly difficult as each year passes. At this rate, students entering high school will find reading and comprehension nearly impossible.

The importance of a well-developed vocabulary is documented in the literature. Research has shown a weak vocabulary to be strongly correlated with academic failure (Becker, 1977) and a strong vocabulary is correlated with high levels of comprehension and academic success (Beck, McKeown, \& Kucan, 2002). Beck, McKeown, and Kucan (2002) also found that vocabulary is related to general reading achievement and school success. Given that knowledge in school is largely acquired through reading materials and listening to teachers speak, a large vocabulary can only aid in comprehension and learning in general. Even after high school, vocabulary has a great effect on achievement. Students with vocabularies of less than 11,000 root words were unable to succeed in college programs in the Netherlands (Biemiller, 2005; Hazenberg \& Hustijn, 1996). Although it is unclear whether these findings would generalize to students in schools in the United States, they do indicate a clear connection between the understanding of root word definitions and academic success. 
Slow vocabulary development is extremely problematic as vocabulary deficits can greatly affect comprehension. This has especially important implications as the end goal of reading is a comprehension of or understanding of what was read. The research on the strength of this relationship tends to be somewhat mixed. Whereas Baumann, Edwards, Boland, Olejnik, and Kame'enui (2003) contend that the evidence that shows a causal relationship between vocabulary and comprehension remains "soft," others feel vocabulary is crucial to comprehension (Baumann \& Kame'enui, 2004; National Reading Panel, 2000; Snow, Burns, \& Griffin, 1998; Snow, Porche, Tabors, \& Harris, 2007). In order for vocabulary instruction to positively affect comprehension, instruction needs to be comprehensive. Instruction in vocabulary needs to go beyond definitions of terms. It should include direct instruction, indirect instruction, multiple exposures, wide-reading, and emphasis on generative word knowledge (Graves, 2000; Nagy, 2005). Generative word knowledge refers to the teaching of vocabulary strategies that can lead to generating new vocabulary knowledge, in lieu of teaching the meaning of one word at a time.

There is also evidence that the age at which comprehension is affected is an important factor. Identifying words in first grade was not predictive of more immediate reading comprehension, but many years later orally tested vocabulary in first grade was correlated with much later reading comprehension (Biemiller, 2005). Some may argue that this finding substantiates the importance of early vocabulary instruction. However, it also illustrates the weakness of current vocabulary instruction. If what happens in first grade can predict what happens in higher grades, one can draw the conclusion that instruction in between has had very little effect on student vocabulary growth and comprehension. 
In order to help high school students with disabilities in the area of vocabulary, there is a need for identification and implementation of more effective methods of vocabulary instruction. In 2000, the National Reading Panel released their report on evidence-based instructional practices for reading based on their extensive meta-analysis of reading research. After analysis, they identified five essential areas for beginning reading instruction: (a) phonemic awareness, (b) phonics, (c) fluency, (d) vocabulary, and (e) comprehension. Even though the National Reading Panel placed a large emphasis on the importance of vocabulary instruction, there are few absolutes in the area of vocabulary instruction, in part due to the lack of a cohesive and thorough research base and the absence of a standardized definition of vocabulary instruction.

One particular area that shows promise is a focus on teaching morpheme definitions and morphemic analysis to improve vocabulary. The research in this area is sparse but offers reason to be optimistic about what this approach can offer struggling students. Two recent literature reviews on morphemic analysis and morphological instruction revealed that teaching morphology can lead to improvements in reading, spelling, writing, and oral language (Bowers, Kirby, \& Deacon, 2010; Carlisle, 2010). Additionally, the number of studies identified for each of these reviews further illustrates that this is a rather understudied area of research. The authors of each review agreed that this is a promising area of literacy instruction that should be further investigated to identify the best methods of teaching the skills involved in morphemic analysis and to attempt to quantify the gains that can be achieved. 


\section{Potential Contributions}

The proposed research addresses some of the shortcomings of the current vocabulary literature base. First, high school students are rarely the focus of vocabulary research. Of the studies included in the National Reading Panel's review of vocabulary interventions, only 5 of the 67 participants across all studies were in grades 9-12. Second, very little research exists on the teaching of morphemes to increase vocabulary. Within the studies that do exist on morphemic analysis, most were focused on teaching the segmentation of words into their morphemes, not on teaching the definitions of morphemes, which is important knowledge if morphemic analysis is to be a viable strategy for teaching vocabulary. The teaching of morpheme definitions can take very little time in the classroom and has the potential for very large impact given that many words can be formed from just a few morphemes. This information can be provided to students in a group setting, which allows the teacher to reach many students at one time. A solid research base on morphemic analysis may help to support the consistent teaching of this skill in the classroom.

\section{Purpose of the Study}

This research aims to extend previous research on GO FASTER by implementing the intervention in a whole group setting, increasing the mastery criteria, and examining the effects of the intervention on participants' writing. The study examined the following research questions:

1. What are the effects of GO FASTER training on morpheme definition fluency? 
2. Will student knowledge of morpheme definitions generalize to the use of whole words containing taught morphemes in writing samples?

3. Will students maintain their fluency over time?

4. Did students improve their performance on a curriculum-based measure from pre- to post-intervention?

5. What are teachers' and students' reported opinions of this intervention?

\section{Definitions}

The following terms are used throughout this dissertation. Each term has multiple meanings; therefore, it is important to understand how each term was applied in this study.

Direct teaching-"Instruction wherein teachers assume a highly structured, active, and dominant role and teacher talk is relied upon to ensure that students interpret a target word in the intended way and achieve the desired outcome" (Duffy \& Roehler, 1986, p. 76).

Fluency- "The rate at which students accurately perform a response" (Alberto \& Troutman, 2009, p. 424).

Maintenance-"The extent to which a learner continues to exhibit a previously learned behavior after a portion or all of the instructional intervention originally used to teach the skill has been terminated" (Cooper, Heron, \& Heward, 2007, p. 698).

Generalization-"The expansion of a student's capability of performance beyond those conditions set for initial acquisition" (Alberto \& Troutman, 2009, p. 425).

Morphemes- "The smallest parts of words that have distinctive meanings" (Bursuck \& Damer, 2007, p. 323). 
Morphemic analysis- "Analyzing the meaningful parts of words" (Baumann et al., 2003, p. 448).

Morphology- "The conventional system by which the smallest units of meaning, called morphemes (bases, prefixes, and suffixes), combine to form complex words" (Bowers \& Kirby, 2010, p. 144).

Self-graphing-"Students measure their own behavior and plot it on a graph" (Moxley, 2007, p. 114). 


\section{Chapter 2: Literature Review}

Effective vocabulary strategies for older students with disabilities need to be identified, given the important role that vocabulary plays in reading, writing, and content area knowledge and given the scarcity of such research. This literature review aims to identify the issues that have led to this gap in the research and to review the existing research on effective instruction as it relates to vocabulary.

\section{Current State of Vocabulary Research}

Although it seems likely that practitioners and researchers would agree that placing an instructional focus on vocabulary is vital to literacy instruction, there does not appear to be a clearly outlined formula for effective and efficient vocabulary instruction. There are many possible reasons for the lack of cohesion in experimental research on vocabulary instruction. Among these are difficulty in defining vocabulary, difficulty in measuring performance and growth in vocabulary, and the difficulties associated with attempting to study vocabulary in isolation.

What is vocabulary? There is much debate on what vocabulary is, precisely. Beck and McKeown (1991) acknowledge inconsistency of the definition of vocabulary by asserting that vocabulary "is not an all or nothing proposition" (p. 791). Most generally, we have a productive and a receptive vocabulary. Productive vocabulary refers to the 
words that one uses when writing or speaking. Receptive vocabulary refers to the words one can understand through written text or when being spoken to. Vocabulary can also include oral and reading vocabulary. Oral vocabulary consists of the words used in speech. Reading vocabulary consists of the words understood when read in print (Hiebert \& Kamil, 2005).

Although vocabulary is commonly thought of as knowing the definition of a key term, it is far more than simply knowing the dictionary definition. Stahl $(1983,1985)$ contends that there are two ways a person can know a word: definitional information and contextual information. Definitional information refers to the ability to recite a dictionarytype definition and contextual information refers to the application of a term across different contexts (Nagy \& Scott, 2006). Hiebert and Kamil (2005) qualify the difficulty in having just one definition of vocabulary by stating that the definition of vocabulary depends on the purpose of vocabulary. Vocabulary can be used for reading or listening (receptive vocabulary) or for writing or speaking (expressive/productive vocabulary). Depending on the purpose, the definition of vocabulary will change. Bryant, Goodwin, Bryant, and Higgins (2003) agree with this assertion and include association, comprehension, and generation in their purposes of vocabulary and conclude that there is not one all-inclusive definition of vocabulary. From these authors' accounts of what vocabulary is, it is difficult to define vocabulary in absolution. The purpose of vocabulary will determine its definition. Because there are many purposes of vocabulary, there are consequently many definitions of vocabulary. It seems that to "know" a word completely and thoroughly, one must know the definition in print, receptively, and within any 
context; be able to define it orally and in written form; and be able to correctly use the word when writing and speaking.

Assessment of vocabulary. The paucity of experimental research on vocabulary interventions may also be tied to the challenges inherent in trying to assess vocabulary growth. Assessment in current vocabulary research is far from uniform (National Reading Panel, 2000). Assessing individuals' vocabularies is difficult for many reasons, including the imprecise nature of the definition of vocabulary, the many types of vocabulary, and the additive nature of vocabulary development. Vocabulary is additive in that knowing certain vocabulary words can lead to encountering new vocabulary (Bryant, Goodwin, Bryant, \& Higgins, 2003). Because word knowledge continues to grow and develop throughout one's life, it is difficult to document this growth through assessments, which can only assess the knowledge of a fixed number of words. Most vocabulary research studies consist of researcher-created assessments that aim to find whether students were able to acquire the vocabulary terms that were targeted in each specific intervention. The National Reading Panel's (2000) analysis of vocabulary interventions found that of 37 studies, 31 used exclusively experimenter-made assessments. This method is the most sensitive to immediate growth; however, it generally measures only whether participants learned what was taught to them in intervention. Although assessments should be designed to measure words taught in the study, having such specific assessments does not allow for synthesis or meta-analysis of study results in order to draw definitive conclusions about effective vocabulary interventions.

Further, with vocabulary instruction for students who have already fallen behind, it is desirable to further vocabulary development beyond what was taught directly. However, 
generalization measures are difficult to create, and this is apparent as there is a notable absence of generalization measures in vocabulary research (Scammacca et al., 2007). It is not possible to truly connect a taught word to the knowledge of an untaught word, without taking into account multiple variables that come into play such as incidental learning or hearing the definition from another source.

Some research utilizes both standardized assessments and researcher-created assessments. Standardized assessments are typically more widely accepted as valid; however, these assessments are not sensitive to growth in shorter periods of time, in which studies are typically carried out. They are most often, and most effectively, used as pretests to identify students who are struggling. Vocabulary assessments need to continue to evolve in order to be sensitive enough to detect vocabulary growth consistently and to be uniform enough to establish a consistent database of effective vocabulary interventions (National Reading Panel, 2000).

Absence of isolated vocabulary instruction. A third possible reason for the lack of experimental research on vocabulary instruction for high school students is the integrated nature of teaching vocabulary terms in content areas. With vocabulary, it is important to teach terms within a context, which can make it difficult to design a "clean" research study on vocabulary instruction, as other elements come into play. It can be difficult to separate effects of vocabulary instruction from other components of literacy or content area instruction, such as teaching of comprehension strategies.

Whatever the reasons may be for the lack of experimental research on vocabulary instruction for high school students, there are students in school now who desperately need to improve their vocabulary skills. Students who are at-risk or have disabilities are 
falling even further behind as the years pass (Hiebert \& Kamil, 2005). Identifying evidence-based practices for improving the vocabulary skills of older students with disabilities should be a research priority.

\section{Effective instruction}

Although there is a paucity of intervention research related to vocabulary, there is evidence about what comprises effective instruction, in general. This section of the literature review focuses on this evidence, with the aim of identifying instructional practices with the most potential for helping older students with disabilities to improve their vocabulary skills. Swanson and Hoskyn (1998) conducted a meta-analysis to investigate which of three instructional approaches was most effective: direct instruction, strategy instruction, or a combined approach. Direct instruction included a) breaking down a task into small steps, b) administering probes, c) supplying repeated feedback, d) providing students with diagrammatic or pictorial presentations, e) allowing independent practice and individually paced instruction, f) breaking down instruction into simpler phrases, g) instructing in a small group, h) teacher modeling of skills, i) providing set materials at a rapid pace, $\mathrm{j}$ ) providing instruction for individual children, $\mathrm{k}$ ) having the teacher ask skill-related questions, and 1) having the teacher provide new materials. Strategy instruction consisted of a) elaborate explanations, b) teacher modeling of processes, c) reminders to use certain strategies, d) step-by-step prompts, e) teacherstudent dialogue, f) teacher asking process-oriented questions, and g) teacher providing only necessary assistance. Combined instruction consisted of an overlap of components in the direct instruction and strategy instruction domains. This combined approach did have components not included in the other approaches such as "frequent inclusion of 
attributions, teacher modeling of problem solving steps, and an emphasis on small interactive groups" (pg. 302). Overall, this combined approach had more instructional components than other approaches.

They also examined whether certain domains were affected more or less by certain interventions as well as whether studies that reported reading scores and/or intelligence scores yielded different results from those that did not. Participants ranged from elementary to high school. The authors found that reading comprehension and vocabulary domains were most likely to be affected through intervention. They also found the definition of "learning disabled" had an effect on results. Studies where psychometric testing was not included had the largest effect sizes. With the absence of psychometric testing, there is no certainty that students included in these particular studies had learning disabilities, which are marked by severe discrepancies between achievement and intellectual ability, as defined by the Individuals with Disabilities Education Act.

Where instructional implications were concerned, the authors found that a combined strategy and direct instruction method was most effective. Further, certain instructional components of each method were closely tied to high effect sizes. These components included sequencing, drill-repetition-practice, controlling task difficulty, segmentation of information, technology, small interactive groups, augmentation of teacher instruction (homework), direct questioning/responding, and strategy cueing.

In a follow-up analysis, Swanson and Hoskyn (2001) analyzed the articles from the previous review that had participants considered to be adolescents. These participants were ages 11 to 18 . The goal of this analysis was to identify the components that were most effective for adolescents with learning disabilities. They found that combining 
advance organizers with explicit practice resulted in the highest effect sizes for this population.

When considering instructional implications from research in this literature review, the most frequent instructional recommendation within the research has been direct instruction, which includes instruction coming directly from the teacher but can involve many other elements. The most extensive description of the elements of direct instruction comes from Swanson (2006), which was listed previously. Malmgren and Trezek (2009) and the National Reading Panel (2000) stated that the direct instruction of vocabulary is comprised of specific word instruction and word learning strategies. Specific word instruction includes the direct teaching of definitions, synonyms, antonyms, and analogies. With this approach, students are also taught to make connections with newly learned word definitions and knowledge they already have. Direct instruction of word learning strategies can involve teaching students how to use dictionaries and analyze those definitions, how to break words apart into known morphemes, and how to access context clues. Direct instruction should be used to tell a student both when and how to use each strategy (Baumann \& Kame'enui, 2004).

Direct instruction is recommended for teaching word study, vocabulary, and comprehension (Roberts et al., 2008). Direct instruction in word study involves directly showing students how to segment words into known word parts, definitions of each word part, letter patterns, and structural features of words (Roberts, et al., 2008). Direct instruction of vocabulary involves (a) giving students vocabulary definitions, examples, and non-examples; and (b) using graphic organizers for each word. When teaching individual terms, it is important to teach their definitions directly (National Reading Panel, 
2000; Stahl \& Fairbanks, 1986). Students with disabilities should not be allowed to construct their own definitions without receiving direct instruction first, as they may not have the skills needed to construct an accurate definition. Instruction on individual words should be carefully planned to be the most efficient and practical for students (Beck, McKeown, and Kucan, 2002).

With such a large number of words that students need to know, it is impossible to directly teach every word. Beck, McKeown, and Kucan (2002) recommend breaking words into three tiers. Tier one words are made up of the most commonly used words that most children acquire through incidental learning and do not usually require instruction. Tier three words are content specific and should be targeted only when they will be used in an upcoming lesson. Direct instruction should target tier two words. Tier two words are used frequently and across multiple contexts and subject areas.

Beck, McKeown, and Kucan (2002) posit that direct instruction is especially vital in the acquisition stage. The acquisition stage differs from the practice stage in that each student response should be followed with teacher feedback (Heward, 1994). This keeps students from making and then practicing errors. Many researchers share the common belief that direct instruction is vital for students with learning disabilities, but they acknowledge that direct instruction is not sufficient for fluency and generalization (Bursuck \& Damer, 2007). Direct instruction is best when combined with other instructional techniques that promote generalization and exposure to words in multiple contexts.

Rich and robust instruction. A common assertion among vocabulary researchers is that vocabulary instruction should be integrated into entire classroom environments 
rather than merely a part of isolated instructional situations (Baumann, Edwards, \& Ware, 2007; Beck, McKeown, \& Kucan, 2002; Cunningham \& Stanovich, 1997; Hiebert \& Kamil, 2005; Kucan, Trathen, \& Straits, 2007; McKeown 1993; McKeown \& Beck, 2006; Nagy, 2005; Nagy, Herman, \& Anderson, 1985; Phillips, Foote, \& Harper, 2008;). For instance, Beck et al. (2002) call for a rich environment where teachers imbed multiple opportunities to interact with language in receptive and expressive contexts. Richness goes beyond simple definitions and requires that students be actively involved in analyzing and manipulating words while also making connections among words (Nagy, 2005). When students are able to make connections between conceptually related words, they are able to learn them more easily (Hennings, 2000; Kucan et al., 2007). Because the goal of vocabulary instruction is to have children use and understand vocabulary in their everyday interactions, it is important that teachers model this by using key vocabulary across multiple contexts and environments (Beck et al., 2002). It is essential that teachers incorporate many opportunities for students to interact with vocabulary in reading, speaking, and writing. Within these multiple contexts, incidental learning can take place. Students can pick up information and vocabulary just from reading. Older students appear to improve vocabulary consistently when they read often, accurately, and widely (Cunningham \& Stanovich, 1998; Roberts et al., 2008). According to Stanovich (1986), "Vocabulary knowledge is both a cause and a consequence of wide-reading" (p. 373). When reading, students formulate meanings for unknown words based on the context and their oral vocabulary. This independent practice is the ultimate goal of instruction, although it is largely unreliable for producing impactful changes in vocabulary size consistently across students (Nagy et al., 1985). Students who are reading independently 
and who are able to learn incidentally, generally have a strong vocabulary already. This is a case of what Stanovich (1986) refers to as the Matthew Effect. The Matthew Effect is a term used to describe the phenomenon of students with a strong vocabulary continuing to develop more extensive vocabularies because of it, whereas children with small vocabularies read less and in turn acquire less vocabulary (Cunningham \& Stanovich, 1997). It is often referred to as the "rich getting richer."

For struggling students, targeting oral vocabulary can be especially important (Beck et al., 2002). We know that the growth of a student's reading vocabulary depends largely on words already in his or her oral vocabulary. Teachers should model the correct use of vocabulary and hold students accountable for using targeted vocabulary in conversations and when answering questions, orally, in class.

In order for students to be able to produce vocabulary in these "rich" environments, robust vocabulary instruction needs to take place. Robust vocabulary goes beyond dictionary definitions into extensions of the terms. It includes giving students information about when and how to use these words, allowing them frequent opportunities to use and think about words, providing them opportunities to use these words to aid comprehension, and opportunities to use the words in their speech and writing (Beck et al., 2002).

In order to meet this criterion, programs needed to teach vocabulary both directly and indirectly (Baumann \& Kame'enui, 2004). Students needed to be provided definitions and then practice using the words in sentences, writing pieces, and spoken language. Additionally, the programs should teach students how to make connections between 
words (antonyms, synonyms, and similar spelling patterns that correspond to meaning) and think critically about them.

Repetition and fluency. Basketball practice in most arenas begins with a routine where the players work on what are called "the fundamentals." These include all of the skills athletes perform constantly throughout the game that need to be automatic in order to play the game with fluidity, such as dribbling with each hand and the various types of passes. Where effective reading is concerned, students need to reach a level of automaticity with the fundamental skills of phonics, phonemic awareness, fluency, comprehension and vocabulary. Vocabulary instruction is one way of ensuring that students reach a fluent level in their reading and comprehension (Binder, 2003). Mastering even the most basic skills is a necessary building block for the higher level skill of comprehension. Students need to be able to identify and understand vocabulary in order to read and comprehend well.

Students, like basketball players, can benefit from what is often called drill and practice. Basketball players need repeated drill and practice with all of the skills they use to play basketball. Students need repeated drill and practice with all of the skills they use to read. These multiple exposures to words help students to better understand and comprehend their meanings (Stahl \& Fairbanks, 1986). Repetition is especially important for students with disabilities (Cooper, Heron, \& Heward, 2007; Swanson \& Hoskyn, 1998; Swanson \& Hoskyn, 2001; Swanson \& Sachse-Lee, 2000). They may need up to 40 exposures to a new word in order to learn it (McCormick, 1999). This statistic is rather glaring and strengthens the case for drill and practice and building ample repetition when learning vocabulary. 
Fluency refers to being able to perform the desired behaviors correctly within a certain amount of time. For example, repeated reading is an intervention used to increase reading fluency. Students read the same paragraphs repeatedly for a minute each session with the goal of increasing the number of correctly read words each session. Fluency has been shown to contribute to generalization and maintenance of taught skills (Binder, 1988, 1998; Lindsley, 1992). One way of teaching a skill to fluent levels is the use of SAFMEDS (Say All Fast for a Minute Each Day Shuffled). The SAFMEDS procedure was first developed and investigated by Dr. Lindsley Ogden (1983) as a way to teach various types of knowledge through the use of note cards. These "note cards" have a question or idea on one side with the correct corresponding answer on the back. There are three very important components of SAFMEDS: shuffling (to avoid memorization of a particular order), the use of a specific graph for performance tracking, and timing of each session. Those using SAFMEDS say their responses aloud in a pre-determined time with the goal to increase the correct number of identifications each session. Timings are typically done daily and performance is graphed on a standard celeration chart. Eshelman (1985) investigated the use of these SAFMEDS with his Introduction to Behavior Analysis class. The results of his study showed that students were able to use SAFMEDS to acquire fluent levels of recognition of vocabulary terms and symbols. In another study, Hartnedy, Mozzoni, and Fahoum (2005) found that SAFMEDS were effective in teaching children with neuropsychiatric diagnoses numbers or multiplication facts to a predetermined fluent level.

It has been argued that teaching these "tool" skills does more harm than good to students (Poplin, 1988). The main argument is that students are simply using rote 
memorization and cannot readily apply these tool skills to composite skills. Research shows this claim to be baseless. In fact, research shows that when students learn these tool skills to a fluent level, better composite performance is achieved. One such study was done in a college classroom, where students were taught Hebrew symbols (Bucklin et al., 2000). Each group had different mastery criteria and focused on a one of two component skills. One group's mastery criterion was set at $100 \%$ accuracy for each given task, while the other group was to meet particular fluency aims before achieving "mastery" of the skill. One group focused on learning the component skill of learning Hebrew symbols associated with syllables and the other group learned syllables associated with Arabic numbers. Composite skills were assessed by asking students to apply Hebrew symbols to Arabic numbers on arithmetic tasks. Those in the fluency-based mastery group performed better on tasks that measured composite skills.

Reaching fluent levels not only has an impact on composite skills, but it may also increase on-task behavior endurance. McDowell and Keenan (2002) investigated the effects of reaching fluent levels on on-task behavior using a reversal design. In this study, a nine-year-old student with ADHD was taught letter sounds using flashcards. During intervention, the student's on-task behavior was consistently at $100 \%$, whereas on-task behavior was around $50 \%$ during the phases similar to baseline conditions. These results are promising but should be interpreted with caution as there was only one participant included. Systematic replications should be conducted to build a case for this claim.

Graphic organizers. Visual displays, as described by Wolgemuth et al. (2007), include graphic organizers. A consistent operational definition for graphic organizers is difficult to find. In general, these are "graphic arrangements of words, phrases, and 
sentences that can include graphic elements such as arrows and boxes" (Ives, 2007, p. 111). The purpose of using a graphic organizer is to help students make connections with a visual component.

Graphic organizers seem to be a well-accepted supplement to instruction in vocabulary learning and can be quite effective. For example, Fore, Boon, and Lowrie (2007) compared a definition-based model of vocabulary instruction to a concept model. In the definition model, students looked up vocabulary terms, recorded their definition, and wrote a sentence containing the word. In the concept model, they learned new vocabulary with a graphic organizer where they were given term, its definition, characteristics of the term, examples and non-examples. Results showed that students were better able to match the words to their definitions on weekly quizzes after using the concept model of instruction.

In Wolgemuth, Trujillo, Cobb, and Alwell's (2007) literature review on visual display interventions with youth with disabilities, they concluded that visual displays were effective for improving comprehension, content learning, and problem solving. In the same review, the authors found that they were most effective when students were the ones completing them. Students showed the highest effects when they used these visual displays alongside of other strategies such as direct instruction, praise, and guided practice.

Malmgren and Trezek (2009) and the National Reading Panel (2000) analyzed the research on graphic organizers. Both recommended the use of graphic organizers but cautioned that the effectiveness of their use in isolation has not been adequately studied. 
Graphic organizers are commonly used alongside other modes of instruction as a supplement; therefore, it is difficult to separate out the effects of each intervention.

Self-monitoring. One of the goals of special education is to move students towards adult success and independence. Teaching self-management skills can benefit students by giving them a strategy they can use, independently, to monitor their behaviors. Mooney, Ryan, Uhing, Reid, and Epstein (2005) list five main types of self-management interventions: self-monitoring, self-evaluation, self-instruction, goal-setting, and strategy instruction. Self-monitoring involves observing one's own behavior and recording it (Mace, Belfiore, \& Hutchinson, 2001). Observing one's behavior consists of both identifying instances of the behavior and non-instances (Mace et al., 2001).

Self-monitoring is a well-researched self-management intervention that has been found to be successful with students across all ability levels (Briesch \& Chafouleas, 2009; Graham et al., 2010; Hughes et al., 2002; Sheffield \& Waller, 2010). Self-monitoring is an intervention that is especially relevant for adolescent learners because of the importance of providing these students with transition skills that prepare them to function independently once they leave school. Wolgemuth, Cobb, and Dugan (2007), reviewed 17 research studies that included adolescent learners (age 13-22) with disabilities. They found that self-monitoring interventions were the most effective for youth with disabilities in the areas of academic and on-task behaviors. Because most of the studies included in the review focused on participants with learning disabilities or an emotional disturbances, self-monitoring was strongly recommended for these populations.

Students with learning disabilities may have trouble with self-control (Mercer, 1991), and self-monitoring has been identified as a promising intervention for helping 
students regulate their behavior (Lloyd \& Landrum, 1990; Mace \& Kratochwill, 1988). Self-monitoring has been shown to be effective with many populations including children with autism (Koegel, Koegel, Hurley, \& Frea, 1992), emotional-behavioral disabilities (EBD; Gumpel \& Schlomit, 2000), severe intellectual disabilities (Grossi \& Heward, 1998), attention-deficit/hyperactivity disorder (ADHD; Graham, Gardner, \& Hsin, 2010; Harris et al., 2005), and learning disabilities (LD; Harris, 1986). Graham and colleagues (2010) investigated the use of self-monitoring to improve the on-task behaviors of three high school sophomores with ADHD. There were two intervention phases, one with selfmonitoring alone and the other with self-monitoring plus reinforcement. All students were able to improve their on-task behavior with self-monitoring. Self-monitoring, alone, was enough to improve the behavior of two participants, whereas the addition of reinforcement was needed for the third student in order for behavior to improve.

Many studies have shown self-monitoring to be successful when targeting academic (Harris, 1986; Harris, Graham, Reid, McElroy, Hamby, 1994; Lee \& Tindal, 1994; Wolfe, Heron, \& Goddard, 2000; Shimabukuro, Prater, Jenkins, \& Edelen-Smith, 1999) and on-task behaviors (Graham et al., 2010; Mathes \& Bender, 1997). One study showed the effects of self-monitoring of academic performance on academic productivity and accuracy as well as on-task behavior. Shimabukuro, Prater, Jenkins, and Edelen-Smith (1999) utilized a multiple baseline across content areas design to study the effects of a self-monitoring procedure. Participants were three middle school students with ADHD and learning disabilities. Students monitored their academic performance in reading, math, and writing. They were trained how to compute their scores into percentages for both completion and accuracy. Those results were charted on a graph, by the students. Results 
show that students improved academic accuracy, productivity, and on-task behavior in all subject areas.

One type of self-monitoring procedure is self-graphing, which allows students to be independent in monitoring their own progress by graphing data. The graph provides the students with a visual representation of their progress. Self-graphing is an intervention that has been shown to be effective in increasing many skills including academic skills. Kasper-Ferguson and Moxley (2002) found self-graphing to be effective in increasing any target behavior being graphed. Researchers have found that self-monitoring all different types of behaviors can produce positive effects. For example, Shimabukuro et al. (1999) investigated the use of self-monitoring on academic productivity and accuracy with middle school students with learning disabilities. The three male students monitored both accuracy and productivity on math, reading comprehension, and written expression skills. They were taught to calculate both productivity and accuracy and record their performance on progress graphs. Results of the study show that all three students were able to increase both accuracy and productivity in all areas. In the areas of math and reading, the self-monitoring of productivity was linked to greater growth. Another study investigated the comparative effects of self-monitoring of academic behavior versus attention. Harris and colleagues (2005) asked students to respond with a yes or no on a self-monitoring sheet at pre-determined intervals to the question, "Was I paying attention?" (self-monitoring of attention). To measure academic performance, students graphed their total number of spelling words practiced correctly. Data was collected on spelling performance and attention in both conditions. Results show that students improved both attention and spelling performance with both types of self-monitoring. 
Greater gains were shown academic performance with the self-monitoring of attention, however, students showed a strong preference for the self-monitoring of academic performance over attention. In both of these studies (Shimabukuro et al., 1999; Harris et al., 2005), data show that self-monitoring, and self-graphing specifically, played a role in increasing students' academic and behavioral skills.

Aside from the effectiveness of self-graphing, it is a strategy that allows students to be independent in monitoring their progress. In a time when teachers are feeling the increased demands and pressures of meeting strict performance standards as well as planning for the wide range of ability levels in their classes, there is certainly a need for student-led interventions (Konrad, Walker, Fowler, Test \& Wood, 2008). Self-graphing gives teachers an intervention that is both student-implemented and highly portable, and requires minimal teacher support after initial training stages.

Morphemic analysis. The goals of vocabulary instruction are for students to a) improve their reading fluency and comprehension and b) be able to independently decipher novel word pronunciations and meanings. Considering the large number of words in the English language, teachers cannot possibly teach students each word individually, however, this is a common vocabulary instructional strategy implemented in classrooms across the country. Teachers provide students with a list of vocabulary terms and ask them to look up each definition in a dictionary (Beck, McKeown, \& Kucan, 2002). However, dictionary definitions can be confusing, as each word typically has multiple meanings and can contain words that may be too difficult to understand for some students. Further, knowing the dictionary definition of a word does not ensure that students can understand a word in context or be able to use it correctly when speaking and 
writing (Bursuck \& Damer, 2007). Even if dictionary definitions were appropriate for struggling students, the Oxford Dictionary has over one million words (Nagy \& Anderson, 1984). It is impossible to directly teach each word during the time children are in school. Instead, students can be taught word learning strategies that they can use independently while reading and that apply to a large percentage of words they may encounter. It is important to give students multiple strategies, as all strategies are not applicable in all situations. One strategy with lots of potential is morphemic analysis.

Morphemic analysis involves breaking words apart into their morphemes, or the smallest units of a word that hold meaning. The meanings of $60 \%$ of multisyllabic words can be inferred by analyzing word parts (Bromley, 2007). Morphemes commonly make up words that students will encounter and these morphemes generally have a consistent spelling and meaning (Baumann \& Kame'enui, 2004). Morphemes can be prefixes, suffixes, or root words. They can be bound (cannot stand alone) or free (can stand alone). The morphemic analysis strategy can help students to identify and comprehend words more efficiently as well as decipher novel word meanings and pronunciations (Irvin 1990). Nagy and Anderson (1984) state that the meanings of roughly $60 \%$ of words used in English in grades four through nine may be predicted through analysis of their morphemes. Also, more than $82 \%$ of the terms in the Academic Word List (Coxhead, 2000), a compilation of high-frequency words seen in academic texts, derive from Greek and Latin roots. Instead of teaching individual words, students can be taught the definitions of morphemes that appear frequently and consistently in many words.

Teaching morphemic analysis has been found to be effective in increasing high school students' abilities to consistently find the meaning of novel words in text (Carnine 
\& Carnine, 2004; Graves \& Hammond, 1980; Wysocki \& Jenkins, 1987), more so than textbook vocabulary instruction (Baumann, Edwards, Boland, Olejnik, \& Kame'enui, 2003) and context-only vocabulary instruction (Baumann, 2005; Edwards, 2004). It has also been shown to be most effective with struggling students and alongside other literacy instruction (Bowers, Kirby \& Deacon, 2010), although limited research in this area has been conducted.

Even though the research is sparse, results are promising. Because research has shown students with these skills can be more successful with literacy-related tasks, the next step is to identify the most effective and efficient ways of instructing students in this area. In an integrative review, Carlisle (2010) synthesized 16 studies that included morphological awareness. The author found that all of these studies fell within four basic approaches to instruction. The first approach was to "heighten student awareness of the morphological structure of words" (p. 478). Within this approach, instruction relied on learning games or activities. A second approach was based on teaching morpheme meanings. This approach was used in almost all of the morpheme studies reviewed; however, it was used as a supplement to other instruction. Carlisle also states that it was impossible to tell whether a large emphasis was actually being placed on learning the definitions or if the purpose was more to show the relationship between word parts and meanings. The third instructional approach was fostering problem-solving skills applied to morphology. This included tasks such as analyzing words to find morphemes, examining morpheme spellings, and analysis of the changing definitions of morphemes depending on the other morphemes within the same word. Reasoning and problem solving were emphasized in this approach. The fourth and final approach relates to using morphemic 
analysis as a strategy. It begins with teaching the strategy, providing guided practice with using it, and eventually independent practice of applying morphemic analysis as a strategy for deciphering unknown words.

Many morphemic analysis studies include an emphasis on teaching students the strategy of breaking words apart into their morphemes. This was referred to in multiple studies as teaching students to be "word detectives" (Carlisle, 2010). For example, Bowers and Kirby (2009) taught students what they called a "structured word inquiry approach" to unknown words. Students were given a matrix that guided them through the process of testing their hypotheses regarding the patterns of words. Bowers and Kirby (2009) found significant effects on vocabulary after teaching students this "structured word inquiry approach" to break words apart into their morphemes. However, vocabulary growth was limited to words that contained morphemes that were either directly taught or morphemes that were considered to be in the family of directly taught morphemes.

Because this is an area that is relatively new, more research is needed to find the most efficient ways of teaching students this skill. In order for students to use this strategy they must first be taught how to recognize morphemes and segment whole words into their morphemes. Additionally, students must know the definitions of these morphemes. For example, as a student approaches the term subterranean while reading, a teacher can instruct him or her to break the word apart into its morphemes (sub, terr, etc.). But, how will the student know which word parts contain meaning if they have not been taught? And, in the case where they can identify the morphemes because of their familiarity due to repeated presence in multiple words (anti, un, dis, etc.), does that mean they will necessary know the correct meaning of those morphemes? Therefore, it is 
important to address the teaching of common morpheme definitions. Students can learn these definitions through direct instruction (McBride-Chang, Wagner, Muse, Chow, \& Shu, 2005). Only one study was identified that placed the sole emphasis on teaching students morpheme definitions. Fishley, Konrad, Hessler, and Keesey (2011) used a direct teaching package, "GO FASTER," to teach high school students with disabilities morpheme definitions. Results showed that using this package, students were able to acquire the definitions to a fluent level, maintain the definition knowledge over time, and apply this knowledge to novel word definitions and spelling of words containing the taught morphemes. With the preliminary success of this intervention, it is worth further investigating the most efficient methods for teaching morpheme definitions, as it seems that would be an important component skill needed for morphemic analysis.

A gap in the morphemic analysis research, and vocabulary instruction in general, is with older students and students with disabilities. Reed's (2008) analysis of morphology-based interventions found that only three of eight studies in the analysis included subjects with reading deficits, and no research was conducted on morphological interventions with students in grades 9-12. This is a glaring lapse in light of Bowers, Kirby, and Deacon's (2010) finding that an emphasis on morphological knowledge can have an even greater effect for students with disabilities than for students without disabilities. Further, they question the utility of teaching early learners this skill and suggest that it may be more beneficial for students who have already acquired at least basic reading skills. This has implications for targeting older students with more developed reading skills. 


\section{Implications and Recommendations}

Research informs us there are evidence-based practices in the area of vocabulary instruction. Effective vocabulary instruction includes rich and robust instruction (multiple/extended contexts), morphemic analysis, multiple exposures (drill/repeated practice), graphic organizers, and direct teaching of words and definitions. One area of weakness in the research that was identified is instruction morphemic analysis. Even though it has been identified as a strategy with potential, it has not received the depth of focus as other areas of literacy, such as phonology (Bowers et al., 2010; National Reading Panel, 2000). The data reveal that this particular strategy has great potential for improving the outcomes for students, but the research base is scarce compared to all other areas of literacy. Although this strategy has potential for improving the outcomes for students with disabilities, who have at least a basic set of literacy skills, there is a need to investigate further the most efficient and effective ways of teaching component and composite skills involved in morphemic analysis. One of those component skills is knowledge of individual morpheme definitions. Up to this point, little attention has been directed towards the isolated teaching of morpheme definitions.

This dissertation study aims to extend upon the findings of Fishley et al. (2011) who used a multiple baseline across morpheme sets design to investigate the effects of a direct teaching package on morpheme definition acquisition. The direct teaching package, GO FASTER, consisted of the direct teaching, graphic organizers, fluency training with flashcards, and self-graphing of fluency. The elements included in GO FASTER were chosen because of the strong research base that exists for each. Direct teaching (Beck, McKeown, \& Kucan, 2002; Baumann \& Kame'enui, 2004; Malmgren \& Trezek, 2009; 
NRP, 2000; Roberts et al., 2008; Stahl \& Fairbanks, 1986; Swanson, 2006), graphic organizers (Fore, et al., 2007; Malmgren \& Trezek, 2009; National Reading Panel, 2000), fluency training (Cooper et al., 2007; Eshelman, 1985; McCormick, 1999; Swanson \& Hoskyn, 1998; Swanson \& Sachse-Lee, 2000), self-monitoring (Briesch \& Chafouleas, 2009; Graham et al., 2010; Hughes et al., 2002; Sheffield \& Waller, 2010, Lloyd \& Landrum, 1990; Mace \& Kratochwill, 1988; Koegel, et al., 1992; Gumpel \& Schlomit, 2000; Grossi \& Heward, 1998; Graham, 2010; Harris et al., 2005; Harris, 1986), and the teaching of morphemes (Carnine \& Carnine, 2004; Graves \& Hammond, 1980; Wysocki \& Jenkins, 1987; Baumann, et al., 2003; Baumann, 2005; Edwards, 2004) are all supported by empirical evidence. Participants were three high school students with highincidence disabilities. The teaching phase of intervention included dictating to students the morphemes, their definitions, sample words containing the morphemes with their definitions, and a sample sentence containing one of the sample words. As these elements were dictated, students recorded them onto graphic organizers. After each teaching session, students did fluency timings with flashcards, where they identified as many morpheme definitions as they could in 30-seconds. Each session's performance was charted on a graph by the students. If students did not meet mastery criteria during the teaching phase, they moved into a sprint-training phase of multiple 10 -second sprints to prepare for a 30-second timing. Results of the intervention revealed that the direct teaching package was effective in teaching students 45 morpheme definitions and maintaining that knowledge for four to six weeks after each set was mastered. Further, generalization measures showed that students were able to improve their spelling of words 
containing the taught morphemes and improved the accuracy of definitions for words containing the taught morphemes from pre- to post-intervention.

The current study was designed to extend Fishley et al's (2011) study by implementing the intervention in a whole group setting, instead of one-on-one. Teachers are rarely afforded the opportunity to work one-on-one with their students; therefore, studying the intervention in a more naturalistic setting will help to improve its social validity. Although this intervention was implemented in a whole group setting, fluency drills and self-graphing were both done in a peer-tutoring situation. This made it more practical and also allowed for each participant to get additional exposure to the morphemes as his or her partner took his or her turn with the timings. The previous GO FASTER research is also extended by increasing the fluency aim from 25 corrects in 30 seconds to 40 corrects in 30 -seconds. This was done because of the ease at which students met the previously set aim of 25 . Increasing the aim allowed for an investigation of the effects of raising the aim on maintenance performance. 


\section{Chapter 3: Method}

This section will describe the process of conducting this study. Elements include the study's setting where the study took place, participants involved in the research, and each phase of the study from the initial recruitment of participants to post-intervention data collection. Each step in the process will be detailed.

\section{Setting}

The study took place in a high school within a public suburban school district in the Midwest. Roughly $75 \%$ of the students who attend this school are white, $6 \%$ are black, $12 \%$ are Asian, and 2\% are Hispanic. About $8 \%$ of students are considered to be economically disadvantaged. Ten percent of students receive special education services.

Before beginning recruitment of participants, permission was granted by the building principal to conduct the research in the school (Appendix A) and IRB approval was secured. Students were recruited from a resource room senior English class. Intervention and data collection were conducted in two different rooms. Most of the intervention took place in the English classroom, which was set up like a typical classroom with 12 front-facing desks with chairs. The teacher's desk was in the front

corner of the room. She sat at her desk during each session, but did not participate in any 
way with the research. On three occasions, a substitute was the teacher of record and she also sat at the teacher's desk and did not participate in the research.

Data collection occurred in a computer lab next to the English classroom at a small table with two chairs. Fluency timings were conducted at this table with one student at a time. The computer lab was always quiet and empty during data collection.

\section{Participant Recruitment}

The students were given paperwork containing an explanation of the study and a permission form to sign, (Appendix B) as they were all 18 or older and did not need to consult their parents, although the researcher recommended they do so. After providing the signature, students turned the form in to a locked box that was on a desk in the back of the classroom. After a week, the locked box contained all five permission forms signed by the students who were 18 or older. Before beginning any phase of the study, the researcher met with the students to review the purpose of the study and the procedures involved. Students were able to ask questions at this time and were free to leave the study at this time, or any time during the study, without consequence.

\section{Participants}

Five high school students with high-incidence disabilities were recruited for participation in this study (See Table 1). To be included in the study, students had to have an Individualized Education Program (IEP) with reading and/or written expression objectives. Students in this class are seniors (ages 18-19). Of the five participants, future

plans included entering the Coast Guard (Leila), attending a four-year university (Allen), and three planned to attend a regional state campus near the city they live (Jordan, Salena, and Nathan). 


\begin{tabular}{lccccccc}
\hline Pseudonym & Gender & Race & Grade & Age & Disability & $\begin{array}{c}\text { WISC-IV } \\
\text { Full Scale }\end{array}$ & $\begin{array}{c}\text { Literacy } \\
\text { Standard } \\
\text { Score }\end{array}$ \\
\hline Salena & Female & Black & 12 & 18 & $\begin{array}{c}\text { SLD (math } \\
\text { and basic } \\
\text { reading) }\end{array}$ & 77 & $88^{2}$ \\
Jordan & Male & White & 12 & 18 & OHI & 89 & $82^{3}$ \\
Leila & Female & White & 12 & 19 & OHI & 80 & $87^{3}$ \\
Nathan & Male & White & 12 & 18 & OHI & 95 & $97^{4}$ \\
Allen & Male & White & 12 & 18 & $\begin{array}{c}\text { SLD (basic } \\
\text { reading and } \\
\text { written } \\
\text { expression) }\end{array}$ & 90 & $88^{4}$ \\
\hline
\end{tabular}

Table 1. Participant Characteristics.

${ }^{1}$ Wechsler Intelligence Scale for Children

${ }^{2}$ Woodcock Reading Mastery Test: Letter-Word Correspondence

${ }^{3}$ Woodcock Reading Mastery Test: Passage Comprehension

${ }^{4}$ Wechsler Individual Achievement Test: Written Expression

\section{Researchers}

The researcher was a third-year special education doctoral candidate in the College of Education and Human Ecology at The Ohio State University. She held a Master's degree in special education and a teaching license in mild/moderate disabilities in grades K-12. She was a classroom teacher for two years in both self-contained and inclusion settings at the high school level. Additionally, prior to her public school teacher, she worked in a clinical setting for two years with children with autism from ages 2-12. 
The second data collector was a second-year special education doctoral student in the College of Human Ecology at The Ohio State University. She holds a master's degree in special education and has worked in the private sector and as a college disability services coordinator.

\section{Dependent Variables}

The primary dependent variable was the number of correct morpheme flashcard definitions stated in 30 seconds. For each morpheme, students were taught a definition. In order for a response to be counted as correct, the student must have used each word in the taught definition. Data were also collected on incorrect responses. If the students did not say each word in the taught definition, it was considered incorrect.

Generalization measures. To assess generalization, students were given writing probes to assess whether they could correctly use targeted morphemes in their writing. These data were collected at the conclusion of baseline, tier one, tier two, tier three, and maintenance phases of the study. In each writing piece, students were scored on the number of words they used that contain targeted morphemes. To be counted, students must have spelled the morpheme correctly and used the word correctly within the sentence. If the morpheme was misspelled or if the word was not used correctly within the sentence, it was not counted. The following examples illustrate how writing samples were scored. If a targeted morpheme was "un" and a student wrote, "I am very unselfish and gave the money to charity," the student would receive one point for using and spelling the word unselfish correctly. If the students wrote, "I am very unselfish and kept the money and bought what I wanted," the student would not receive a point because although the student spelled the morpheme correctly, he did not use the word in a way 
that indicated he understood the meaning of the word. Therefore, the word is used incorrectly and would not be counted as correct.

As a pre/post generalization assessment, students' writing fluency was assessed before and after intervention using AIMSweb written expression probes. Writing fluency was defined as the number of correct writing sequences written in 3 minutes in response to a story starter. Writing probes were administered following the AIMSweb Administration and Scoring Written Expression Curriculum-Based Measurement Training workbook.

Maintenance. Maintenance was assessed approximately two and four weeks after each set was mastered. To assess maintenance, students completed 30-second timings with their flashcards, without any review.

\section{Independent Variable: GO FASTER}

GO FASTER (Graphic Organizer, Flashcards Added up, Self-graph to Track progress, Errors Reviewed) is a direct teaching package used to teach students morpheme definitions. The package consists of the direct teaching of morphemes, their definitions, sample words containing the morphemes, and a sentence containing one of the sample words using a graphic organizer. After teaching the morphemes, students participate in fluency timings with flashcards that contain the morphemes on one side and their definition on the other side. Timings are done with peers, and students self-graph their performance. The intervention schedule is included in Appendix C.

\section{Social Validity}

Students and the classroom teacher completed consumer-satisfaction surveys when intervention concluded (Appendix D). The survey consisted of eight (student) to 
ten (teacher) positively stated statements where the level of agreement with the statement was circled. Statement were aimed at evaluating each of the following: Goals, Objectives, and Outcomes. For each statement, students and the teacher had the option of circling: agree, somewhat agree, somewhat disagree, or disagree. Their circled responses corresponded with the level of agreement with the positively stated statement.

\section{Instructional Materials}

The following materials were needed to carry out this study: lined, three-hole punched paper; writing utensils; list of potential target morphemes found in various high school level text books; AIMSweb Written Expression Administration and Scoring Guide; writing prompts from the AIMSweb website; digital timer; 3 x 5 index cards in a variety of colors; LCD projector; graphic organizers (blank for the students); graphic organizers (completed by the teacher on PowerPoint slides); graph paper for students to self-graph timings; data collection sheets; and a plastic bin to contain student materials.

\section{Experimental Design}

A multiple probe across morpheme sets design was used. Each participant was given a minimum of three baseline probes before beginning intervention. The decision regarding when to move a morpheme set into intervention was made based upon the most stable baseline. Because baselines were equally stable, the researcher chose the set that contained words that were identified in consultation with the classroom teacher as most relevant to currently targeted classroom material. Intervention continued until students reached mastery, which was set at 40 correctly identified morpheme definitions in 30 seconds. Once mastery criteria were met, that set moved into maintenance. 
Upon meeting the aim of 40 corrects in 30 seconds over two consecutive sessions, the morpheme set was mastered. This process was repeated for all three sets of morphemes. Once aim was met for all three sets, intervention concluded. When 4 out of 5 participants were able to meet mastery criteria (but the other one had scores lower than 30), the whole class would have continued with the 30-second timings and been asked to set their own goal (higher than mastery criteria). When $4 / 5$ of participants met aim and the other one had scores of 30 or above, the participant who had not met aim continued fluency-training sessions one-on-one with the experimenter and the whole group moved onto the next set at this time.

\section{Procedures}

Pre-baseline. Before collecting baseline data, the researcher conducted probes of 100 morphemes on flashcards. These morphemes were identified by the researcher as frequently used morphemes by high school students, and were discussed with and agreed upon by a high school English teacher. Potential target morphemes were first identified in the books Greek and Latin Roots: Keys to Building Vocabulary (Rasinski, Padak \& Newton, 2008), Words on the Vine (Vurnakes, 1998), and Red Hot Root Words (Draze, 2005). To ensure that these were commonly used by high school students and teachers, the researcher searched through high school English, social studies, math, and science textbooks making sure there were multiple words containing each morpheme in the texts.

Students were given a stack of morphemes flashcards and asked to proceed through them and either say the definition aloud or say pass if they did not know the definition. The goal was to identify 45 morphemes that were unknown to all students in the class. The first student probed was given the stack of 100. The second student was 
given the stack of cards that were unknown to student one. The third student was given a stack of flashcards that consisted of the morphemes that were unknown to students one and two. This continued with the last two students. Because the goal was to identify 45 morphemes that were unknown to all students, it was not necessary to give each student the entire stack of 100 if previous students already knew some of them.

Before beginning baseline, students were given an AIMSweb writing probe as a pre-intervention measure. Two probes were chosen randomly to use in this study from the AIMSweb website. One was given before intervention began and one was given after intervention had concluded. Probes were counterbalanced to address the possibility of one probe being easier than the other. Three students received probe A during preintervention and two received probe B at this time. During post-intervention, the three students who received probe A during pre-intervention were given probe B. The two students who received probe B during pre-intervention received probe A during postintervention.

Pre- baseline training. Before beginning baseline probes, students were trained on the proper way to flip through their cards, how to graph, and how to serve as a peer partner for the timings (Appendix E). Training began with an explanation of the importance of fluency in this intervention. They were also told to pass on any flashcards they did not know without penalty and that passing would allow them to get to the ones they did know. The procedures for flipping through the cards were explained (flipping so that the partner can see the correct answer on the back). Students were then informed of the role they would play as a partner (i.e., counting cards, separating them into piles) and how to graph. After a brief explanation, the teacher and the researcher modeled fast 
timings (saying pass for each one), separated cards into the correct piles, and recorded and graphed the results. Students then had an opportunity to practice the procedure with their partners using the flashcards containing morphemes that were known to the students, which had been eliminated in pre-baseline probes.

Baseline. The 45 unknown morphemes were divided into three sets of 15 (Appendix F). Each morpheme was written on an index card, and each morpheme/card was repeated for a total of three cards per morpheme (e.g., 3 "un" cards, 3 "bio" cards, etc.). Thus, each morpheme set consisted of 45 cards. Students were given 30 seconds to flip through each morpheme set and state as many definitions as they could. Students repeated this process until a steady baseline was established for at least one morpheme set. During baseline, students continued to participate in their regular English classes. The current classroom literacy instruction consisted of reading the book War of the Worlds. Class began with a discussion of the previous night's chapters read for homework and students were asked if they came across any words that they did not know. The teacher would then define those words and give examples of how those words were used in everyday language. During this class, students were given weekly quizzes over the book and other projects such as creating study guides and writing reactions and predictions based on the book.

Intervention phase 1: Direct teaching with graphic organizers. The first phase of the intervention consisted of using a scripted direct teaching procedure (Appendix G) with graphic organizers (Appendix $H$ ) to help students learn the meanings of the morphemes. Specifically, each of the first three intervention sessions for each morpheme set consisted of the experimenter introducing five morphemes using direct instruction and 
a graphic organizer. Each student had blank copies of the graphic organizers, and the experimenter used an LCD projector to display the PowerPoint slides (Appendix I) that showed students what to write onto their copies. On each graphic organizer, students recorded the target morpheme, its definition, two sample words containing the morpheme, definitions for the sample words, and a sentence that included one of the sample words. All sections of the graphic organizer were dictated to the participants following a script, and a visual model was provided on the overhead. Additionally, students located the flashcard containing the morpheme and placed it next to the organizer. Upon completion of each graphic organizer, students chorally read aloud the morpheme, its definition, both sample words, and the sample sentence. The experimenter asked the students to turn over the graphic organizer and asked for the definition, aloud in a choral response format. After completing each graphic organizer, students chorally said the definition of each morpheme learned in that session. For example, if the first two morphemes taught were bio and anti, then after learning the third morpheme they would chorally say the definition of bio, anti, and the most recently learned morpheme as the morphemes were presented to them on the PowerPoint slide. The students continued to say each definition chorally as they complete each graphic organizer.

After completing the five graphic organizers for each session, the students paired up with their partner for one 30 -second timing with all 45 flashcards in the current set. Because there was an uneven number of students, three of the participants rotated partners each session. The participant who did not have a partner that day was paired up with the researcher or an aide in the classroom. After the first intervention session, students had learned only five morpheme definitions, but because they are repeated 3 
times each, they could potentially have identified up to 15 definitions of morphemes taught that session. By session two, they had been taught 30 of the flashcards and by session three they had been taught all 45 in the stack.

Beginning at session 2, each student was reminded of the previous score by referring to his or her graph and encouraged to beat it. Participants held the flashcards with the morpheme facing them and said the definition or "pass" if the word was unknown. Each card was flipped and placed on the desk so that the definition was visible to the partner sitting across from them. The partner separated corrects from the incorrects and passes as the participant progressed through the cards. At the conclusion of the 30second timing, the partner counted the cards and alerted the participant of the number of corrects and incorrects/passes. Participants graphed the number of corrects on their graphs. After the first timing, they were instructed to switch roles with their partner and allow the second partner to do a 30 -second timing.

After each student had the opportunity to do a 30 -second timing and graph the results, each student came into the computer lab to do one 30 -second timing with the researcher for data collection purposes. These individual performances were used to measure the dependent variable. When 4 out of 5 of the participants mastered the currently targeted set and the fifth student had scores of 30 or more, the class moved to the next set.

Phase two: Sprint training. If 4 out of 5 of the participants did not reach aim with one having scores of 30 or more after three teaching sessions with the graphic organizers, sprint training was implemented (Appendix J). Students were informed that in this phase they will do four consecutive timings that were 10 -seconds long and with 
only 15 cards (the original 15 morphemes). Each stack of cards was of one color. There was a pink set, a green set, and a yellow set. In order to make it easier for the students to find 15 cards that included all of the morphemes, one of the sets of three in each set was a lighter shade of that set's color. For example, within the yellow set, there were 45 cards. Fifteen cards were light yellow and consisted of one copy of each morpheme in that set. The other 30 flashcards in the yellow set were darker yellow and consisted of two copies of the 15 morphemes in that set. They were told that they would be doing four timings in a row, with their partner, with the 15 lighter colored cards and would record their results on the sprint graph after each timing. Students were told that if they were able to say 15 correctly in less than 10 seconds, they would be asked to add more cards to the stack. Between each timing, they were to review missed and/or passed morphemes. The partner played a very important role in this phase. They were to separate cards quickly, count them and report the totals, and then give any missed or passed cards to their partner to review very quickly. After four sprint timings, they would be given a 30 -second timing with their partner. Each partner completed the sprints and one 30-second timing before having the individual 30 -second data collection timing with the researcher in the computer lab. These procedures were modeled by the teacher and the researcher before asking the students to do this independently. Students were then given an opportunity to practice the procedure.

Training began with the students reviewing all 15 morphemes in the current set on their own. After reviewing each morpheme on their own, the experimenter then instructed the students to find a partner, shuffle their 15 cards, and get ready to begin their four 10second sprint timings. When the instructor said, "go," the partner who was doing the 
timing began saying as many definitions as he/she could in 10 seconds. The other partner separated the pile into corrects and incorrects/passes. The instructor told the students when 10 seconds was up and the partner counted the total corrects and reported them to their partner. After each timing, the student recorded his or her corrects on the graph. This continued for four consecutive 10-second timings. After the sprint training session, the participants had a 30 -second timing with their partner and graphed their performance. Each partner went through these steps. Once each partner went through the sprint training, they individually met with the researcher in the computer lab for their official 30 -second timing.

Maintenance. To assess students' maintenance of learned morpheme definitions, students participated in 30-second timings for each mastered set two and four weeks after mastery. Students were timed, individually, in the computer lab with the morpheme set(s) that was in maintenance. They were not given any time to look at the cards before beginning the timing. They were instructed to begin when they were ready with the top card. Once they said the first definition or "pass," the researcher started the timer. Students continued to flip through the stack, saying the definition or "pass," for 30 seconds while the researcher separated the cards into piles of corrects, incorrects or passes. After 30-seconds, the total corrects and incorrects were recorded as official maintenance data. These timings were done for each set, two and four weeks after each set was mastered.

Generalization. The researcher distributed worksheets that included a writing prompt, lines for writing on, and a morpheme bank to each student (Appendix K). Prompts were expository in nature and contained the beginning of a sentence and 
students were asked to finish the sentence and continue writing on the topic. The following is one example of a writing prompt that was used: When I graduate, I plan to... Writing prompts were counterbalanced according to the following table.

\begin{tabular}{llllllllllll}
\hline Student & Phase & Prompt & Student & Tier & Prompt & Student & Tier & Prompt & Student & Tier & Prompt \\
\hline 1 & BL & A & 1 & 1 & B & 1 & 2 & C & 1 & 3 & D \\
2 & BL & B & 2 & 1 & C & 2 & 2 & D & 2 & 3 & A \\
3 & BL & C & 3 & 1 & D & 3 & 2 & A & 3 & 3 & B \\
4 & BL & D & 4 & 1 & A & 4 & 2 & B & 4 & 3 & C \\
5 & BL & A & 5 & 1 & B & 5 & 2 & C & 5 & 3 & D \\
\hline
\end{tabular}

Table 2. Writing Prompt Schedule.

Students were told to use as many of the morphemes in the morpheme bank within whole words in their writing. Additionally, they were informed that they could use a morpheme as many times as they want but only the first use of each word would be counted. After passing out the writing sheets, students were given one minute for thinking time and three minutes to write. If they stopped writing before the three-minutes had elapsed, they were encouraged to "keep going." Writing pieces were evaluated to see how many of the morphemes from the word bank were used correctly within the writing pieces. In order to be counted as correct the morphemes, but not the whole word, had to be spelled correctly. Students were asked to complete these writing probes in each phase.

\section{Inter-rater reliability}

To assess inter-rater reliability on the dependent variable, a second observer scored the total morpheme corrects and incorrects during researcher-student timings. The experimenter and second scorer sat side-by-side while each student flipped through their 
cards during their official 30-second timing. As each student flipped a card, the scorers put a check in the "correct" or "incorrect" box on the IOA sheet. At the conclusion of each student's timing, each scorer added up their checks and circled the totals. Those numbers were then compared and calculated using total count IOA.

To assess IOA for generalization data, a second scorer scored the generalization writing pieces. A photocopy was made of each participant's writing pieces and scored by both the researcher and the second scorer. IOA data were collected on two writing pieces in each phase. The other pieces were used for training purposes.

Training was provided to this second scorer in the form of defining which words will be counted as correct and which words will not. The scorer was also trained on how to identify whether the word was used correctly within the sentence. To practice trained skills, the second scorer and the researcher independently scored multiple sample writing pieces and compared and discussed scores. When at least $90 \%$ agreement was reached on two consecutive writing pieces, training concluded. The first phase of IOA included the two scorers independently circling each word that included a morpheme from the morpheme bank. After circling each independently, the scorers compared their circled words. If there was a disagreement, the two scorers discussed their differences and tried to reconcile. If the two were not able to agree, the researcher's opinion prevailed. This first phase is important, as a discrepancy in this first stage would have greatly affected the scores in the second phase. Therefore, it was important to ensure each scorer was assessing the same words in the second phase. Once the scorers completed this phase, they moved onto independently scoring whether the morpheme was spelled correctly within the word and whether the whole word was used correctly in the sentence. 
When scoring, the scorers evaluated each of the words circled in the first phase. If the word was spelled correctly and used correctly within the sentence a + was made above the word. If it was spelled wrong or used incorrectly, a - was placed above the word. Agreement was calculated using the formula agreement/agreements + disagreements x 100. An interobserver agreement measure was also taken on the number of morphemes identified by the scorers using a gross method. Specifically, the number of morphemes identified by the first scorer was divided by the second scorer's identified morphemes.

To ensure inter-rater reliability for the primary dependent variable, the second observer collected data in 33\% of sessions with at least one observation in each phase. During these observations, the researcher and second observer each had a sheet with two columns marked correct and incorrect/pass (Appendix L). As the students flipped through their flashcards during their individual 30-second timings, both scorers made tallies in the correct columns. These totals were compared. Agreement was calculated using the formula agreement/agreements + disagreements x 100 .

\section{Procedural integrity}

The second scorer observed 33\% of the sessions. Every phase of each baseline was observed at least once. The second scorer was given a checklist of steps (Appendix M) that the researcher was to have followed during that session. As the researcher completed each step a + was recorded. If a step was missed a - was recorded by that step on the checklist. The percentage of completed steps was calculated. 


\section{Chapter 4: Results}

In this chapter, data will be presented regarding inter-observer agreement, procedural integrity, fluency, generalization, short-term maintenance, long-term maintenance, and social validity.

\section{Inter-observer Agreement}

Inter-observer agreement (IOA) was calculated for fluency scores, generalization probes, and pre- and post-intervention measures. Agreement was calculated in two different ways. For generalization and pre- and post-intervention measures, the formula agreements over agreements plus disagreements multiplied by 100 was used. To calculate IOA for fluency scores, total count IOA was used following the formula smaller count divided by larger count multiplied by 100 .

Fluency IOA. IOA data for fluency measures were collected at least once during each phase of the study. For the purposes of this study, fluency was determined to be the number of correctly identified morpheme definitions in 30 seconds, using flashcards. A second scorer observed $33 \%$ of fluency timings. The first and second scorer made tally marks in either the "correct" or "incorrect" columns of the data sheet, as the students did their individual fluency timings. At the conclusion of each timing, totals were calculated 
for corrects. These totals were compared to evaluate IOA on the dependent variable. Mean IOA was found to be $99.7 \%$ with a range of $98 \%$ to $100 \%$.

Generalization IOA. IOA data on generalization measures were taken in all five phases throughout the study. They were taken during baseline, once students achieved mastery for each morpheme set, and once at the time of four-week maintenance checks. These probes consisted of giving students a writing prompt and morpheme bank, and asking students to write for 3-minutes in response to the given probe using as many whole words containing the taught morphemes in their writing pieces. In phase one of IOA, each scorer independently circled the words used in each writing piece that contained taught morphemes. The two scorers then compared these results and reconciled in order to ensure agreement before beginning phase two of IOA. In phase two, each scorer evaluated the agreed upon circled words containing the taught morphemes, by deciding if the morphemes within the words were spelled correctly and were used correctly in the sentence. Two observers scored $40 \%$ of the generalization probes ( 2 in each phase) with 97\% agreement in phase one and 100\% agreement in phase 2 .

IOA data were also taken on the pre- and post-intervention measure: AIMSweb writing probes. Agreement was measured on total words written, correct writing sequences, and words spelled correctly. Sixty percent of these writing pieces were used for IOA. Agreement was at 99.7\% (TWW), 97.3\% (CWS), and 99.8\% (WSC), respectively, for each AIMSweb measure.

\section{Procedural Integrity}

Procedural integrity was calculated for each type of session led by the researcher. A second scorer observed $33 \%$ of sessions, with at least one observation during the 
teaching phase and sprint phase, and during the official independent timings. The second scorer was given a checklist of steps the researcher was to follow when implementing the intervention. When the researcher correctly completed each step, a "+" was placed next to that step. If the researcher had missed a step, a " - " would have been placed in that spot instead. Procedural integrity was calculated to be at $100 \%$ across all phases of the intervention.

\section{Effects of Intervention}

Effects of intervention were measured by assessing morpheme definition fluency using flashcards. Students were given 30 seconds to flip through their flashcards and identify as many morpheme definitions as they could for each set. There were three sets (Green, Yellow, and Pink) that contained 15 morphemes each, and each set contained 45 flashcards (three copies of each morpheme in that set).

Allen. Allen had scores of 0 across all baseline measures. Mean intervention scores across sets were 28.3 (range: 11-41), 29.1 (range: 8-42), and 30.9 (range: 9-45). Overall intervention mean, across all three sets, was 30.4 (range: 8-45). Allen needed either 7 or 8 (mean of 7.6) sessions to meet mastery of a morpheme set. Allen required one-on-one sprint training with the researcher in set one, so it took him two more sessions to reach mastery than his peers. In set one data, the teaching phase shows a slight increase across sessions. Once the sprint-training phase began, there is a sharp upward trend in the data. Set two has a similar trend in the teaching phase, but in the sprint phase, there is a decline after the first data point before the trend turns upward. In set three, data show a rapid upward trend from the teaching phase into the first two data points in the sprint phase. Then, there is a slight dip in scores before the trend turns quickly upward. 
Allen's two- and four-week maintenance scores were 26 and 31 for set one, 35 and 30 for set two, and 34 and 32 for set three. His maintenance scores were all markedly above baseline scores. Further, the overall maintenance mean (31.3) was slightly above the overall intervention mean (30.4), and two- (31.7) and four-week (31.0) mean maintenance scores show that morpheme definition maintenance remained consistent at both two and four weeks after mastery. Allen's results are shown in Figure 1 below. 
BL GO FASTER MAINTENANCE

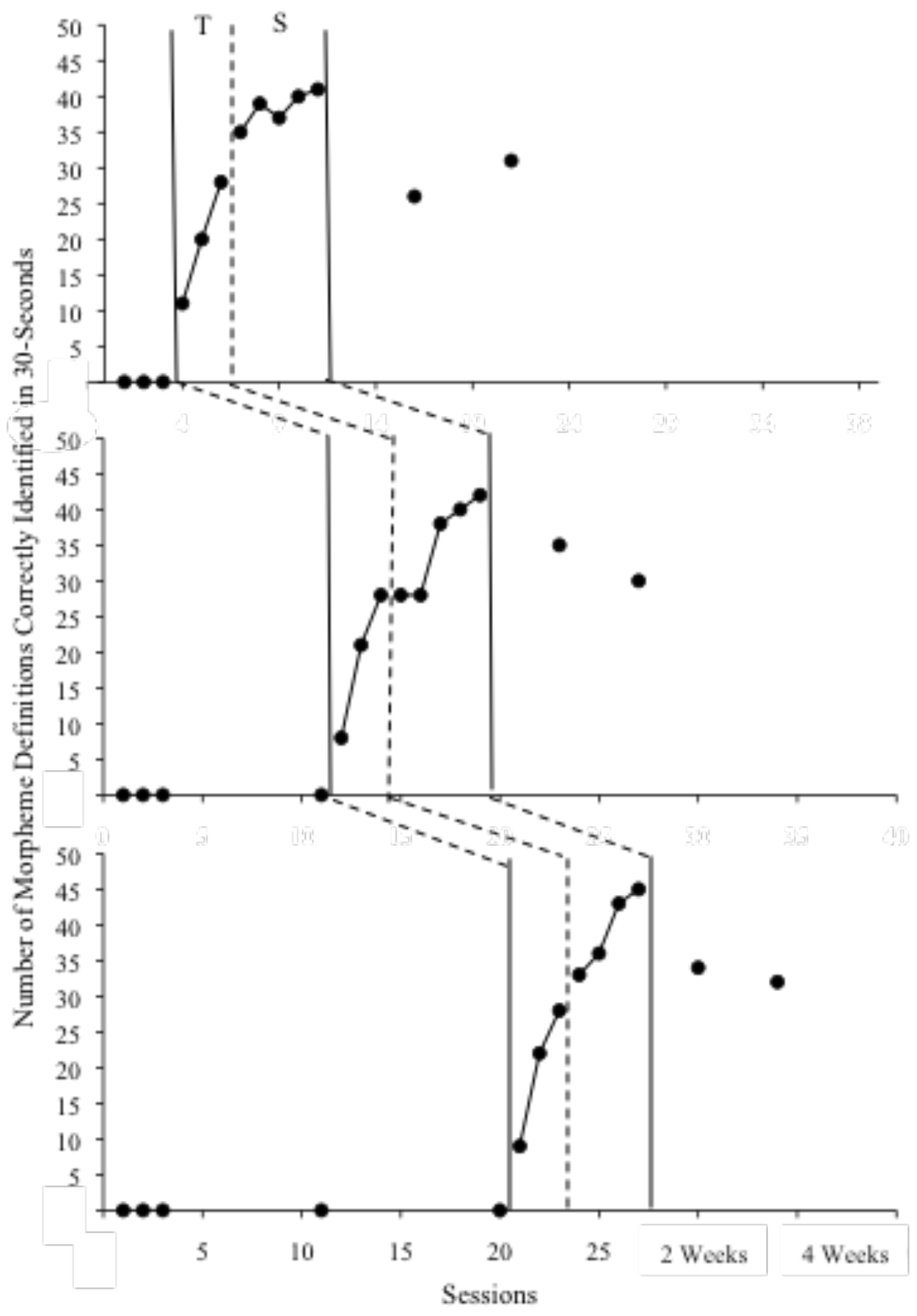

Figure 1. Allen's results.

Note. $\mathrm{T}=$ Teaching Phase; $\mathrm{S}=$ Sprint Phase 
Jordan. In baseline, Jordan had consistent scores of 0 across this phase. His mean intervention scores were 36.2 (range: $23-45$ ), 42.8 (range:18-54), and 44.1 (range: $23-$ 56). His overall mean intervention score was 41.3 . For each set, Jordan was able to meet mastery in five sessions. Jordan's scores often surpassed the total cards in each set (45). He often finished his stack of cards before the timer went off. In these cases, he would pick up already flipped cards and continue to identify those definitions until time expired. Jordan did not require one-on-one sprint training at any time during the study. Visual analysis of his graph shows an immediate change in level and a rapid upward trend at the beginning of intervention across all sets. After the first timing, trends continue upward, gradually. There was on dip in set three when the phase changed from teaching to sprints.

Two- and four-week maintenance scores were 38 and 52 for set one, 47 and 51 for set two, and 55 and 46 for set three. In sets one and two, four-week maintenance scores were higher than two-week. Also, in set one, the four-week maintenance point was higher than scores earned during intervention. The overall maintenance mean (48.2) was higher than the mean intervention score (41.3). Further, Jordan's four-week maintenance mean (49.7) was higher than two-week maintenance (46.7) scores. Jordan's results are shown in Figure 2 below. 


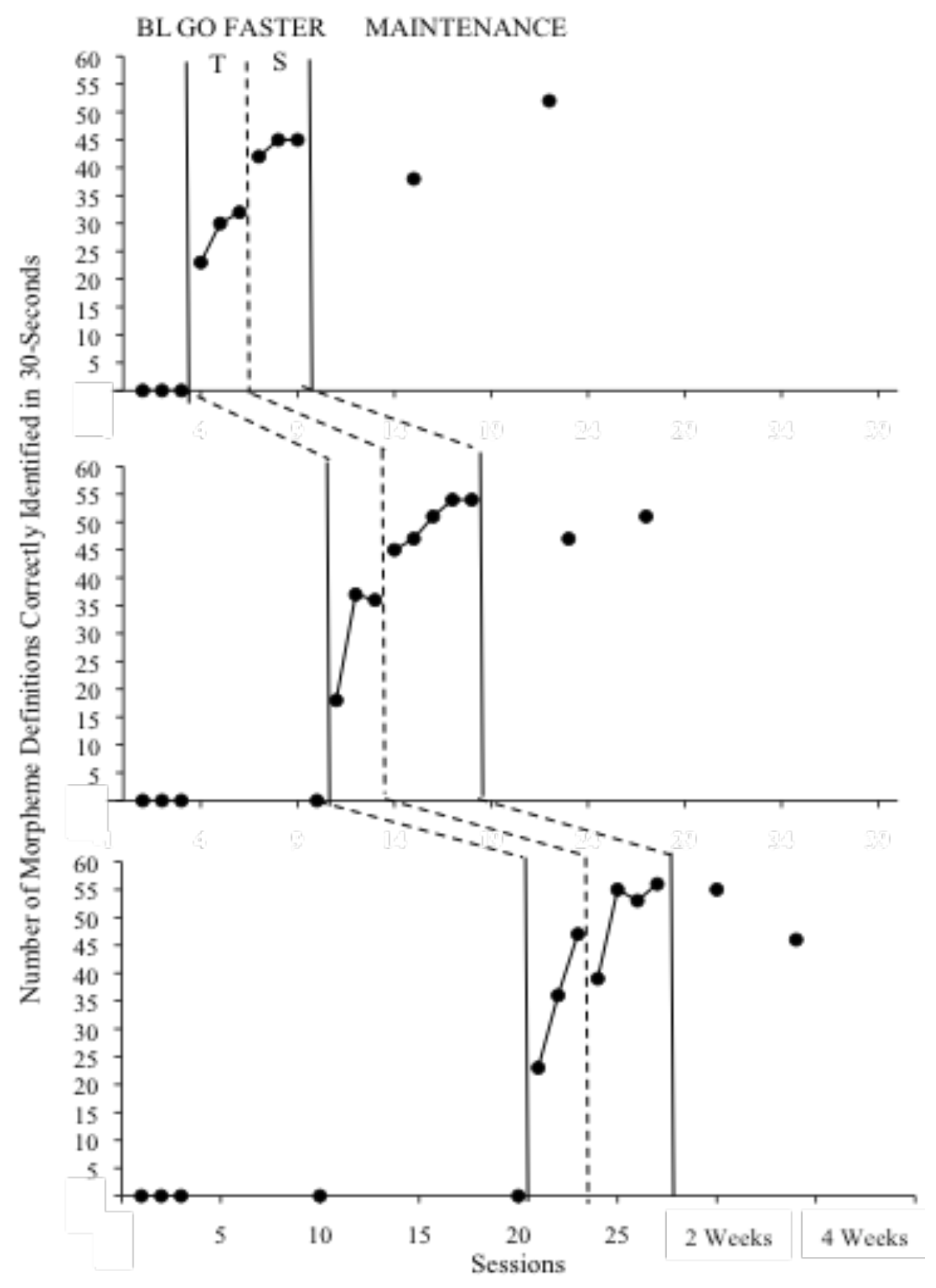

Figure 2. Jordan's results.

Note. $\mathrm{T}=$ Teaching Phase; $\mathrm{S}=$ Sprint Phase 
Leila. Leila's baseline scores were 0 across all sets. Her mean intervention scores were 34.4 (range: 9-44), 30.9 (9-48), and 32.0 (13-45). The overall mean intervention score was 30.6. Leila needed 6 or 8 (mean of 6.3) sessions to meet mastery in each set. In set two, Leila's highest score surpassed the 45 cards in the set. In this set, she picked up the flashcards she had already completed and continued to identify morpheme definitions until the timer expired. Leila did not require one-on-one sprint training in order to meet aim at any time during the study. In sets one and two, a steady incline is seen from the first intervention session to the final session. Set three's trend is a bit different. It starts out with a steady upward trend in the teaching phase and first session of sprint training. Then, a rapid increase is seen before the final three scores remain steady around mastery. Leila's maintenance scores were 18 and 34 in set one, 43 and 45 in set two, and 36 and 35 in set three. Her mean overall maintenance score (35.2) is higher than the mean intervention score (30.6). Additionally, four-week maintenance scores (35.5) were higher than two-week maintenance scores (32.3). Leila's results are shown in Figure 3 below. 


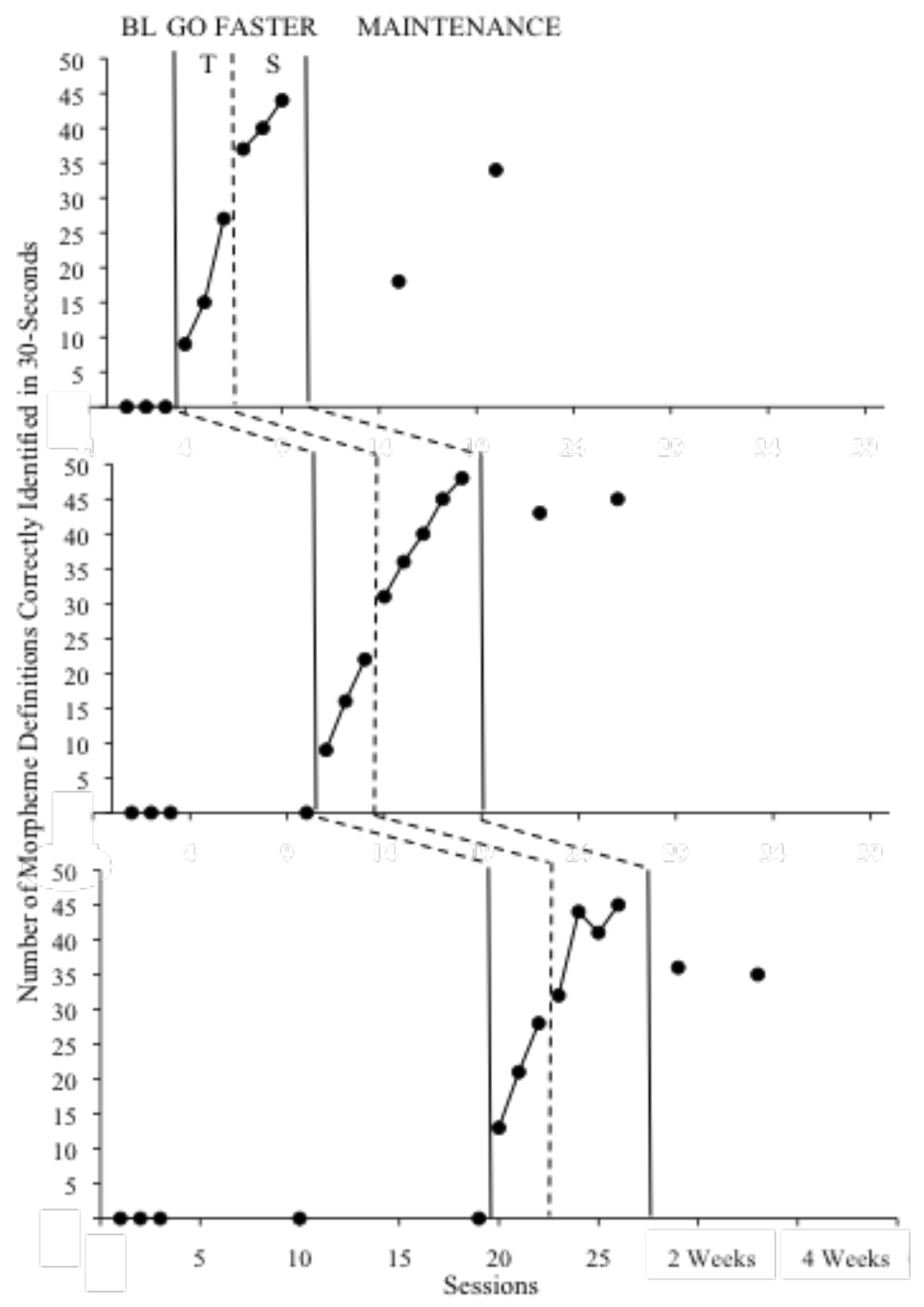

Figure 3. Leila's results.

Note. $\mathrm{T}=$ Teaching Phase; $\mathrm{S}=$ Sprint Phase 
Nathan. Nathan's baseline scores were all zero across each set. His mean intervention scores were 30.4 (range: 10-41), 31.1 (range: 13-44), and 29.2 (range: 1143). His overall mean intervention score was 28.7. Nathan needed between 6 and 10 (mean of 8.6) sessions to meet mastery for each set. He required one-on-one sprint training with the researcher in sets two and three. In set two he needed one extra sprint session to meet aim and three extra in set three. In set one, Nathan's trend shows a steady increase in scores across all sessions. In sets two and three, there is a steady increase in the teaching phase but scores show a slight decrease before a rapid upward trend in the sprint phase.

Two- and four-week maintenance scores were 28 and 26 for set one, 36 and 24 for set two, and 21 for set three. The school year ended before four-week maintenance data could be collected for the set three. Nathan's mean maintenance scores (27.0) were slightly below the intervention mean (28.7). His two-week mean maintenance score (30.0) was higher than his four-week mean maintenance score (25.0). Nathan's results are shown below in Figure 4. 


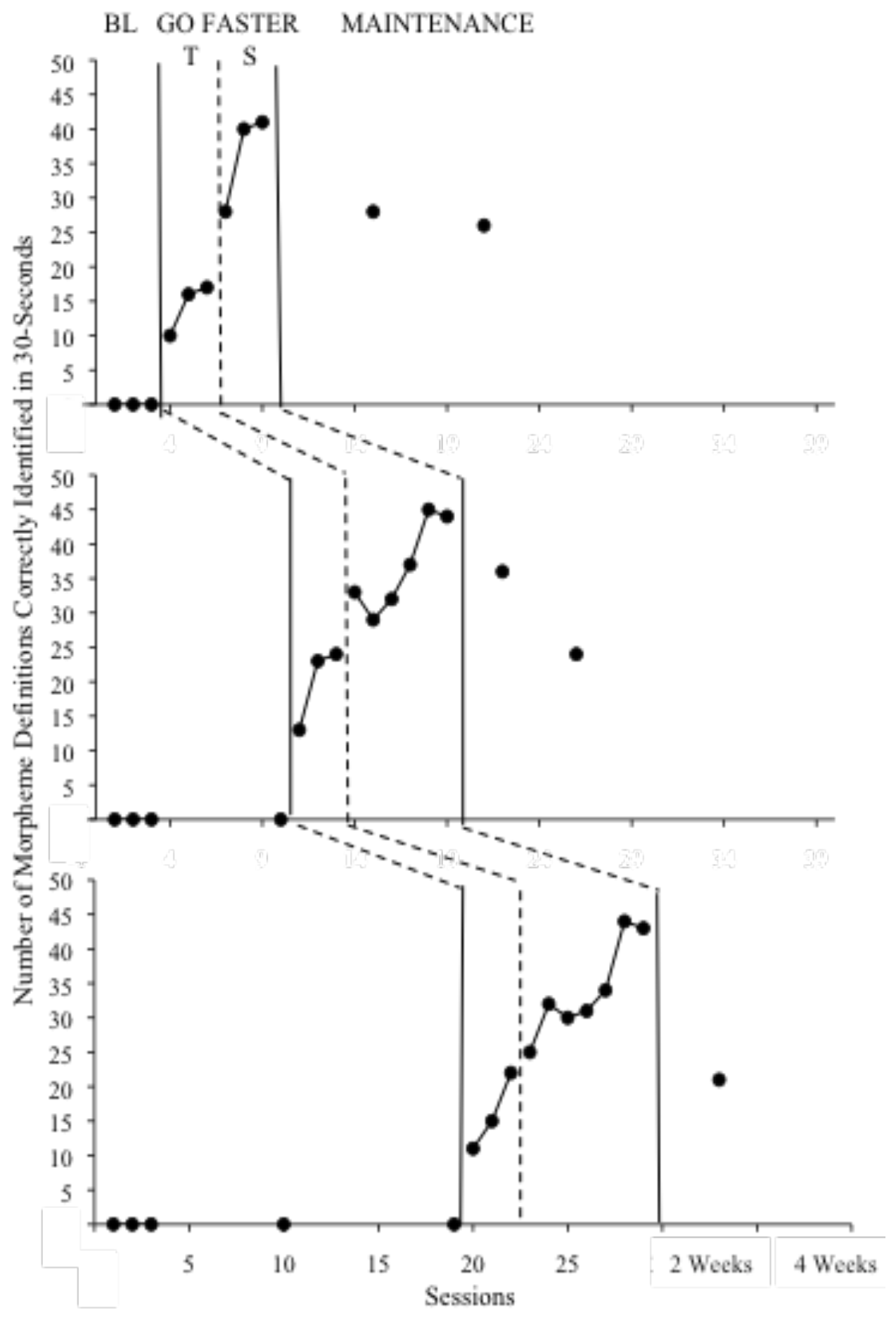

Figure 4. Nathan's results.

Note. $\mathrm{T}=$ Teaching Phase; $\mathrm{S}=$ Sprint Phase 
Salena. During baseline, Salena's scores were all steady at zero. Her mean intervention scores were 31.0 (range: 9-42), 34.3 (9-51), and 41.4 (range: 14-45). Her overall mean intervention score was 33.6. For each set, Salena needed just 5 intervention sessions to meet mastery. In set two, Salena's highest score exceeded the number of flashcards in the set. To achieve this score, she picked up flashcards that she had already identified and continued to name definitions until the 30 -seconds expired. Salena did not require any one-on-one sprint training during the study. Trends show a rapid upward climb in the teaching phases across all sets. Trends continue upward in the sprint phases, although a more gradually increasing stable trend is seen there.

Salena's two- and four-week maintenance scores were 38 and 45 for set one, 45 and 43 for set two, and 38 and 43 for set three. Salena's overall mean maintenance scores (42.0) were higher than overall mean intervention scores (33.6). Her four-week maintenance scores (43.7) were higher than two-week maintenance scores (40.3). Salena's results are shown below in Figure 5. 
BL GOFASTER MAINTENANCE

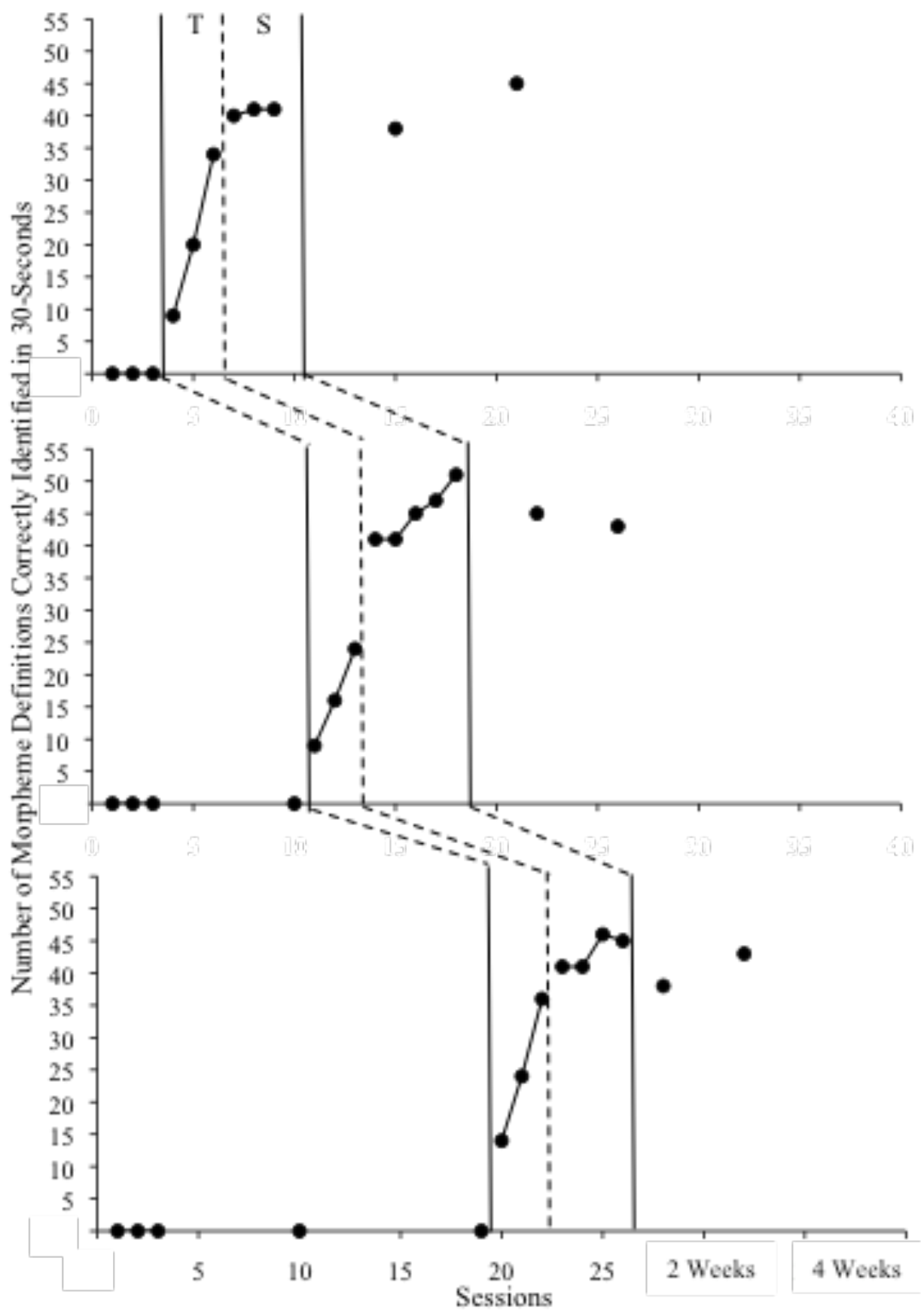

Figure 5. Salena's results.

Note. $\mathrm{T}=$ Teaching Phase; $\mathrm{S}=$ Sprint Phase 


\section{Generalization}

Generalization was assessed using two measures. The first generalization task required students to respond to a writing prompt and incorporate as many whole words containing the taught morphemes as they could, within their response. This task was completed by the students in each tier of intervention; during baseline, after each set was mastered and once during maintenance. The second generalization task used AIMSweb

writing probes to measure correct writing sequences (CWS), total words written (TWW), and words spelled correctly (WSC). Students were assessed using the AIMSweb measures once before intervention began and once after the final maintenance data point was collected. For both generalization tasks, students were given one minute of think time after being presented with the story starter, and three minutes to write.

Morpheme writing probes. On morpheme writing probes, the mean baseline score across all participants was 0.8. In tier one, mean scores improved to 2.6. Tier two and tier 3 means were 3.0 and 3.6, respectively. The mean maintenance probe score on this measure was 4.4. Detailed results are listed below (Table 3). 


\begin{tabular}{lccccc}
\hline \multirow{2}{*}{ Participant } & \multicolumn{5}{c}{ Morpheme Usage in Generalization Writing Probes } \\
\cline { 2 - 6 } & Baseline & Tier 1 & Tier 2 & Tier 3 & Maintenance \\
\hline Salena & 0 & 3 & 0 & 4 & 3 \\
Jordan & 2 & 1 & 2 & 4 & 4 \\
Leila & 0 & 2 & 4 & 3 & 3 \\
Nathan & 1 & 6 & 7 & 7 & 9 \\
Allen & 1 & 1 & 2 & 0 & 3 \\
& & & & & \\
\hline
\end{tabular}

Table 3. Morpheme Usage in Generalization Writing Probes.

AIMSweb writing probes. Most students showed large gains from the preintervention to post-intervention scores on the this task. Mean pre-intervention scores were 48.4 (TWW), 43.4 (CWS), and 44.2 (WSC). Mean post-intervention scores improved to 67.2 (TWW), 68.0 (CWS), and 64.0 (WSC). Detailed results are listed below (Tables 4 and 5). 


\begin{tabular}{lcccccccc}
\hline \multirow{2}{*}{ Participant } & \multicolumn{2}{c}{$\begin{array}{c}\text { Total Words } \\
\text { Written }\end{array}$} & \multicolumn{2}{c}{$\begin{array}{c}\text { Correct Writing } \\
\text { Sequences }\end{array}$} & \multicolumn{3}{c}{ Words Spelled Correctly $^{2}$} \\
\cline { 2 - 8 } & Pre & Post & Pre & Post & Pre Total $^{1}$ & Pre $\%^{2}$ & Post Total $^{1}$ & ${\text { Post }{ }^{2}}^{2}$ \\
\hline Salena & 41 & 65 & 32 & 63 & 37 & 90 & 62 & 95 \\
Jordan & 31 & 47 & 30 & 47 & 29 & 94 & 46 & 98 \\
Leila & 43 & 82 & 43 & 86 & 40 & 93 & 78 & 95 \\
Nathan & 55 & 69 & 46 & 68 & 49 & 89 & 67 & 97 \\
Allen & 72 & 73 & 66 & 76 & 66 & 92 & 67 & 92 \\
\hline
\end{tabular}

Table 4. AIMSweb Writing Probe Results.

${ }^{1}$ Total words spelled correctly

${ }^{2}$ Percentage of words spelled correctly

\begin{tabular}{lccc}
\hline \multirow{2}{*}{ Pseudonym } & \multicolumn{3}{c}{ Correct Writing Sequences } \\
\cline { 2 - 4 } & $\begin{array}{c}\text { Pre-Intervention } \\
\text { Percentile Rank }\end{array}$ & $\begin{array}{c}\text { Post-Intervention } \\
\text { Percentile Rank }\end{array}$ & $\begin{array}{c}\text { Change in Percentile from } \\
\text { Pre- to Post-Intervention }\end{array}$ \\
\hline Salena & 10 & 61 & +51 \\
Jordan & 9 & 31 & +22 \\
Leila & 20 & 89 & +69 \\
Nathan & 24 & 69 & +45 \\
Allen & 63 & 79 & +16 \\
\hline
\end{tabular}

Table 5. AIMSweb Percentile Ranks for Correct Writing Sequences.

Note. Participants' CWS scores were compared to winter norms for pre-intervention probes and to spring norms for post-intervention probes.

\section{Social Validity}

All five participants and the classroom teacher were asked to complete a social validity form. Both forms consisted of positively stated opinions about elements of the intervention. Each participant was asked to circle their level of agreement with each opinion: Disagree, Somewhat Disagree, Somewhat Agree, or Agree. On the student form, 
students were provided with 8 statements to respond to. Two of the statements targeted the goals of the intervention, four statements addressed the methods used within the intervention and two statements were related to the outcome of the intervention. The teacher form contained 10 statements. On the teacher form, the first two statements addressed the goals of the intervention, the next four addressed the methods, and the final four were aimed at assessing the social validity of the outcomes. Both forms had a comment section where participants could feel free to add any notes or suggestions. Students were given the assessments in a group format. They were asked to put their names on the forms. The researcher read each statement to the students and asked them to circle their level of agreement.

Overall social validity results show that students reported enjoying the intervention and that the intervention was successful in helping them to learn new vocabulary. They also strongly preferred the flashcards for learning to the graphic organizers. Jordan's comments were that this intervention was "fun" and that "doing this made me feel smart." Allen and Salena also thought the intervention was fun. Nathan and Leila both appreciated that the intervention was different from anything that they have done in class before and liked the change in routine. Throughout the study, all students voluntarily shared different words they had seen in other classes that contained morphemes that they were learning.

The teacher results were also largely positive. On her social validity sheet, the teacher circled agree for six out of ten statements and somewhat agree for the other four. She strongly agreed with the teaching of morphemes to high school students and said she plans to use a similar intervention to teach students these skills next year. In her 
comments, she reported that she would like to see this intervention used with a more open format. She felt as if students would benefit from a deeper discussion of the morphemes and allowing the students to be more active participants in coming up with their own words and sentences in the graphic organizers. She expressed that if students are able to make their own connections, the impact on generalization may be greater.

\begin{tabular}{lcccc}
\hline Question & Disagree & $\begin{array}{c}\text { Somewhat } \\
\text { Disagree }\end{array}$ & $\begin{array}{c}\text { Somewhat } \\
\text { Agree }\end{array}$ & Agree \\
\hline $\begin{array}{l}\text { 1. Learning about morphemes is } \\
\text { important to learning new vocabulary. }\end{array}$ & 0 & 1 & 2 & 2 \\
$\begin{array}{l}\text { 2. Learning new vocabulary words will } \\
\text { help me do better in school. }\end{array}$ & 0 & 0 & 2 & 3 \\
$\begin{array}{l}\text { 3. Using flashcards helped me learn } \\
\text { morpheme definitions. }\end{array}$ & 0 & 0 & 0 & 2 \\
$\begin{array}{l}\text { 4. I will use flashcards to learn } \\
\text { definitions in the future. }\end{array}$ & 0 & 0 & 3 & \\
5. Using a graphic organizer helped me \\
$\begin{array}{l}\text { to learn morphemes and new words } \\
\text { containing the morphemes. }\end{array}$
\end{tabular}

Table 6. Student Social Validity Results. 


\section{Chapter 5: Discussion}

The purpose of this study was to investigate the effects of a direct teaching package, GO FASTER, on morpheme definition acquisition, maintenance, and generalization. The direct teaching package was implemented by the researcher in a group format with five high school seniors with high-incidence disabilities. A multiple baseline across morpheme sets design was used to investigate the effectiveness of this intervention package. Results indicate that GO FASTER was successful in teaching students morpheme definitions to a pre-determined fluency level. Students were able to maintain morpheme definition knowledge two and four weeks after mastery was reached. Further, students were able to generalize their knowledge of morpheme definitions to their writing. Students and their classroom teacher reported high levels of consumer satisfaction, indicating that this was a socially valid intervention.

The findings of this investigation are consistent with those found by Fishley et al. (2011) in a previous study that investigated the effects of GO FASTER. Further discussion of the results of the present study will be discussed in this chapter. Each research question will be addressed along with the limitations, future research, and implications for classroom practice, below. 


\section{What Are the Effects of GO FASTER Training on Morpheme Definition Fluency?}

Data indicate that a functional relation was established between GO FASTER and morpheme definition fluency. All five students showed an increase in morpheme definition fluency across all morpheme sets, once intervention was introduced. Some students reached much higher levels of fluency than others, but all made noticeable improvements from initial baseline scores.

All students acquired morpheme definition knowledge in the teaching phase, but they required fluency training to meet mastery criteria. Two students needed additional one-on-one fluency training to meet mastery. Specifically, in set one, Allen needed one additional sprint training session with the researcher before mastering the set. In sets two and three, Nathan needed additional training. In set two, he required one individual training session, but in set three he required three additional sessions to reach mastery. One possible reason for the need for additional sessions were the environmental variables associated with the last week of his high school career. He appeared very distracted during the end of the third set and would often attempt to engage in conversations unrelated to the intervention with his peer partner and with the researchers between each timing in his sprint training sessions. It is possible this contributed to his slow progress towards mastery in the third set.

Given that GO FASTER is an intervention package on which only one previous study has been conducted (Fishley et al. 2011), discussion of the current findings in light of existing literature must be done by examining research on the components that comprised the package. One such component is direct instruction. Direct instruction was found to be effective in many studies (Malmgren \& Trezek, 2009; Reed, 2008; Swanson 
\& Hoskyn, 2000; Swanson \& Hoskyn, 2001). Results of the current study support these recommendations to use direct instruction when teaching skills, particularly vocabulary knowledge. Roberts and colleagues (2008) found direct instruction to be effective in teaching many elements of vocabulary, particularly word definitions and how to segment words into their known word parts. The current study supports Roberts et al. in that direct instruction was successfully used to teach morpheme definitions. Swanson and Hoskyn (1998) found a combined direct instruction and strategy instruction approach to produce the largest effect sizes. The current study used direct instruction along with a component of morphemic analysis. Therefore, it was not a true examination of a combined approach, as a strategy was not directly taught, only a component skill of a strategy. In future research on GO FASTER, the intervention package can include an element of teaching students to segment words into their morphemes (morphemic segmentation) in order to further investigation the combination of direct and strategy instruction.

Another recommendation from previous literature is the fostering of a rich and robust environment where teaching vocabulary goes beyond dictionary definitions (Beck et al., 2002). The current study used graphic organizers not just to teach morpheme definitions, but also sample words that contained the morphemes with their definitions and sample sentences. Even though social validity results revealed that students did not value this part of the intervention, anecdotal evidence suggests that all students called upon connections they had made with the sample words and the morpheme definitions to help them remember definitions. Graphic organizers are just one way to accomplish working towards a rich and robust environment, but anecdotal results of the current 
study support their use for helping students to make connects among morphemes and whole words. Swanson and Hoskyn (2001) found that advanced organizers (graphic organizers) were most effective when used along with explicit practice. Explicit practice and advanced organizers made up a significant part of this intervention package in the current study, and this study's findings are consistent with those of Swanson and Hoskyn (2001).

A review of previous literature on morphemic analysis reveals that generalization may be an area of weakness with this type of skill. Bowers and Kirby's (2009) review of morphemic analysis research revealed that vocabulary growth was often limited to words that contained the taught morphemes, or closely related morphemes. The current study did not explicitly measure the growth of vocabulary to words containing untaught morphemes, however, analysis of writing pieces did not show an increase in the use of words containing morphemes beyond the morphemes targeted in this study.

Overall results of this study are consistent with the initial investigation of $G O$ FASTER (Fishley et al., 2011) and serve to build the evidence for the effectiveness of GO FASTER in teaching students morpheme definitions. The present study also extended the previous study by implementing the intervention in a group setting, increasing fluency mastery criteria, and investigating the generalization of morpheme definition knowledge to writing.

\section{Did Students Maintain Fluency Over Time?}

All students were able to maintain their morpheme definition knowledge two and four weeks after mastering each set. Across the five participants, two- and four-week maintenance data were collected in 14 total tiers (14 morpheme sets). Of the 14 tiers, 
half show that four-week maintenance scores were higher than two-week scores. Further, Jordan and Salena had maintenance scores that surpassed their highest intervention scores.

Nathan and Laura had two particularly low scores in their two-week maintenance data. In Laura's set one, two-week maintenance data were collected immediately following her receiving notice of a suspension for a fight she was in earlier in the day. This may have affected her performance. All of Nathan's maintenance scores were lower than his last intervention scores; however, all maintenance scores were notably higher than baseline scores. Nathan was often off-task during the intervention and needed frequent reminders to attend to the graphic organizer and the flashcards during his timings. This consistent off-task behavior may have contributed to his needing more intervention sessions to reach mastery and to his lower maintenance scores.

Maintenance results are also consistent with the previous research on $G O$ FASTER (Fishley et al., 2011) and fluency. Previous research recommends the use of interventions that focus on fluency as a way to ensure that skills are maintained after intervention ends. The current study supports the fluency research (Binder, 1988; Binder, 1998; Lindsley, 1992) in that students were taught morpheme definitions to a fluent level, and all students were able to maintain morpheme definition knowledge at levels markedly higher than their baseline scores. Also consistent across GO FASTER studies is the increase in scores from two- to four-week maintenance checks for some students.

When comparing the maintenance data from the current study to the Fishley et al. (2011) study, it is worth noting that maintenance scores are higher in the current study. 
Student maintenance means in the Fishley et al. study were 24.3, 30.0, and 33.2.

Whereas the student maintenance means from the current study were 27.0, 31.3, 35.2, 42.0, and 48.2. Higher maintenance scores in the current study may be related to a higher aim, which afforded students more practice opportunities with each morpheme. However, a functional relation between the aim and increased maintenance was not established.

\section{Did Student Knowledge of Morpheme Definitions Generalize to the Use of Whole}

\section{Words Containing Taught Morphemes in Writing Samples?}

Student writing sample scores improved from baseline through maintenance.

Students steadily increased their number of whole words containing the taught morphemes in their writing. During intervention, two students did receive scores of zero on their generalization probes. In both instances, the students did not follow the directions to use whole words. Instead, students used a bound morpheme to represent a whole word. For example, Salena wrote, "But, that is just how vit (life) goes sometimes." Also, she wrote, "When I first saw him he made my cardi (heart) jump." She completed her entire writing piece following this format. Allen also used bound morphemes in this way in one of his generalization pieces. Both students had already completed successful writing probes in this study before making this mistake, so it is unclear why this happened. In future replications, a thorough review of the directions for the task each time a generalization measure is used may be beneficial. Also, including examples of whole words that would be counted as correct may help students to better understand the directions. 
Even though overall generalization scores steadily improved in each successive tier and phase of the study, a functional relation cannot be determined due to a lack of experimental control as it relates to generalization measures. There were many other variables in play at this time such as a possible increase in comfort with the procedures in the generalization task and continued vocabulary instruction in English class.

\section{Did Students Improve Their Performance on a Curriculum-based Measure from Pre- to Post-intervention?}

Overall, students made large gains on AIMSweb writing probes from pre- to postintervention. Four of five students made particularly large gains in the areas of words spelled correctly, correct word sequences, and total words written. Even with a rather large jump, a functional relation cannot be established due to a lack of experimental control on this measure.

A previous literature review on morphemic analysis (Bowers \& Kirby, 2010) investigated the effects of morphological instruction on the layers of literacy and found that the effects at the lexical level (spelling, word reading, vocabulary) were "modest." When analyzing the current study's results at the "lexical" level (WSC on AIMSweb probes), students did show a rather large increase in words spelled correctly from pre- to post-assessment, but students wrote more words, which affected the total number of words spelled correctly. Students did not show a decrease in misspelled words from preto post-intervention. These results should be interpreted cautiously, though, as generalization assessments were not extensive enough to thoroughly measure generalization to spelling skills. 
When comparing participant CWS scores to the AIMSweb normative scores in CWS, all participants showed at least a moderate increase in percentile ranks. Salena, Leila, and Nathan all showed considerable increases in percentile ranks from pre- to post-intervention. Although these results appear very promising, it is important to look at the relevance of these scores in showing an accurate picture of student progress and student potential. A review of curriculum-based measures in written expression (McMaster \& Campbell, 2008) reveals that these measures are rather limited in their ability to show an accurate large-scale picture of student progress in writing. For example, these assessments are not sensitive enough to measure the quality of what is written. In this study in particular, four of five students showed large increases across all measures of written expression; however, examination of students' writing samples indicate that these scores do not reflect growth in the complexity of the words written. Therefore, the CWS measure only shows that the students wrote more words, not that their vocabulary grew in quality. Even though these measures are not sensitive enough to show whether a student's vocabulary is maturing, being able to measure their written production holds value. When a student produces more words in their writing, the teacher is able to increase the amount of feedback given to students about their writing. Also, seeing more of students' writing can provide teachers with a clearer picture of their current abilities, and can guide teachers in future instruction.

Student AIMSweb writing pieces did not reflect that they generalized morpheme knowledge to these tasks. In pre-intervention writing pieces, the students used a total of two words containing targeted morphemes. In post-intervention pieces, the students did not use any words containing the taught morphemes. This lack of generalization of 
learned morphemes to student writing has implications for the importance of providing more rich and robust instruction, as well as guided practice across literacy skills as students are learning the definitions.

\section{What Are Teachers' and Students' Reported Opinions of This Intervention?}

Social validity was examined by assessing participant opinions of the social significance of teaching morpheme definitions, the appropriateness of GO FASTER and its individual components, and the results of the intervention. Both the teacher and the students reported agreement that the teaching of morpheme definitions was an effective way to improve vocabulary knowledge. They also reported agreement that the use of flashcards was an effective method for learning morpheme definitions. Anecdotally, this part of the intervention, along with the self-graphing, appeared to be the most enjoyable component for students. They were very competitive during the timings, and all five engaged in conversations after their 30 -second timings about who had the highest scores. They frequently compared graphs and commented on who made the biggest jumps. During the official timings, it was not uncommon for students to ask to do "just one more" timing when they did not get a score they wanted.

The lowest ratings came on the statements regarding the effectiveness of the graphic organizers and whether they would recommend using graphic organizers in the future. Opinions on these two statements varied, but were largely negative. Four of the five opinions on whether they would recommend using graphic organizers in the future were "somewhat disagree." Opinions about the usefulness of the graphic organizer ranged from somewhat agree to disagree. Anecdotally, students did not appear to enjoy completing the graphic organizers. They completed this part very quickly and often 
needed reminders to fill them out completely. A couple students asked at different times if they could skip this part. All students felt that GO FASTER would be more enjoyable and no less effective if the graphic organizer was eliminated.

It is possible that the dissatisfaction with the graphic organizers was due to the amount of effort required to complete them. It is not uncommon for students to dislike tasks that require a large amount of effort, but that does not mean graphic organizers should not be used again in the future. It is possible that these organizers contributed to the success of the intervention. Future research focused on a component analysis would reveal the effectiveness of this component of GO FASTER.

Where outcomes are concerned, all of the students and the teacher reported agreement that they had improved their vocabulary after completing this intervention. The teacher noted that she was impressed with students' attention and motivation during the study. She reported that she plans to focus on teaching morpheme definitions next year and would incorporate the flashcard fluency component into her own instruction. Social validity results are largely consistent with the results from the previous study on GO FASTER (Fishley et al., 2011). The only discrepancy is regarding the opinions of the graphic organizer, as they were markedly less positive in the current study. It is possible that students lacked the motivation to do all of the writing that the graphic organizers required. They often needed prompts to complete each section of the graphic organizer in its entirety and would say that it was too much writing. These students were in their last months of high school and were ready for the school year to be over.

The results of the intervention indicate that GO FASTER is both an effective and a socially valid intervention. With a movement in education towards using evidence-based 
practices, it is important to continue to add to the limited literature base on vocabulary study for older students with disabilities, especially in the area of morphemes and morphemic analysis. The current study has great implications for targeting morphemes in vocabulary instruction.

\section{Limitations}

Even with rather robust intervention results, there are some areas of the study that merit discussion. The limitations addressed in this section include decision rules about when to move students to new morpheme sets, mastery criteria, generalization, and the use of an intervention package.

One of the procedures included in this intervention package was moving onto the next morpheme set when four of five students had met mastery criteria, and the other student was able to identify at least 30 morpheme definitions in 30 seconds. Whereas the goal of the intervention was for all students to meet mastery criteria together before moving on, a decision was made to move on when the majority reached mastery. In this study, two students met mastery criteria sooner than the other three. In these cases, they were asked to set goals for themselves that exceeded the researcher-set criterion of 40 . Even with new goals to work towards, it was important to make sure they did not lose interest. Further, the decision to move forward before all students met mastery was more in line with practices within a classroom. Teachers cannot always wait until all students master a concept before moving on. In a situation like this within the classroom, the teacher would move on with the whole class but remediate and re-teach the students who did not master the concept. Similarly, in this study, even though the whole class moved onto the next set when four of five met mastery, the researcher continued one-on-one 
fluency training with the one student who had not met mastery. This one-on-one training continued until that student met mastery.

Even though data show that students made gains on the generalization measures, it was difficult to control for extraneous variables on each measure. It is possible that the increase in scores was due to practice effects. Even though prompts were counterbalanced across phases and participants, students had no prior experience with AIMSweb writing probes or the researcher-created writing probes prior to this study. Therefore, it is possible that the increase from pre- to post-intervention was due to a better understanding of the procedures rather than to an increase in writing fluency. Other possible extraneous variables were the uncontrollable elements in the environment. For example, students continued to receive vocabulary instruction in their classes. It was not possible to control for any vocabulary knowledge gained within their classes.

A third limitation is the mastery criteria set for students. Fluency aims are not available for morpheme definition identification; therefore, aims were set in accordance with see-say sight words (Kubina, 2002). It is worth investigating how raising and lowering aims might affect student morpheme definition acquisition, maintenance and generalization.

The inconsistency in the definition of "learning disability" could be seen as a limitation to this study. If the IDEA definition were used, the participants in this study might not be considered as having true learning disabilities. However, the school district that these students attend felt it was appropriate to identify these students with learning disabilities due to their need for more intensive intervention. Additionally, language deficits caused by learning disabilities may have affected students' IQ scores, making a 
discrepancy difficult to identify. This limitation is consistent with the findings of Swanson and Hoskyn (1999) that studies with participants being described as "learning disabled," but did not include psychometric testing, yielded larger effect sizes. It would be important to replicate this study with students whose disabilities meet the psychometric definition of learning disabilities to see if their results are as robust as those in the current study.

A final limitation is that GO FASTER is a package consisting of multiple evidence-based practices. When studying the effects of an intervention package, it is not possible to identify the components that were most effective in increasing student performance. Future research might include a component analysis to identify the elements of the package that correlate with the most robust results.

\section{Future Research}

There are many areas of this intervention that can be extended upon in future research. Recommendations for future research are based on the above limitations as well as social validity reports from the teacher and students. In order for GO FASTER to be considered a true evidence-based practice, replications are needed. One set of criteria for establishing evidence-based practices was developed by Horner et al. (2005). According to these criteria, a practice cannot be determined evidence-based until it is replicated "across a sufficient number of studies, researchers, and participants" (p. 176). Future replications of GO FASTER should incorporate these criteria by implementing the intervention with more participants across a wider age range and with varying disabilities and having other researchers and classroom teachers implement the intervention. It may be beneficial to investigate which elements of GO FASTER are the most effective in 
teaching morpheme definitions to a fluent level. This can be accomplished by systematically removing one component of GO FASTER at a time. It is possible that certain elements contribute to different areas of student learning. For example, graphic organizers may not contribute largely to increasing fluency, but may have a large impact on generalization. Therefore, a thorough investigation of how the elements of the package impact both student morpheme acquisition and generalization is important. Identifying which components are most vital to student learning will improve instructional efficiency for teachers using GO FASTER in their classrooms, where time constraints are an issue.

When consumer opinions were analyzed, it was found that students did not feel the graphic organizer was an effective way of learning morpheme definitions. Further, the classroom teacher felt that students would benefit from having more independence when working with the graphic organizer. To address this issue, future research can focus on using the graphic organizer as a form of structured worksheet. The researcher can provide the morpheme, its definition, and two sample words, but then allow the students to add another word containing the morpheme and to formulate their own sentences.

Another limitation was that some of the participants had maintenance scores that were below intervention scores. Future research can include booster sessions for students whose maintenance scores drop. Providing booster training in the context of this study is in line with good classroom practice. Direct teaching includes reviewing previously learned skills and concepts. Therefore, investigating the inclusion of booster sessions in GO FASTER could hold social significance while also improving maintenance.

Efforts to improve generalization measures are another area worthy of future research. Because vocabulary knowledge is additive, it is difficult to gain a clear picture 
of how much generalization has taken place when teaching vocabulary. Further investigations can assess growth in any area of literacy including spelling, comprehension, oral vocabulary, and written expression. All of these areas require further investigation to better understand whether GO FASTER can impact the generalization of morpheme definition knowledge. For instance, paragraphs can be created that include unknown vocabulary terms that contain taught morphemes. These vocabulary terms should be important to understanding the paragraph. Students can be asked to read these paragraphs and then answer comprehension questions about the paragraph, as a measure of how knowing morpheme definitions can improve comprehension. Another interesting skill to investigate is oral reading fluency. Two paragraphs can be created that include unknown morphemes that will be targeted during intervention. One paragraph can be used prior to beginning intervention and the other can be used after the students have learned the previously unknown morphemes. Oral reading rates can be compared from pre- to post-intervention to investigate how learning morpheme definitions can affect oral reading fluency rate.

\section{Classroom Implications}

Teaching efficiency can be improved through the identification of effective interventions and strategies. Aside from efficiency, the use of evidence-based practices is vital with current educational reform. Through No Child Left Behind and the incorporation of Response to Intervention into schools, there is certainly a large focus being placed on using practices that have been validated by research. GO FASTER offers teachers a promising research-backed intervention that addresses the teaching of vocabulary, by teaching an important component of morphemic analysis. GO FASTER 
had high levels of consumer satisfaction and resulted in morpheme definition acquisition that showed the potential for generalization and long-term maintenance.

GO FASTER is effective for teaching morpheme definitions, but teachers should incorporate opportunities to practice morpheme definition knowledge within classroom activities. Providing students with exposure to taught vocabulary in multiple contexts can help the student to better comprehend the terms (Stahl \& Fairbanks, 1986). Using a graphic organizer is one way that teachers can guide discussion on the morpheme and allow students to make deeper, more personal connections, with the morpheme and its meaning.

Teachers should also take the time to incorporate morphemes into their rich and robust vocabulary-rich classroom environment. Direct instruction in vocabulary is vital at the acquisition stage, but to ensure fluency and maintenance, students should be exposed to the words in multiple contexts (Beck, McKeown, \& Kucan, 2002). Providing an environment that encourages rich and robust vocabulary use will allow students to make connections between learned vocabulary and vocabulary already in their repertoire (Hiebert \& Kamil, 2005). For example, when reading a textbook chapter or chapter book with the class, the teacher can point out words in the books that contain targeted morphemes and discuss the whole word definition in relation to the morpheme definitions.

There are ample opportunities to expand on this knowledge outside of the English classroom. Morpheme knowledge translates to all subject areas as morphemes are present in many words used across the curriculum. Students should be encouraged to make these connections in all of their classes and subject areas. Teachers can begin by providing 
students with examples of morphemes in other subject areas such bilateral, (bi)

quadrangle (quad), heptagon (hepta) in math class. Or anti-American (anti), socialism (ism), and postwar (post) in history. There are also many examples in science, such as biology (bio and ology), microorganisms (micro and ism), and bronchitis (bronch and itis). The teacher can directly give these words to students and then ask the students to find other words in their classes that contain morphemes.

\section{Summary}

This research investigated the effects of GO FASTER on morpheme definition acquisition, maintenance, and generalization. GO FASTER is a direct teaching package that consists of teaching students morphemes and their definitions using graphic organizers, flashcard fluency timings, and self-graphing of fluency performances. To study the effects of GO FASTER, a multiple baseline across morpheme sets design was used. Participants included five high school seniors with high-incidence disabilities.

Because morphemic analysis has been identified as a promising area of vocabulary instruction (Bowers, et al., 2010), the goal of this intervention was to work towards identifying an effective and efficient way of teaching students a component skill of the morphemic analysis strategy. Morphemic analysis involves breaking down unknown words into their word parts, or morphemes, in order to construct a total meaning of the whole word. If students are to effectively use morphemic analysis, they must have knowledge of what those morphemes mean. GO FASTER addresses the teaching of this knowledge.

Data reveal that GO FASTER was effective in teaching students morpheme definitions to a pre-determined fluency level. All students were able to acquire these 
definitions during intervention and maintain that knowledge at two- and four-week maintenance checks. All maintenance data was significantly higher than baseline levels. Further, students were able to generalize that morpheme knowledge to their writing on researcher-created generalization probes and AIMSweb pre- and post-intervention writing probes.

Overall, GO FASTER is a promising strategy for teaching students morpheme definitions. It is an intervention package consisting of only evidence-based practices, which supports current educational reform aimed at ensuring that all students receive high quality, research-based instruction. Not only is this package effective, but students and teachers seem to like it. 


\section{References}

Alberto, P.A., \& Troutman, A.C. (2009). Applied Behavior Analysis for Teachers $8^{\text {th }}$ Ed. Upper Saddle River: Pearson.

Baumann, J. F., Edwards, E. C., Boland, E. M., Olejnik, S. \& Kame'enui, E. (2003). Vocabulary tricks: Effects of instruction in morphology and context on fifth-grade students' ability to derive and infer word meanings. American Educational Research Journal, 40(2), 447-494.

Baumann, J. F. (2005). Vocabulary-comprehension relationships. In B. Maloch, J.V. Hoffman, D. L. Shallert, C. M. Fairbanks, \& J.Worthy (Eds.), Fifty-fourth yearbook of the National Reading Conference (pp. 117-131). Oak Creek, WI: National Reading Conference.

Baumann, J. F., Edwards, E. C., \& Ware, D. (2007). Bumping into spicy, tasty words that catch your tongue: A formative experiment on vocabulary instruction. The Reading Teacher, 61(2), 108-122.

Baumann, J. F., Edwards, E. C., \& Font, G. (2002). Teaching morphemic and contextual analysis to fifth-grade students. Reading Research Quarterly, 37(2), 150-176.

Baumann, J. F., \& Kame'enui, E. J. (2004). Vocabulary instruction: Research to practice. New York, NY: Guilford.

Beck, I. L. \& McKeown, M. G. (1985). Learning words well: A program to enhance vocabulary and comprehension. The Reading Teacher, 36, 622-625.

Beck, I. L. \& McKeown, M. G. (1991). Conditions of vocabulary acquisition. In R. Barr, M. Kamil, P. Mosenthal, \& P. D. Person (Eds.), Handbook of reading research, (Vol. 2, pp. 789-814). New York: Longman.

Beck, I., McKeown, M., \& Kucan, L. (2002). Brining words to life: Robust vocabulary instruction. New York: Guilford Press. 
Becker, W. C. (1977). Teaching reading and language to the disadvantaged-what we have learned from field research, Harvard Educational Review, 47, 518-543.

Biemiller, A., \& Slonim, N. (2001). Estimating root word vocabulary growth in normative and advantaged populations: Evidence for a common sequence of vocabulary acquisition. Journal of Educational Psychology, 93(3), 498-520.

Biemiller, A. (2005). Addressing developmental patterns in vocabulary: Implications for choosing words for primary grade vocabulary instruction. In E. H. Hiebert \& $\mathrm{M}$. L. Kamil (Eds.), Teaching and learning vocabulary: Bringing research to practice. Hillsdale, NJ: Erlbaum.

Binder, C. (2003). Doesn’t everybody need fluency? Performance Improvement, 42(3), $14-20$.

Bowers, P. N., \& Kirby, J. R. (2010). Effects of morphological instruction on vocabulary acquisition. Reading and Writing: An interdisciplinary journal, 23(5), 515-537.

Bowers, P. N., Kirby, J. R. \& Deacon, S. H. (2010). The effects of morphological instruction on literacy skills: A systematic review of the literature. Review of Educational Research, 80(2), 144-179.

Briesch, A. M., \& Chafouleas, S. M. (2009). Review and analysis of literature on selfmanagement interventions to promote appropriate classroom behaviors. School Psychology Quarterly, 24(2), 106-118.

Bromley, K. (2007). Nine things every teacher should know about words and vocabulary instruction. Journal of Adolescent \& Adult Literacy, 50(7), 528-537.

Bryant, D. P., Goodwin, M., Bryant, B. R., \& Higgins, K. (2003). Vocabulary instruction for students with learning disabilities: A review of the research. Learning Disability Quarterly, 26, 117-128.

Bucklin, B. R., Dickinson, A. M., \& Brethower, D. M. (2000). A comparison of the effects of fluency training and accuracy training on application and retention. Performance Improvement Quarterly, 13(3), 140-163.

Bursuck, W. D. \& Damer, M. (2007). Reading instruction for students who are at risk or have disabilities. Boston: Pearson.

Calderon, M., Hertz-Lazarowitz, R., \& Slavin, R. E. (2005). Bringing words to life in classrooms with English-language learners. In E. H. Hiebert \& M. L. Kamil (Eds.), Teaching and learning vocabulary (pp.115-136). Mahwah, NJ: Erlbaum. 
Carnine, L., \& Carnine, D. (2004). The interaction of reading skills and science content knowledge when teaching struggling secondary students. Reading and Writing Quarterly, 20, 203-218.

Carlisle, J. F. (2010). Effects of instruction in morphological awareness on literacy achievement: An integrative review. Reading Research Quarterly, 45(4), 464487.

Collins COBUILD English Dictionary. (1995). $2^{\text {nd }}$ ed. London: HarperCollins.

Cooper, J., Heron, T., \& Heward, W. (2007). Applied Behavior Analysis $2^{\text {nd }}$ Ed. New Jersey: Prentice Hall.

Coxhead, A. (2000). A new academic word list. TESOL Quarterly, 34, 213-238.

Cunningham, A. E. \& Stanovich, K. E. (1997). Early reading acquisition and its relation to reading experience and ability 10 years later. Developmental Psychology, 33(6), 934-945.

Deshler, D. D., Palincsar, A. S., Biancarosa, G., \& Nair, M. (2007). Informed choices for struggling adolescent readers: A research-based guide to instructional programs and practices. Newark, DE: International Reading Association.

Duffy, G., \& Roehler, I. R. (1986). Why strategy instruction is so difficult and what we need to do about it. In C. McCormick, G, Miller, ft. M. Pressley (Eds.). Dialogues in literacy research. Chicago, IL: National Reading Conference.

Eshleman, J. W. (1985). Improvement pictures with low celerations: An early foray into the use of SAFMEDS. Journal of Precision Teaching, 6, 54-63.

Fishley, K., Konrad, M., Keesey, S. \& Hessler, T. (2011). Effects of GO FASTER on morpheme definition fluency for high school students with high incidence disabilities. Submitted for publication.

Fore, C., Boon, R. T. \& Lowrie, K. (2007). Vocabulary instruction for middle school students with learning disabilities: A comparison of two instructional models. Learning Disabilities: A Contemporary Journal, 5(2), 49-73.

Graham-Day, K. J., Gardner, R., \& Hsin, Y. (2010). Increasing on-task behaviors of high school students with attention deficit hyperactivity disorder: Is it enough? Education and Treatment of Children, 33(3), 205-221.

Graves, M. F., \& Hammond, H. K. (1980). A validated procedure for teaching prefixes and its effect on students' ability to assign meaning to novel words. In M.L. Kamil \& A. J. Moe (Eds.), Perspectives on reading research and instruction (pp. 184-188). Washington, DC: National Reading Conference. 
Grossi, T. A., \& Heward, W. L. (1998). Using self-evaluation to improve the work productivity of trainees in a community-based restaurant training program. Education and Training in Mental Retardation and Developmental Disabilities, 33(3), 248-263.

Gumple, T. P., \& David, S. (2000). Exploring the efficacy of self-regulatory training as a possible alternative to social skills training. Behavioral Disorders, 25, 131-141.

Harris, K. R., Friedlander, B. D., Saddler, B., Frizzelle, R., \& Graham, S. (2005). Selfmonitoring of attention versus self-monitoring of academic performance: Effects among students with ADHD in the general education classroom. Journal of Special Education, 39, 145-156.

Hart, B., \& Risley, T. (1995). Meaningful differences in the everyday experience of young American children. Baltimore, MA: Brookes.

Hartnedy, S. L., Mozzoni, M.P. \& Fahoum, Y. (2005). The effect of fluency training on math and reading skills in neuropsychiatric diagnosis children: A multiple baseline design. Behavioral Interventions, 20, 27-36.

Hasselbring, T. S., \& Goin, L. I. (2004). Literacy instruction for older struggling readers: What is the role of technology? Reading and Writing Quarterly, 20(2), 123-144.

Hazenberg, S., \& Hulstijn, J. H. (1996). Defining a minimal receptive second-language vocabulary for non-native university students: An empirical investigation. Applied Linguistics, 17, 145-163.

Heward, W. L. (1994). Three "low-tech" strategies for increasing the frequency of active student response during group instruction. In R. Gardner, D. M. Sainato, J. O. Cooper, T. E. Heron, W. L. Heward, J. Eshleman, \& T. A. Grossi (Eds.), Behavior analysis in education: Focus on measurably superior instruction (pp. 283-320). Monterey, CA: Brooks/Cole.

Hiebert, E. H., \& Kamil, M. L. (2005). Teaching and learning vocabulary. Mawha, NJ: Erlbaum.

Hughes, C., Copeland, S.R., Agran, M., Wehmeyer, M.L., Rodi, M.S. \& Presley, J.A. (2002). Using self-monitoring to improve performance in general education high school classes. Education and Training in Mental Retardation and Developmental Disabilities, 37, 262-271.

Irvin, J. L. (1990). Vocabulary knowledge: Guidelines for instruction. Washington, D.C.: National Education Association.

Kamil, M. L. (2004). Vocabulary and comprehension instruction: Summary and implications of the National Reading Panel findings. In P. McCardle \& V. Chabra 
(Eds.), The voice of evidence in reading research (pp. 213-234). Baltimore, MD: P.H. Brookes.

Kasper-Ferguson, S., \& Moxley, A. (2002). Developing a writing package with student graphing of fluency. Education and Treatment of Children, 25, 249-267.

Kavale, K. A. \& Forness, S. R. (2000). History, rhetoric, and reality: Analysis of the inclusion debate. Remedial and Special Education, 21, 279-296.

Koegel, L. K., Koegel, R. L., Hurley, C., \& Frea, W. D. (1992). Improving social skills and disruptive behavior in children with autism through self-management. Journal of Applied Behavior Analysis, 25, 341-353.

Konrad, M., Walker, A. R., Fowler, C. H., Test, D. W., \& Wood, W. M. (2008). A model for aligning self-determination and general curriculum standards. Teaching Exceptional Children, Jan/Feb, 53-64.

Kucan, L., Trathen, W. R., \& Straits, W. J. (2007). A professional development initiative for developing approaches to vocabulary instruction with secondary mathematics, art, science, and English teachers. Reading Research and Instruction, 46(2), 175195.

Learning Disabilities Association of America. Social adjustment problems associated with learning disabilities. Retrieved June 12, 2011 from Learning Disabilities Association of America Web site: www.ldanatl.org.

Lloyd, J. W., \& Landrum, T. J. (1990). Self-recording of attending to task: Treatment components and generalization of effects. In T.E. Scruggs \& B.Y.L. Wong (Eds.), Intervention research in learning disabilities (pp. 235-262). New York: SpringerVerlag.

Malmgren, K. W. \& Trezek, B. J. (2009). Literacy instruction for secondary students with disabilities. Focus on Exceptional Children, 41(6), 2-12.

McBride-Chang, C., Wagner, R. K., Muse, A., Chow, B. W. Y., \& Shu, H. (2005).The role of morphological awareness in children's vocabulary acquisition in English. Applied Psycholinguistics, 26, 415-435.

McCardle, P. \& Chabra, V. (eds). (2004). The voice of evidence in reading research. Baltimore: Brookes.

McCormick, S. (1999). Instructing students who have literacy problems. City: Merrill.

McDowell, C., Keenan, M. and Kerr, K. P. (2002). Comparing levels of dysfluency among students with mild learning difficulties and typical students. Journal of Precision Teaching \& Celeration, 18(2), 16-29. 
Mace, F. C., Belfiore, P. J. \& Hutchison, J. M. (2001). Operant theory and research on self-regulation. In B. Zimmerman \& D. Schunk (Eds.), Self-regulated learning and academic achievement: Theoretical perspectives (pp. 39-65). Mahwah, NJ: Lawrence Erlbaum.

Mace, F. C., \& Kratochwill, T. R. (1988). Self-monitoring. In J. C. Witt, S. N. Elliott, \& F. M. Gresham (Eds.), Handbook of behavior therapy in education (pp. 489-522). New York: Plenum.

McKeown, M. G. \& Beck, I. L. (2006). The effects of vocabulary instruction: A modelbased meta-analysis. In K.A.D. Stahl \& M.C. McKenna (Eds.), Reading research at work (pp. 262-271). New York, NY: Guilford Press.

McMaster, K. L., \& Campbell, H. (2008). Technical features of new and existing measures of written expression: An examination within and across grade levels. School Psychology Review, 37 (4), 550-566.

Mastropieri, M. A. \& Scruggs, T. E. (1989). Mnemonic social studies instruction: classroom applications. Remedial and Special Education, 10, 40-46.

Mercer, C. (1991). Students with learning disabilities ( $4^{\text {th }}$ ed.). New York: Merrill.

Mooney, P., Ryan, J. B., Uhing, B. M., Reid, R., \& Epstein, M. H. (2005). A review of self-management interventions targeting academic outcomes for students with emotional and behavioral disorders. Journal of Behavioral Education, 14(3), 203221.

Moxley, R.A. (2007). Graphing in the classroom for improving instruction: From lesson plans to research. Education and Treatment of Children, 30(2), 111-126.

Nagy, W. (2005). Why vocabulary instruction needs to be long-term and comprehensive. In E. H. Hiebert \& M. L. Kamil (Eds.), Teaching and learning vocabulary (pp. 27-44). Mahwah, NH: Erlbaum.

Nagy, W. E., Herman, P. A., Anderson, R. C. (1985). Learning words from context. Reading Research Quarterly, 20(2), 233-253.

Nagy, W. \& Anderson, R. (1984). The number of words in printed school English. Reading Research Quarterly, 19, 304-330.

Nagy, W. \& Scott, J. A. (2006). The state of vocabulary research in the mid-1980s. In K. A. D. Stahl \& M. C. McKenna (Eds.), Reading research at work (pp.217-261). New York, NY: Guilford Press.

National Center for Educational Statistics. Retrieved June 2, 2010, from Institute of Education Sciences Web site: http://nces.ed.gov. 
National Institute of Child Health and Human Development. (2000). Report of the National Reading Panel. Teaching children to read: An evidence-based assessment of the scientific research literature on reading and its implications for reading instruction. Retrieved June 6, 2010 from http://www.nichd.nih.gov/publications.

National Reading Panel (NRP). Teaching children to read: An evidence-based assessment of the scientific research literature on reading and its implications for reading instruction. Washington, DC: National Institute of Child Health and Human Development.

Pearson, P. D., Hiebert, E. H. \& Kamil, M. L. (2007). Vocabulary assessment: What we know and what we need to learn. Theory and Research into Practice, 42(2), 282296.

Phillips, D. C., Foote, C. J., Harper, L. J. (2008). Strategies for effective vocabulary instruction. Reading Improvement, 45(2), 62-68.

Poplin, M. (1988). The reductionist fallacy in learning disabilities: Replicating the past by reducing the present. Journal of Learning Disabilities, 21(7), 389-400.

Reed, D. K. (2008). A synthesis of morphology interventions and effects on reading outcomes for students in grades k-12. Learning Disabilities Research \& Practice, 23(1), 36-49.

Roberts, G., Torgesen, J. K., Boardman, A. \& Scammacca, N. (2008). Evidence-based strategies for reading instruction of older students with learning disabilities. Learning Disabilities Research \& Practice, 23(2), 63-69.

Scammacca, N., Roberts, G., Vaughn, S., Edwards, M., Wexler, J., Revtebuch, C. K., \& Torgesen, J. K. (2007). Interventions for adolescent struggling readers. Portsmouth, NH: RMC Research Corp. Center on Instruction.

Sheffield, K., \& Waller, R. J. (2010). A review of single-case studies utilizing selfmonitoring interventions to reduce problem classroom behaviors. Beyond Behavior, 19(2), 7-13.

Shimabukuro, S. M., Prater, M. A., Jenkins, A. \& Edelen-Smith, P. (1999). The effects of self-monitoring of academic performance on students with learning disabilities and ADD/ADHD. Education and Treatment of Children, 22(4), 397-414.

Snow, C. E., Burns, M. S., \& Griffin, P. (Eds.). (1998). Preventing reading difficulties in young children. Washington, DC: National Academic Press.

Snow, C. E., Porche, M.V., Tabors, P. O., \& Harris, S. R. (2007). Is literacy enough? Pathways to academic success for adolescents. Baltimore, MD: Paul H. Brookes. 
Stahl, S. A. (1983). Differential word knowledge and reading comprehension. Journal of Reading Behavior, 15(4), 33-50.

Stahl, S. A. (1985). To teach a word well: A framework for vocabulary instruction. Reading World, 24, 16-27.

Stahl, S. A. \& Fairbanks, M. M. (1986). The effects of vocabulary instruction: A modelbased meta-analysis. Review of Educational Research, 56(1), 72-110.

Stahl, S. A., \& Miller, P. D. (1989). Whole language and language experience approaches to beginning reading: A quantitative research synthesis. In K.A.D. Stahl \& M. C. McKenna (Eds.), Reading research at work (pp. 9-35). New York, NY: Guilford Press.

Stanovich, E. E. (1986). Matthew effects in reading: Some consequences of individual differences in the acquisition of literacy. Reading Research Quarterly, 21, 360407.

Swanson, H. L. (2006). Intervention research for adolescents with learning disabilities: A meta-analysis of outcomes related to high-order processing. National Center for Learning Disabilities. Retrieved June 2, 2010, from http://www.ncld.org/index.php?option=content\&task=view\&id=523

Swanson, H. L. \& Hoskyn, M. (1998). Experimental Intervention Research on students with learning disabilities: a meta-analysis of treatment outcomes. Review of Educational Research, 68(3), 277-321.

Swanson, H. L. \& Sachse-Lee, C. (2000). A meta-analysis of single-subject-design intervention research for students with LD. Journal of Learning Disabilities, 33(2), 114-136.

Torgesen, J. K. (2005). Recent discoveries from research on remedial interventions for children with dyslexia. In M. Snowling \& C. Hulme (Eds.), The science of reading (pp. 521-537). Oxford, UK: Blackwell.

White, T. G., Graves, M. F., \& Slater, W. H. (1990). Growth of reading vocabulary in diverse elementary schools: decoding and word meaning. Journal of Educational Psychology, 82, 281-290.

Wolgemuth, J. R., Cobb, R. B. \& Dugan, J. J. (2007). The effects of self-management interventions on academic outcomes for youth with disabilities. Unpublished manuscript, Colorado State University, Fort Collins, Colorado.

Wolgemuth, J. R., Trujillo, E., Cobb, R. B. \& Alwell, M. (2007). The effects of visual display interventions on academic outcomes for youth with disabilities: A 
systematic review. Unpublished manuscript, Colorado State University, Fort Collins, Colorado and Appalachian State University, Boone, North Carolina.

Wysocki, K., \& Jenkins, J. R. (1987). Deriving word meanings through morphological generalization. Reading Research Quarterly, 22, 66-81. 
APPENDIX A: PRINCIPAL SUPPORT LETTER 


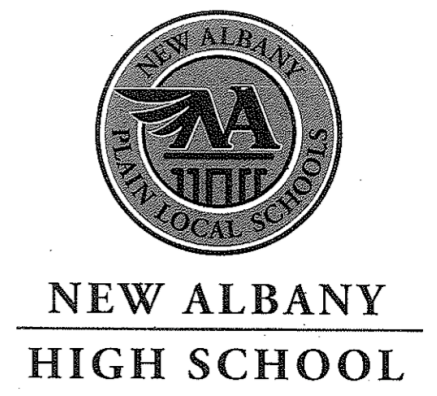

\section{Participation in Educational Research}

Provided that prior consent has been provided by the parents, I will allow the researcher, Katelyn Fishley, to study the effects of an explicit teaching package on teaching students morpheme definition acquisition.

I realize that this study will be conducted over a period of 10 to 12 weeks by Katelyn Fishley and Susan Keesey under the supervision of Moira Konrad, assistant professor of special education at The Ohio State University. The purpose of this research is to examine the effects of an explicit teaching package with our high school students who demonstrate reading deficits, including those with high incidence disabilities (e.g., learning disabilities).

I understand that the children's identity will not be revealed in any publication, document, or any other form of report developed from this project. Additionally, I understand that I may withdraw consent for my school and students" participation at any time without penalty.

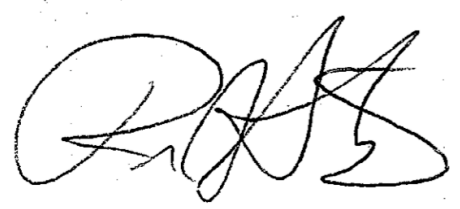

Mr. Ric J. Stranges

Principal

New Albany High School

Plain-Local School District 
APPENDIX B: STUDENT CONSENT FORM 


\title{
The Ohio State University Consent to Participate in Research
}

\author{
Study Title: definition acquisition and fluency \\ Researcher: \\ Moira Konrad and Katelyn M. Fishley
}

This is a consent form for research participation. It contains important information about this study and what to expect if you decide to participate.

Your participation is voluntary. Please consider the information carefully. Feel free to ask questions before making your decision whether or not to participate. If you decide to participate, you will be asked to sign this form and will receive a copy of the form. You will all be doing this intervention with me regardless of whether you sign the permission form. Your signing of the form will allow me to use your results in my research.

\section{Purpose:}

The purpose of this study is to examine the effects of using flashcards, graphic organizers, and a self-graphing procedure on students' abilities to identify the definitions of morphemes. Morphemes are the smallest word parts that have meaning. An example is bio which means life. Another example is struct, which means to build. Many words in the English language contain these morphemes, and being able to recognize them may help students figure out the meanings of new words. Also, many content area vocabulary terms within math, science, and social studies contain these morphemes.

\section{Procedures/Tasks:}

I will come into your English class three to five days per week and teach the class morphemes. You will use flashcards with the morphemes on one side and their definitions on the opposite side. You will flip through the flashcards saying the definitions as quickly as you can in 30 -second timings, each time we meet. You will graph your best performance with the timings on a graph. To teach the meanings, we will use a graphic organizer. These organizers will provide the you with a morpheme, its definition, sample words that contain the morpheme, and sentences that use those sample words. A graphic organizer will be completed for each morpheme.

\section{Duration:}

This study is expected to last 6-18 weeks.

Each session will last 10-20 minutes.

You may leave the study at any time. If you decide to stop participating in the study, there will be no penalty to you, and you will not lose any benefits to which you are otherwise entitled. Your decision will not affect your future relationship with The Ohio State University.

\section{Risks and Benefits:}

There are no foreseeable risks to your participation in this study. As a result of this study, students may benefit by increasing their vocabulary and morphemic analysis skills. 


\section{Confidentiality:}

Efforts will be made to keep your study-related information confidential. Your files are kept in locked cabinets in the guidance office. These files will not be removed from this room at any time. In my records, your name will never be used. Instead, you will be asked to make up a pseudonym and you will be referred to by this name throughout the study. However, there may be circumstances where this information must be released. For example, personal information regarding your participation in this study may be disclosed if required by state law. Also, your records may be reviewed by the following groups (as applicable to the research):

- Office for Human Research Protections or other federal, state, or international regulatory agencies;

- The Ohio State University Institutional Review Board or Office of Responsible Research Practices;

- The sponsor, if any, or agency (including the Food and Drug Administration for FDA-regulated research) supporting the study.

\section{Incentives:}

There are no incentives for participating in this study. However, students may be given edible rewards for their hard work during the study sessions. Examples of edible rewards include candy, gum, or sports drinks.

\section{Participant Rights:}

You may refuse to participate in this study without penalty or loss of benefits to which you are otherwise entitled. If you are a student or employee at Ohio State, your decision will not affect your grades or employment status.

If you choose to participate in the study, you may discontinue participation at any time without penalty or loss of benefits. By signing this form, you do not give up any personal legal rights you may have as a participant in this study.

An Institutional Review Board responsible for human subjects research at The Ohio State University reviewed this research project and found it to be acceptable, according to applicable state and federal regulations and University policies designed to protect the rights and welfare of participants in research.

\section{Contacts and Questions:}

For questions, concerns, or complaints about the study you may contact Kate Fishley at 330-447-3777.

For questions about your rights as a participant in this study or to discuss other studyrelated concerns or complaints with someone who is not part of the research team, you may contact Ms. Sandra Meadows in the Office of Responsible Research Practices at 1800-678-6251.

If you are injured as a result of participating in this study or for questions about a studyrelated injury, you may contact Kate Fishley at 330-447-3777. 


\section{Signing the consent form:}

I have read (or someone has read to me) this form and I am aware that I am being asked to participate in a research study. I have had the opportunity to ask questions and have had them answered to my satisfaction. I voluntarily agree to participate in this study.

I am not giving up any legal rights by signing this form. I will be given a copy of this form.

\section{Date and time}

Printed name of person authorized to consent for subject (when applicable)
Signature of person authorized to consent for subject

AM/PM

\section{Relationship to the subject}

Date and time

\section{Investigator/Research Staff}

I have explained the research to the participant or his/her representative before requesting the signature(s) above. There are no blanks in this document. A copy of this form has been given to the participant or his/her representative.

Printed name of person obtaining consent
Signature of person obtaining consent

$\mathbf{A M} / \mathbf{P M}$

Date and time 
APPENDIX C: INTERVENTION SCHEDULE 


\begin{tabular}{|c|c|c|c|}
\hline $\begin{array}{c}\text { Teaching Phase: } \\
\text { Day } 1 \\
\end{array}$ & $\begin{array}{c}\text { Teaching Phase: } \\
\text { Day } 2 \\
\end{array}$ & $\begin{array}{c}\text { Teaching Phase: } \\
\text { Day } 3 \\
\end{array}$ & Fluency Training \\
\hline $\begin{array}{l}\text { 1. Pass Out Blank } \\
\text { Graphic organizers } \\
\text { 2. Tell students they will } \\
\text { be learning } 5 \\
\text { morphemes today } \\
\text { 4. Introduce } 1 \\
\text { morpheme at a time } \\
\text { with PowerPoint } \\
\text { a. Morpheme in Middle } \\
\text { b. Definition } \\
\text { c. Sample } \\
\text { words/definitions } \\
\text { d. Sample sentence } \\
\text { 5. Have students read } \\
\text { back sections (Choral } \\
\text { Response) after } \\
\text { 6. Have students say } \\
\text { definition without } \\
\text { looking, when prompted } \\
\text { to do so on the } \\
\text { PowerPoint } \\
\text { 8. Repeat this process } \\
\text { for other } 4 \\
\text { 9. After each graphic } \\
\text { organizer, review each } \\
\text { learned morpheme } \\
\text { 10. After teaching all } 5 \text {, } \\
\text { have students pair up } \\
\text { and shuffle all } 45 \text { cards } \\
\text { in the set } \\
\text { 12. Each student does } \\
\text { one } 30 \text {-second timing } \\
\text { with partner, then } \\
\text { partners switch roles so } \\
\text { that each do one } 30- \\
\text { second timing } \\
\text { 13. Self-graph } \\
\text { performance } \\
\text { 14. Pull out students } \\
\text { individually for official } \\
\text { timing. }\end{array}$ & $\begin{array}{l}\text { 1. Review the } 5 \\
\text { morphemes taught } \\
\text { yesterday on the } \\
\text { PowerPoint slide } \\
\text { 2. Follow steps 2- } \\
14 \text { from previous } \\
\text { day }\end{array}$ & $\begin{array}{l}\text { 1. Review the } 10 \\
\text { morphemes taught } \\
\text { in previous days on } \\
\text { the PowerPoint } \\
\text { slide } \\
\text { 2. Follow steps 2- } \\
14 \text { from previous } \\
\text { days }\end{array}$ & $\begin{array}{l}\text { 1. Have students } \\
\text { find one flashcard } \\
\text { for each } \\
\text { morpheme (light } \\
\text { or dark colored } \\
\text { ones in the stack) } \\
\text { 2. Allow them } \\
\text { time to review on } \\
\text { their own } \\
\text { 3. Students pair up } \\
\text { 4. Shuffle (15 } \\
\text { cards) } \\
\text { 5. } 4 \text { 10-second } \\
\text { sprints } \\
\text { a. Between each } \\
\text { one, have students } \\
\text { review any missed } \\
\text { cards } \\
\text { b. Students graph } \\
\text { performance after } \\
\text { each sprint } \\
\text { 6.30-second } \\
\text { timing with } \\
\text { partner } \\
\text { 7.Self-graph } \\
\text { 8. Switch partners } \\
\text { and repeat } \\
\text { 9. Pull out } \\
\text { students } \\
\text { individually for } \\
\text { official timings }\end{array}$ \\
\hline
\end{tabular}


APPENDIX D: SOCIAL VALIDITY FORMS 


\section{$\underline{\text { Social Validity (Student Form) }}$}

1. Learning about morphemes is important to learning new vocabulary. Disagree Somewhat Disagree Somewhat Agree Agree

2. Learning new vocabulary words will help me do better in school.

Disagree Somewhat Disagree Somewhat Agree Agree

3. Using flashcards helped me to learn morpheme definitions.

Disagree Somewhat Disagree Somewhat Agree Agree

4. I will use flashcards to learn definitions in the future.

Disagree Somewhat Disagree Somewhat Agree Agree

5. Using a graphic organizer helped me to learn morphemes and new words containing the morphemes.

Disagree Somewhat Disagree Somewhat Agree Agree

6. I would recommend that teachers use graphic organizers to teach vocabulary in the future.

Disagree Somewhat Disagree Somewhat Agree Agree

7. I feel this intervention has helped me improve my vocabulary.

Disagree $\quad$ Somewhat Disagree $\quad$ Somewhat Agree Agree

8. I feel this intervention will help me in the future.

Disagree Somewhat Disagree Somewhat Agree Agree

Comments: 


\section{$\underline{\text { Social Validity (Teacher Form) }}$}

1. I think teaching high school students morphology is important to their vocabulary growth.

Disagree Somewhat Disagree Somewhat Agree Agree

2. I believe that increasing my students' vocabulary will improve their academic skills.

Disagree Somewhat Disagree Somewhat Agree Agree

3. Using flashcards to teach morpheme definitions seems efficient.

Disagree Somewhat Disagree Somewhat Agree Agree

4. I will use flashcards to teach vocabulary in the future.

Disagree Somewhat Disagree Somewhat Agree Agree

5. Using a graphic organizer to teach vocabulary definitions seems efficient.

Disagree Somewhat Disagree Somewhat Agree Agree

6. I will use a graphic organizer to teach vocabulary in the future.

Disagree Somewhat Disagree Somewhat Agree Agree

7. I feel that my students have increased their vocabulary as a result of this intervention.

Disagree Somewhat Disagree Somewhat Agree Agree

8. I feel that students will do better on the OGT/in college with this knowledge.

Disagree Somewhat Disagree Somewhat Agree Agree

9. I feel students will be better readers, spellers, and writers with this knowledge.

Disagree Somewhat Disagree Somewhat Agree Agree

10. Based on my observations of the teaching sessions (flashcards and graphic organizers, self-graphing), I will use methods similar to what I observed in the future/with current students.

Disagree Somewhat Disagree Somewhat Agree Agree 
Comments: 
APPENDIX E: PRE-INTERVENTION TRAINING SCRIPT 


\section{Introduction to GO FASTER}

\section{Introduction to morphemes}

E: Morphemes are small units of words that have meaning. More than half of the words you will come across in the English language contain these morphemes. If you know what these morphemes mean, that will help you understand what those words mean even if you have never seen them before. You will see these morphemes in social studies, science, English and math. This is why I will be teaching you their meanings, so you can use this knowledge to help you in any subject.

\section{Introduction to flashcard timings}

E. To help you learn these morphemes, you will be using flashcards to practice identifying their definitions. Many of you have probably used flashcards before, but this might be a little different. The flashcards will have the morpheme on one side and the definition on the other side. When you flip through the flashcards, you will hold them with the morpheme facing you like this (demonstrate for students). You will try to say the definition aloud as you flip through them. When you flip each card, there is a special way you will flip each one onto your desk. As you go through your stack of flashcards, you will have a partner who will sit across from you and keep track of the ones that you get right and the ones that you get wrong. Therefore, it will be important to flip the cards so that the answer is showing to make it easier for your partner to separate your cards. As you flip the cards, you will turn the cards like this (demonstrate for the students) and place the card on the desk with the answer facing up, and facing your partner. Please pick up your stack of cards and practice this with me. (Circulate room to make sure students are doing it correctly) 
E: Now that you know how to flip your cards, you need to know a few more things. First, as you are flipping through your flashcards, you will be timed. You will have 30-seconds to flip through as many cards as you can, and say as many correct definitions as you can, out loud. Keeping track of how many you can get correct in 30 -seconds is a measure of fluency. Fluency is important because research tells us that the more fluent you are, or the more flashcards you can get in 30-seconds, the more likely you will be to remember those in the future. Does anyone have any questions about fluency?

P: (varies)

E: There is one more thing I need to tell you before we practice with your flashcards. As we go through these next few weeks, you will come across flashcards that you don't know yet because you haven't had a chance to learn them. It will be very important that you learn to say, "pass" when you do not know the answer. Passing is not wrong and does not mean that you missed a card. It simply means that you know that you do not know that morpheme yet. You will know at least some of the cards in the stack, so the sooner you say pass and put that card down, the sooner you can get to the cards that you do know, and the more you will get right. Do you have any questions about this?

P: (varies)

E: Now we will do a practice 30 -second timing. Pick up your stacks of cards. We will just practice on our own this time, so you do not need a partner for this. Remember to flip the cards the way I taught you and to say pass if you do not know the morpheme. Do not worry about the cards after you put them down. Stay focused on the cards in front of you. Do you have any questions before we begin?

P: (varies) 
E: You will have 30-seconds. Ready, set, go.

P: (students practice for 30 -seconds)

E: (After 30-seconds) Stop! How did you guys do?

P: (varies)

E: Okay, now I need you to find a partner (give students time to pair up). You know how to flip the cards, but now you need to focus on the role of the partner. If your partner is flipping the cards, your job will be to watch the cards as your partner lays them down and separate the cards into two piles (corrects and incorrects/passes). At the end of the 30seconds you will add up the number of corrects and report them to your partner. Mrs. Cheney and I will demonstrate a peer timing for you (do demonstration with teacher). Now it is your turn to practice. Does anyone have any questions?

P: (varies)

E: Decide which partner is going to go first (allow students time). Raise your hand if you are going to flip through the flashcards first (wait on those students to raise their hands). Raise your hand if you are going to be separating the cards for your partner as they do the timing (wait on those students to raise their hands). Okay, I will start the timer. Read, set, go.

P: (students flip through cards for 30-seconds)

E: (circulate room giving feedback to students throughout the 30-seconds) STOP! If you were separating cards, you need to now count up how many corrects your partner had. Make sure you remember that number; we will do something with it later. Now switch roles with your partner. If you flipped through the flashcards last time, it is your turn to separate the cards for your partner as they do the 30 -second timing. Ready, set, go. 
P: (students flip through cards for 30-seconds)

E: (circulate room giving feedback to students throughout the 30 -seconds) STOP! Count up the total correct and tell your partner how they did (give students time to do this).

E: Now that you have your total number correct in your head, we will be putting your totals each day on a graph (show students a sample completed graph) like this. You all have a graph in front of you. This is your 30-seconds graph. On the left side of the graph (y-axis) you will see numbers from 0 to 60 . On the bottom of the graph (x-axis) you will see dates. Above each date, you will put a dot on the line that represents how many you got correct on that date. For example, if I got 10 right on (today's date), I would put a closed circle here (show on the graph). I am going to ask you all to put a closed circle on your graph to show how many you got correct today. Please do that now and raise your hand if you have any questions. (Circulate room to give feedback) 
APPENDIX F: MORPHEME SETS 


\begin{tabular}{|c|c|c|}
\hline Set 1 (Yellow) & Set 2 (Green) & Set 3 (Pink) \\
\hline Accu & Carn & Anthrop \\
\hline Anti & Chron & Clam \\
\hline Cardi & Cred & Corp \\
\hline $\mathrm{De}$ & Derm & Cur \\
\hline Est & Dis & Dem \\
\hline Ful & Er & Dict \\
\hline Hypo & Hemi & Ex \\
\hline Ignis & Inter & Grat \\
\hline Loc & Morph & In \\
\hline Mis & Neo & Leg \\
\hline Phyt & Ped & Less \\
\hline Poli & Phile & Ous \\
\hline Semi & Phon & Pan \\
\hline Trans & Port & Pot \\
\hline Vit & Un & Tain \\
\hline
\end{tabular}


APPENDIX G: TEACHING PHASE SCRIPT 


\section{Full Script:}

E: We are going to use the next few days to learn the first set of morphemes. Today we are going to take a closer look at 5 of them. Those five are

, and

. In your folder, you have five graphic organizers and we will

work together to fill one out for each morpheme. (Take out sample completed graphic organizer) This is what a completed organizer will look like. I will give you one section at a time and you will record it on your own sheet. When I say the morpheme you will write it in the middle like this (point at the example sheet). I will then give you the definition and you will record it in the top left box. Next I will give you two words that contain the morpheme and you will record them in the top right box (point) long with their definition. Last, I will use one of those words in a sentence and you will write that sentence in the bottom box (point). After you have completed each graphic organizer, we will say each section together, out loud. We will do this for 5 words each day. Do you have any questions?

P: (responses may vary)

E: Let's begin. Take out your graphic organizers.

E: The first morpheme is . (Have GO on ppt. Reveal the morpheme in the middle), (give participant time to write) (If incorrect, ask the student to erase it and write it exactly as its written on the PowerPoint.) (If correct, praise and move on to next step) 
E: The definition of is . (Reveal this section on the PowerPoint model) (Give participant time to write) (If incorrect, ask the student to erase it and write it exactly as it's written on the finished copy.) (If correct, praise and move on to next step)

E: There are many words that contain this morpheme. You will write some of those words here (point to box) and their definitions so you'll have some examples. The first word that contains is . Please underline it. means . The second word containing is . Please underline it.

means . (If incorrect, ask the student to erase it and write it exactly as it's written on the finished copy.) (If correct, praise move on to next step).

E: The sentence is . Please copy that sentence here (point to box). (Give participant time to write) (If incorrect, ask the student to erase it and write it exactly as its written on the PowerPoint slide.) (If correct, move on to next step)

E: Now I'd like for you to read back some of what you wrote, out loud, all together. First, what is the morpheme?

P: (Read morpheme all together, if they do not say it aloud together, have them do it again until solid)

E: What does (target morpheme) mean?

P: (Reads definition)

E: What is the first word that contains (target morpheme)? 
P: (Reads target word) (if incorrect, experimenter pronounces the word then asks participants to repeat it until correct)

E: What is the second word that contains (target morpheme)?

P: (Reads target words) (if incorrect, experimenter pronounces the word then asks participants to repeat it until correct)

E: Please turn the GO over. (Reveal morpheme on the PowerPoint) What does (target morpheme) mean?

P: (definition)

E: (If incorrect) No, (target morpheme) means (definition). What does (target morpheme)mean?

(If correct) Good, lets move onto the next morpheme.

*Repeat for each of the remaining morphemes, after teaching each morpheme, review all of the morphemes taught in that session. For example, after teaching the fourth morpheme, you should be reviewing the first three morphemes along with the fourth one. 


\section{Modified Script:}

E: So far you have learned (5 or 10) morphemes in this set using a graphic organizer. Please take out your blank graphic organizers. Today you will learn five more. Let's begin.

E: The first morpheme is . (Reveal morpheme in the middle of

PowerPoint slide), (give participant time to write) (If incorrect, ask the student to erase it and write it exactly as its written on the PowerPoint) (If correct, praise and move on to next step)

E: The definition of is . (Reveal this section on the PowerPoint model) (Give participant time to write) (If incorrect, ask the student to erase it and write it exactly as it's written on the PowerPoint) (If correct, move on to next step)

E: The first word that contains is . Please underline it. means The second word containing is . Please underline it.

means . (give participant time to write) (If incorrect, ask the student to erase it and write it exactly as it's written on the PowerPoint) (If correct, move on to next step).

$\mathbf{E}$ : The sentence is - (Give participant time to write) (If incorrect, ask the student to erase it and write it exactly as it's written on the PowerPoint) (If correct, move on to next step)

E: Now read back each section. First, what is the morpheme?

P: (Reads morpheme) 
E: What does (target morpheme) mean?

P: (Reads definition)

E: What is the first word that contains (target morpheme)?

P: (Reads word)

E: (If incorrect, experimenter reads word correctly and asks participants to read it again)

E: What is the second word that contains (target morpheme)?

P: (Reads word)

E: (If incorrect, experimenter reads word correctly and asks participants to read it again)

E: Turn it over. What does (target morpheme) mean?

P: (definition)

E: (If incorrect) No, (target morpheme) means (definition). What does (target morpheme)mean?

E: (If correct) Good, lets move onto the next morpheme.

*Repeat for the remaining morphemes. After teaching each morpheme, review all of the morphemes taught in that session. For example, after teaching the fourth morpheme, you should be reviewing the first three morphemes along with the fourth one. 
APPENDIX H: GRAPHIC ORGANIZER TEMPLATE 


$$
-0
$$


APPENDIX I: POWERPOINT SLIDES FOR TEACHING SESSIONS 

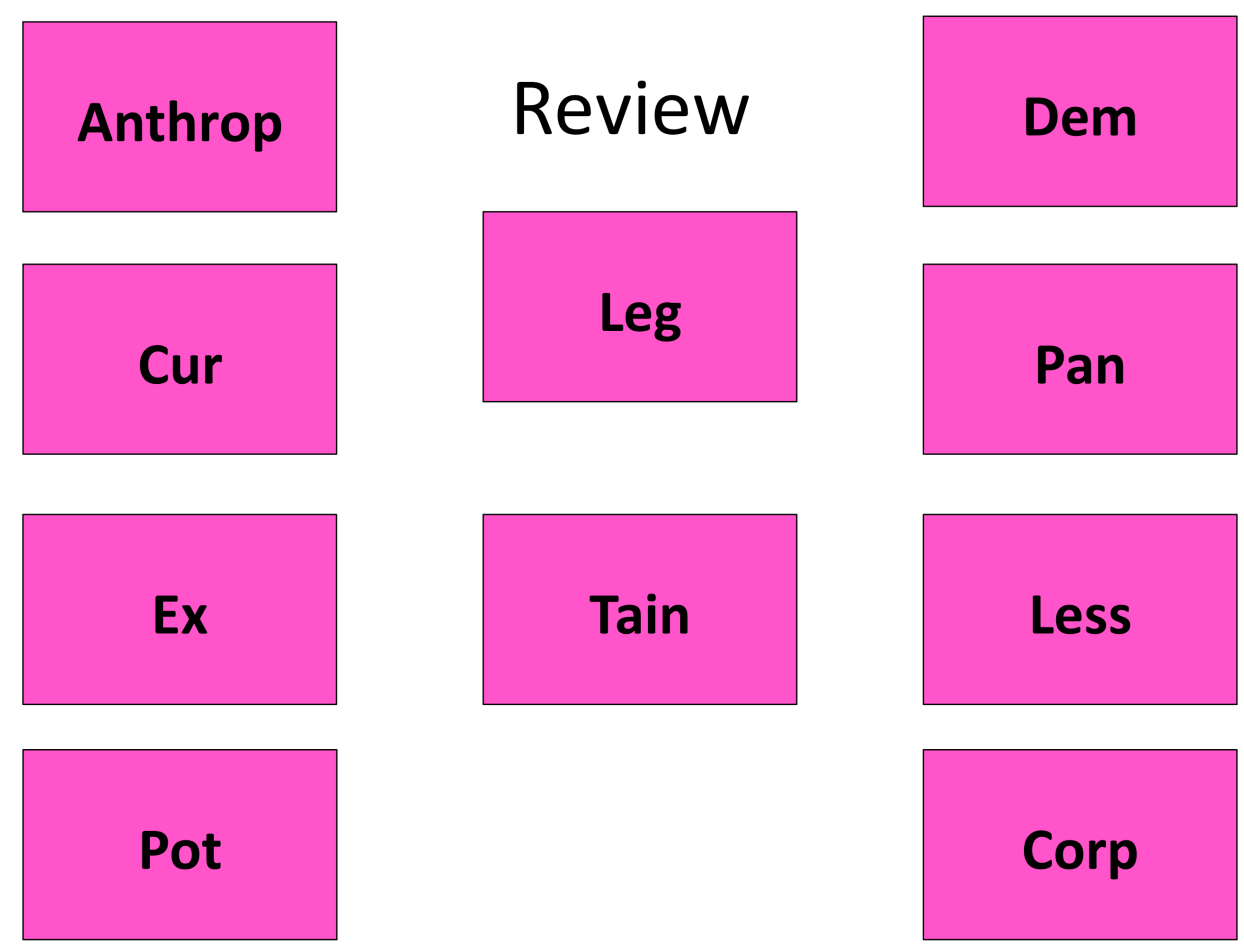


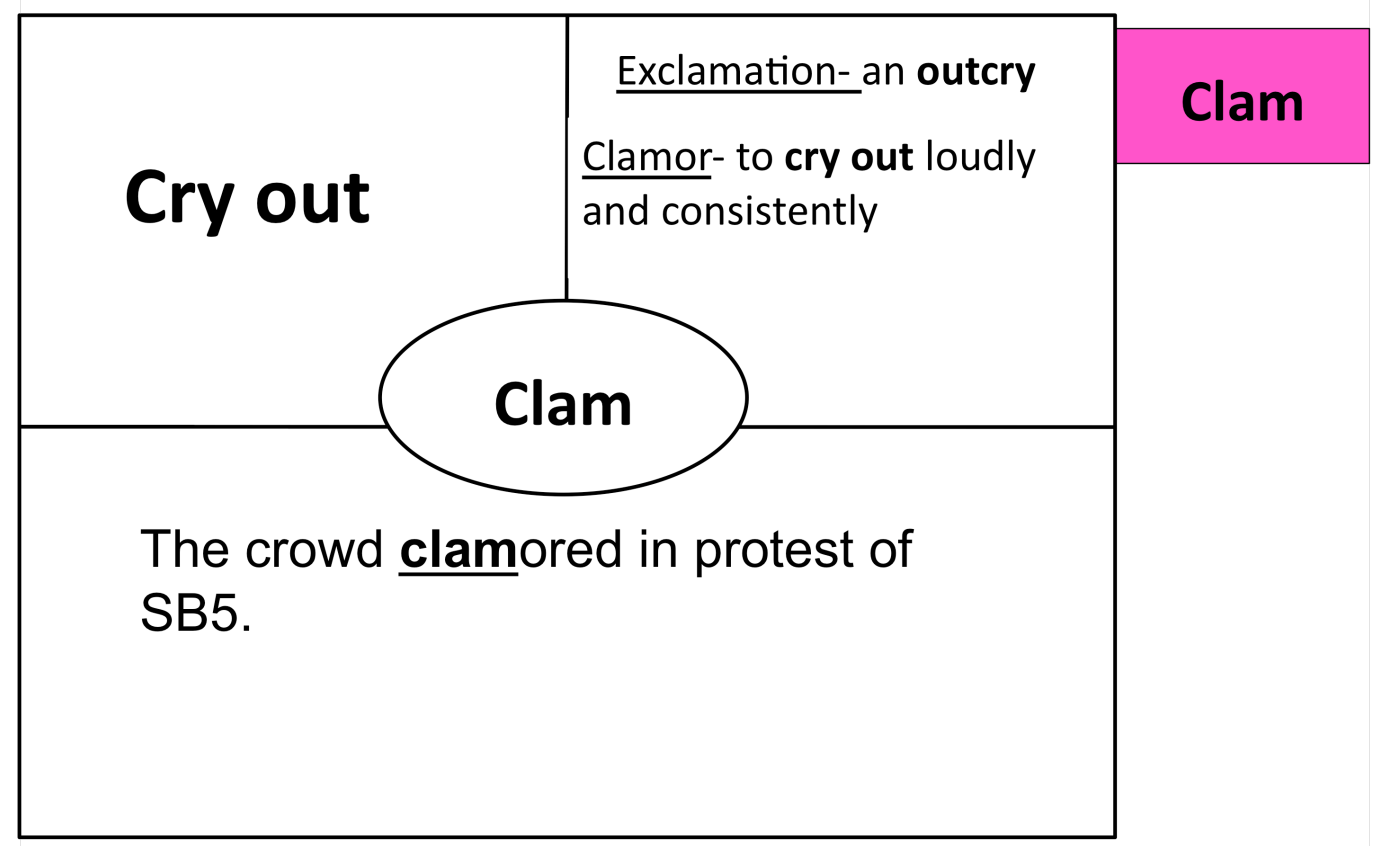




\section{Review}

\section{Clam}




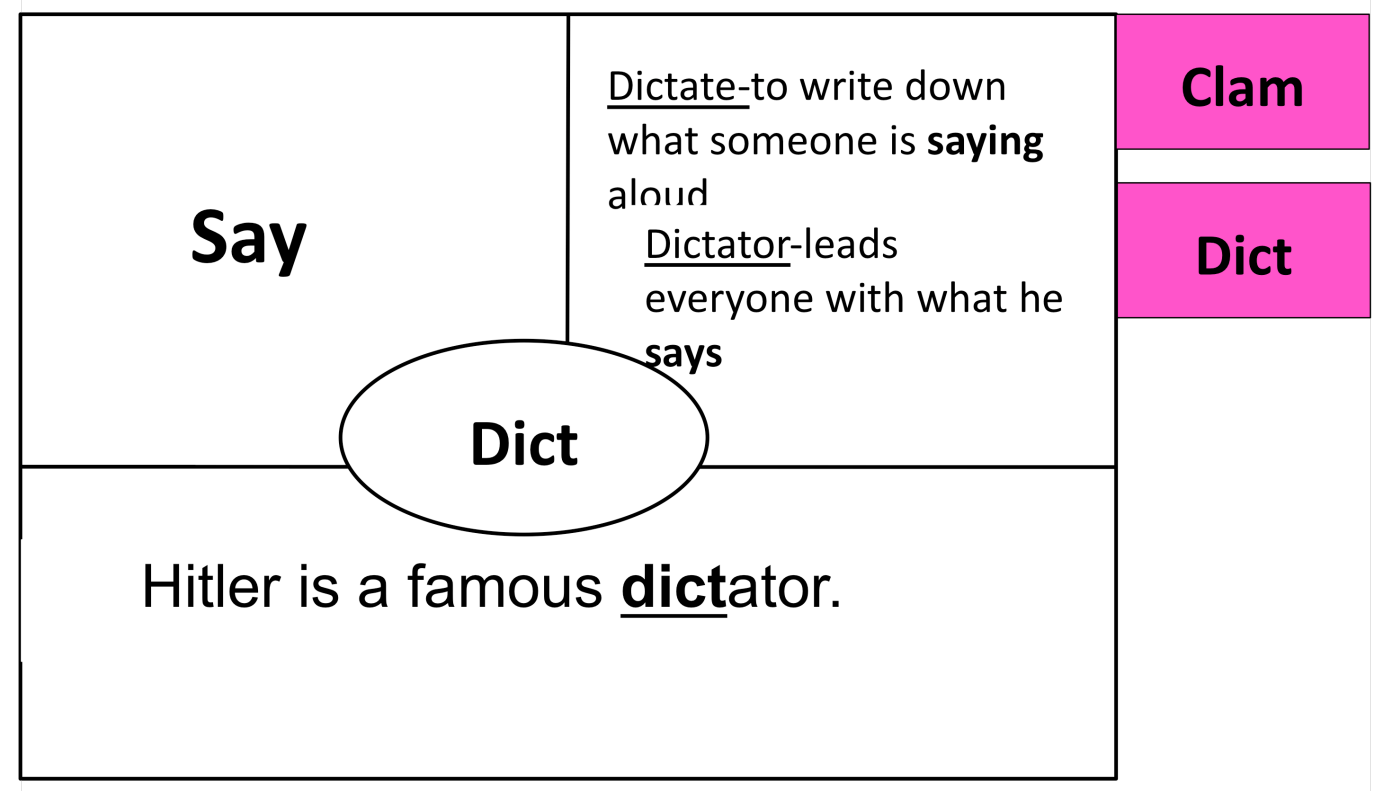




\section{Review}

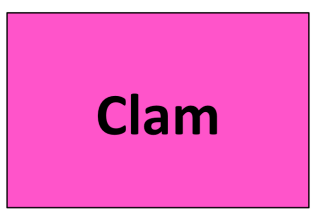

Dict 


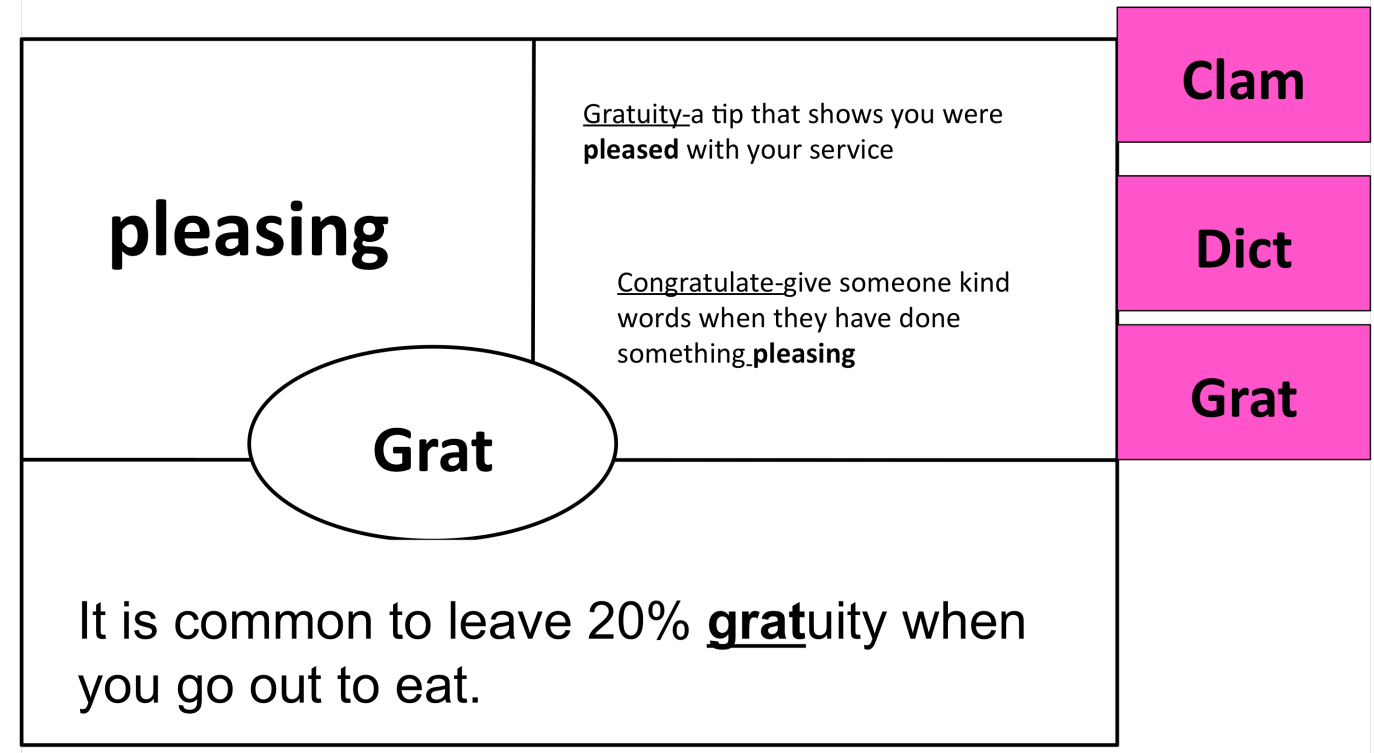




\section{Review}

Clam

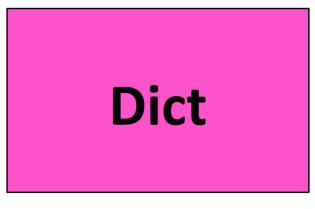

Grat 


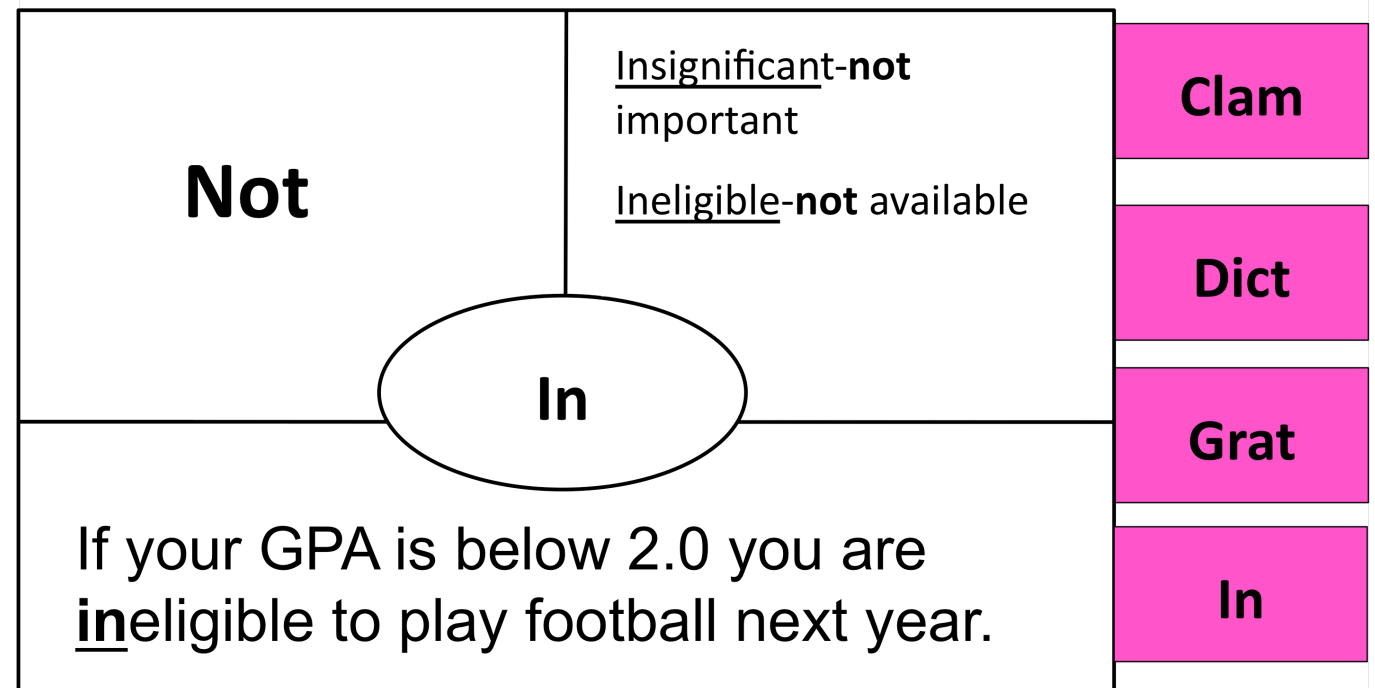




\section{Review}
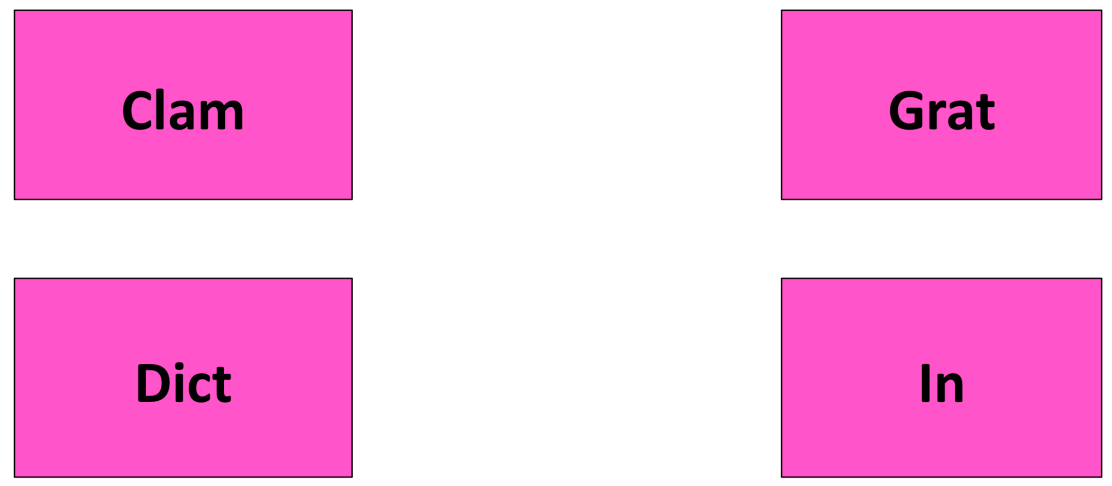


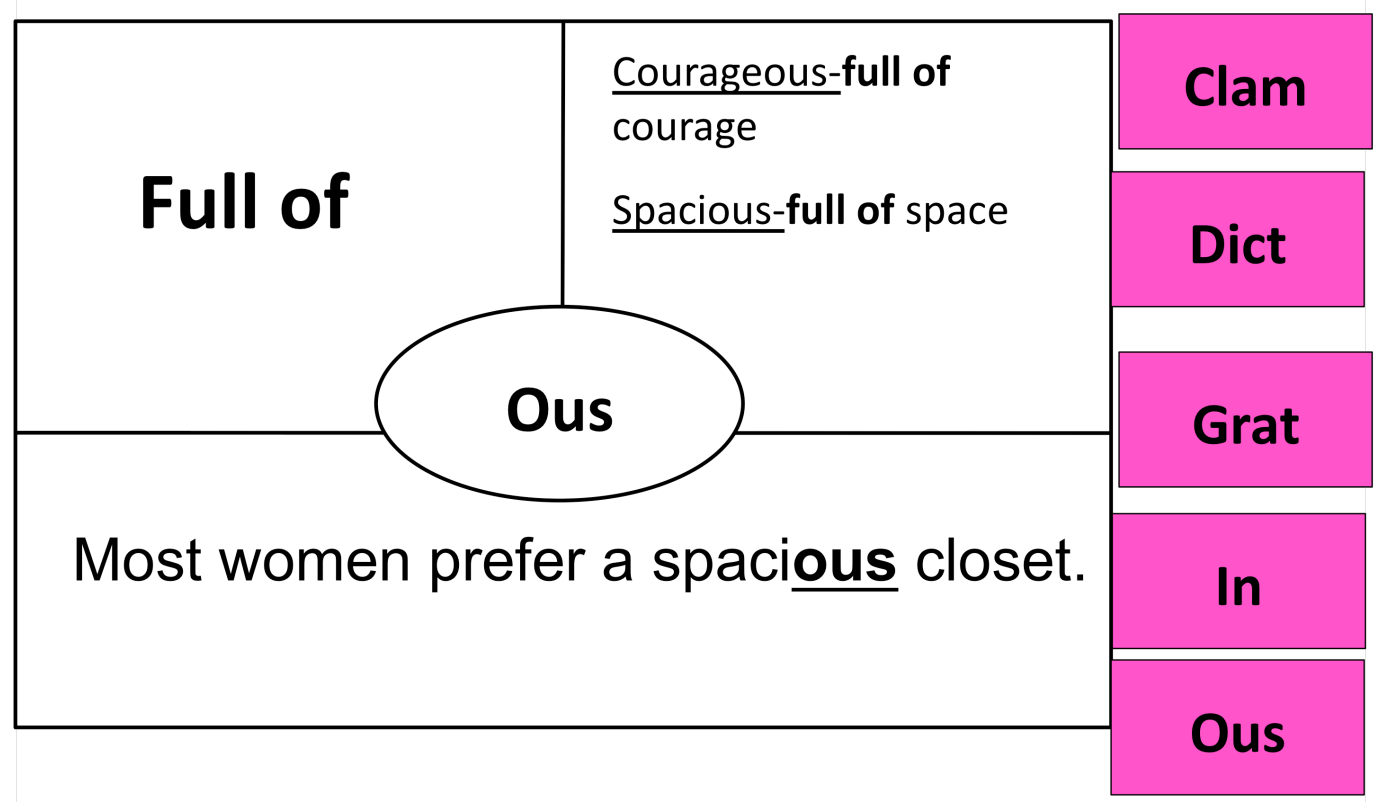




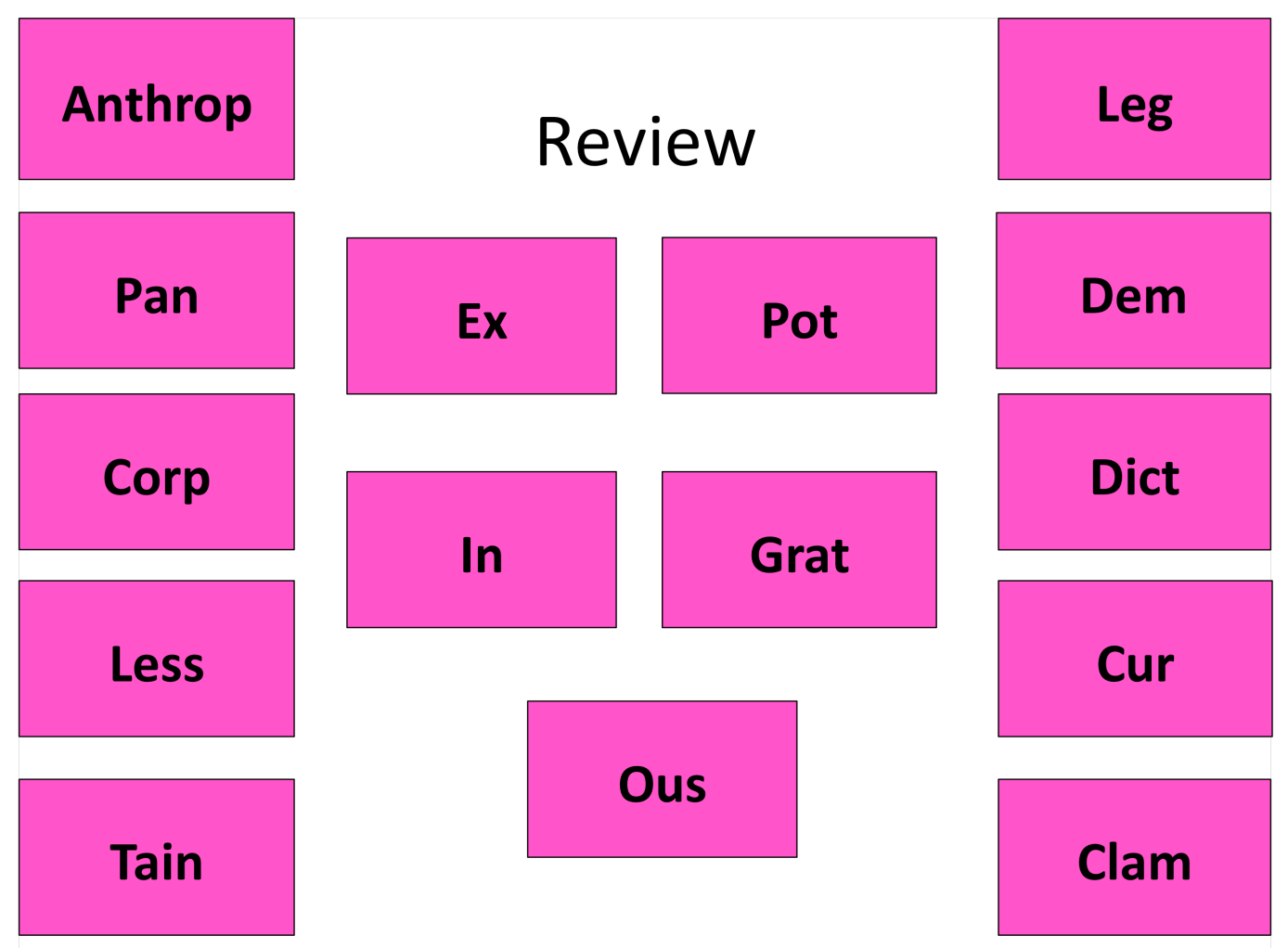


APPENDIX J: SPRINT TRAINING SCRIPTS 


\section{Fluency Training Scripts:}

E: In order to move on to the next set, you need to get at least 40 morphemes in 30seconds two days in a row. In order to reach that goal we are going to review the current set of flashcards you are working on for extra practice so you can get quicker. Pull out the top 15 cards from your stack. These are the 15 we are going to work with today. You can put the rest of your cards away. These cards have each of the 15 morphemes on them that you learned this week, so there is only one of each morpheme in your hand. You have 1 minute to go through these 15 and review the definitions without being timed.

P: (students go through morpheme flashcards on their own)

E: Now we will begin some short timings, called sprints, to help you get even faster. Find your partner and decide who is going first. Each timing will be 10 -seconds. Do as many as you can in that time. Don't forget you can pass if you don't know the definition. Each of you will do 4 of these 10-second timings in a row before doing your official 30 -second timing. As the partner, you will need to do the same thing as you do with the 30 -second timings. Be sure to separate these into two piles too. After each timing, you will add up the corrects. If you are the one who is doing the timing, you will still be graphing your performance. You will use the sprint timings graph (show students where it is on the back of the 30 -second timings graph). Try to get all 15 morphemes in 15 seconds.

(Begin sprint timings using all 15 flashcards) (after each timing, prompt partners to count corrects/incorrects/total and prompt other partner to graph those results).

E: (after first sprint timing) Okay, hand the missed or passed cards back to your partner to review. Between each timing, you will have 20 seconds to review the ones you missed 
or passed on. This must be done quickly so make sure you grab those cards you need to review immediately after you graph.

E: (Continue process of 10-second timings, counting of results, graphing, and reviewing missed/passed cards)

E: (After 4 10-second timings) Okay, now we will do your 30-second peer timing. (Do timing and graph)

*Switch partners and follow same script so the other partner does four 10-second sprints and one 30 -second timing with his or her partner. 
APPENDIX K: SAMPLE GENERALIZATION PROBE FORM 
Name:

You will think for ONE MINUTE before beginning. You can make notes about what you want to write about on the side or back of this paper. You will write for THREE MINUTES about the topic using as many of the morphemes as you can.

Write about this:

\section{One of my biggest fears is...........}

Use as many of the morphemes in the box as you can within your writing.

\begin{tabular}{l} 
Accu Anti Cardi De Est Ful Hypo Ignis \\
Loc Mis Phyt Poli Semi Trans Vit \\
\hline Anthrop Clam Corp Cur Dem Dict Ex \\
Grat In Leg Less Ous Pan Pot Tain \\
\hline Carn Chron Cred Derm Dis Er Hemi Inter \\
Morph Neo Ped Phile Phon Port Un
\end{tabular}


APPENDIX L: INTEROBSERVER AGREEMENT CHECKLIST 


\section{IOA}

Scorer:

Date:

\begin{tabular}{|l|l|l|l|l|l|l|}
\hline Name & Date & Set/Ph & Corrects & Incorrects & Total C & Total I \\
\hline & & & & & & \\
& & & & & & \\
\hline
\end{tabular}

\begin{tabular}{|l|l|l|l|l|l|l|}
\hline Name & Date & Set/Ph & Corrects & Incorrects & Total C & Total I \\
\hline & & & & & & \\
& & & & & & \\
\hline
\end{tabular}

\begin{tabular}{|l|l|l|l|l|l|l|}
\hline Name & Date & Set/Ph & Corrects & Incorrects & Total C & Total I \\
\hline & & & & & & \\
& & & & & & \\
\hline
\end{tabular}

\begin{tabular}{|l|l|l|l|l|l|l|}
\hline Name & Date & Set/Ph & Corrects & Incorrects & Total C & Total I \\
\hline & & & & & & \\
& & & & & & \\
\hline
\end{tabular}

\begin{tabular}{|l|l|l|l|l|l|l|}
\hline Name & Date & Set/Ph & Corrects & Incorrects & Total C & Total I \\
\hline & & & & & & \\
& & & & & & \\
\hline
\end{tabular}


APPENDIX M: PROCEDURAL INTEGRITY CHECKLISTS 


\section{Sprint Training Introduction}

1. Pair up and decide who is going first

2. You will be doing 4 10-second sprints and one 30 -second timing with your partner

3. Be sure to graph each of your timings

\begin{tabular}{|l|l|l|}
\hline Sprint Training & Partner 1 & Partner 2 \\
\hline 1. 10 -seconds, ready go & & \\
\hline 2. Stop & & \\
\hline 3. Count them up and graph them & & \\
\hline 4. $2^{\text {nd }}$ timing, ready go & & \\
\hline 5. Stop & & \\
\hline 6. Count them up and graph & & \\
\hline 7. $3^{\text {rd }}$ timing, ready go & & \\
\hline 8. Stop & & \\
\hline 9. Count them up and graph & & \\
\hline 10. Last timing, ready go & & \\
\hline 11. Stop, count them up and graph & & \\
\hline 12. Now, shuffle your whole stack for your 30-second timing & & \\
\hline 13. 30-seconds, ready go & & \\
\hline 14. Stop & & \\
\hline 15. Count them up and graph & & \\
\hline 16. Switch partners & & \\
\hline
\end{tabular}




\begin{tabular}{|c|c|c|c|c|c|}
\hline Teaching Steps & $+/-1$ & $+/-2$ & $+/-3$ & $+/-4$ & $+/-5$ \\
\hline 1. The morpheme is & & & & & \\
\hline 2.__ means __ & & & & & \\
\hline 3. The first word containing ___ is & & & & & \\
\hline 4.__ means & & & & & \\
\hline 5. The second word containing ___ & & & & & \\
\hline 6.___ means & & & & & \\
\hline 7. The sentence is & & & & & \\
\hline
\end{tabular}

\begin{tabular}{|l|l|l|l|l|l|}
\hline \multicolumn{1}{|c|}{ Review Steps } & $+/-\mathbf{1}$ & $+/-\mathbf{2}$ & $+/-\mathbf{3}$ & $+/-\mathbf{4}$ & $\mathbf{+}-\mathbf{5}$ \\
\hline 1. What is the morpheme? & & & & & \\
\hline 2. What does__mean? & & & & & \\
\hline 3. Review all previous morphemes & & & & & \\
\hline
\end{tabular}




\begin{tabular}{|l|l|}
\hline \multicolumn{1}{|c|}{ 30-Second Peer Timings } & +/- \\
\hline 1. Pair up with your partner for 30second timings & \\
\hline 2. Make sure you have your graph ready too & \\
\hline 3. Decide who is going first & \\
\hline 4. Shuffle your cards & \\
\hline 5. Remember to pass if you don't know it... & \\
\hline 6. 30-seconds, ready go & \\
\hline 7. Stop and graph & \\
\hline 8. Switch partners & \\
\hline 9. Remember to shuffle your cards & \\
\hline 10. 30-seconds, ready go & \\
\hline 11. Graph your corrects & \\
\hline
\end{tabular}

\begin{tabular}{|l|l|l|l|l|l|}
\hline \multicolumn{1}{|c|}{ 30-Second Official Timings } & $+/-\mathbf{1}$ & $+/-2$ & $+/-3$ & $+/-4$ & $+/-5$ \\
\hline 1. Shuffle cards & & & & & \\
\hline $\begin{array}{l}\text { 2. Make sure you pass the cards you don't } \\
\text { know... }\end{array}$ & & & & & \\
\hline 3. I'll start the timer when you are ready & & & & & \\
\hline
\end{tabular}

